\title{
Commissioning of the Canadian Primary Standard for Low Dose Rate Brachytherapy
}

\author{
by \\ Hong Shen \\ A thesis submitted to the \\ Faculty of Graduate and Postdoctoral Affairs \\ in partial fulfilment of the requirements \\ for the degree of \\ Master of Science \\ Ottawa-Carleton Institute for Physics \\ Department of Physics \\ Carleton University \\ Ottawa, Canada
}

March, 2016

Copyright (C) 2016 Hong Shen 


\section{Copyright National Research Council 2016}

The NRC has granted a nonexclusive license allowing Library and Archives Canada to reproduce, publish, archive, preserve, conserve, communicate to the public by telecommunication or on the Internet, loan, distribute and sell theses worldwide, for commercial or noncommercial purposes, in microform, paper, electronic and/or any other formats.

The NRC retains copyright ownership and moral rights in this thesis. Neither the thesis nor substantial extracts from it may be printed or otherwise reproduced without the permission of the NRC. 


\section{Abstract}

The purpose of this project is to investigate the performance of the NRC WAFAC and commission it as a primary standard for calibrating LDR sources. Significant enhancements were implemented to the WAFAC for improving signal to noise ratio, measurement reproducibility and eliminating electric field distortion. The validation of the WAFAC, comparing to the existing NRC primary standard, shows that the agreement between the two devices is within the combined measurement uncertainties of less than $0.5 \%$. The measurements made with a ${ }^{125} \mathrm{I}$ LDR seed gave results that were consistent at the $1 \%$ level with the manufacturer's stated seed activity (traceable to NIST). The polarity effect and aperture size effect had been studied during the commissioning.

The overall $\mathrm{k}=2$ standard uncertainty in the determination of air kerma strength using the NRC WAFAC is estimated to be $2.6 \%$, which reaches the target uncertainty for the standard. 


\section{Statement of Originality}

I carried out all the experiments, modifications, tests and measurements described in this thesis. I wrote a new MATLAB macro, which is used for reading the raw data, analyzing the data, applying corrections and producing a report. This report includes the estimated air kerma strength and its uncertainty. I carried out the measurements that first indicated that the NRC WAFAC had a large polarity effect. In discussions with Dr. Ross, we speculated that the polarity current might be coming from the gap between the collector and shield foils. I proposed, set up and carried out the measurements that confirmed that this was the source of the extra current.

Dr. Wesley Culberson at the University of Wisconsin-Madison confirmed that their chamber also showed a similar effect which had gone unnoticed. The paper listed in reference 19, "An investigation of polarity effects for wide-angle free-air chamber", includes data contributed by Culberson as well as the results I obtained using the NRC WAFAC and reported in Chapter 4. Dr. Ross drew attention to the work by Fallone and Podgorsak on electret chambers as a mechanism for explaining how the extra charge was collected.

Dr. Ross drafted the paper but I contributed the data and checked the analysis. All three authors contributed to several revisions as well as responding to the comments of the referees.

The Monte Carlo calculations for filter attenuation and aperture size effect were carried out by Dr. Mainegra-Hing.

I have given presentations on the WAFAC to OMPI (Ottawa Medical Physics Institute) at Carleton University, to OCIP (Ottawa-Carleton Institute for Physics) at the University of Ottawa and to the 2015 NCSL (National Conference of Standards 
Laboratories) International Workshop \& Symposium in Grapevine, Texas. 


\section{Acknowledgements}

The research included in this thesis could not have been performed without the assistance, patience, and support of many individuals. I would like to extend my gratitude first to my thesis supervisors Dr. Carl Ross and Dr. Malcolm McEwen and other research officers at Ionizing Radiation Standard group: Dr. John McCaffery, Dr. John Paul Archambault, Dr. Raphael Galea, Dr. Patrick Saull, Dr. Frèdèric Tessier, for helping me over the course of my graduate studies and supporting me through difficult times with their patience.

I would like to extend my appreciation to Dr. Dave Rogers for his encouragements, help and belief in me.

I would also like to extend my appreciation to Dr. Dave Wilkins for providing me free I-125 seeds.

I would also like to extend my appreciation to Dr. Ernesto Mainegra-Hing for his Monte Carlo simulations and discussions with me.

I would additionally like to thank Mr. Stewart Walker, Mr. David Marchington, and Mr. Brad Downton for their assistance in electrical and mechanical matters.

Finally I would like to extend my deepest gratitude to my wife Meilin and my son Yiwen. Without their love, support and understanding I could never have completed my graduate studies.

This research was supported by the Measurement Science and Standards, National Research Council. 


\section{Contents}

1 Introduction 1

1.1 Primary Standard for low energy photons . . . . . . . . . . . . 3

1.2 Brachytherapy Seeds ..................... 5

1.3 Brachytherapy Seed Calibration . . . . . . . . . . . . 6

2 Wide Angle Free Air Chamber $\quad 12$

2.1 General ............................. 12

2.2 The Working Principles of the WAFAC . . . . . . . . . . . . . . 15

2.3 Major Parts and Features of the WAFAC . . . . . . . . . . . . . 22

2.3.1 Middle Electrode . . . . . . . . . . . . . . . . . . . . 22

2.3.2 Filter Wheel . . . . . . . . . . . . . . . . . . 23

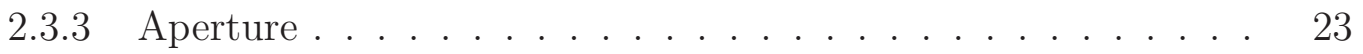

2.3.4 Seed Holder . . . . . . . . . . . . . . . . . . . 25

2.3.5 Cylinder Movement Control . . . . . . . . . . . . . 25

2.3.6 Electrical Equipment . . . . . . . . . . . . 26 
3 Commissioning $\quad 28$

3.1 General . . . . . . . . . . . . . . . . . . . 28

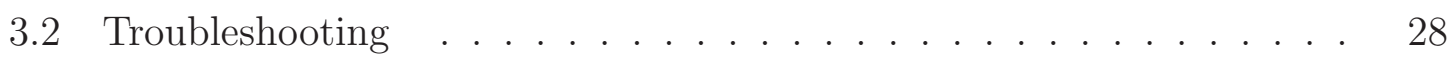

3.2.1 Cylinder Movement . . . . . . . . . . . . . . . . . 29

3.2.2 Leakage of Capacitor, Multimeter and Remote Head . . . . . 31

3.2.3 Electric Field in the Collecting Volume . . . . . . . . . . . . . 31

3.3 Redesigning the Collecting Electrode . . . . . . . . . . . . . . . . 32

3.4 Reproducibility and Effect of Polarity on High Voltage Electrode . . . 36

3.5 Correction Factors . . . . . . . . . . . . . . . . . . . . . 38

3.5.1 Air Attenuation $\left(k_{\mathrm{att}}\right) \ldots \ldots . \ldots . \ldots . \ldots 39$

3.5.2 Ion Recombination Inside WAFAC $\left(k_{\mathrm{sat}}\right) \ldots . . . . . . . .441$

3.5.3 Inverse Square Correction for Aperture $\left(k_{\text {invsq }}\right) \ldots \ldots$. . . . . . 41

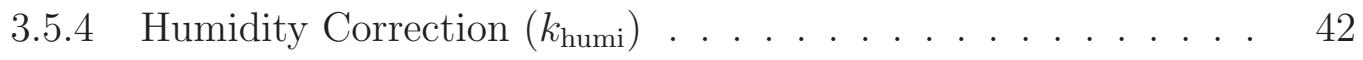

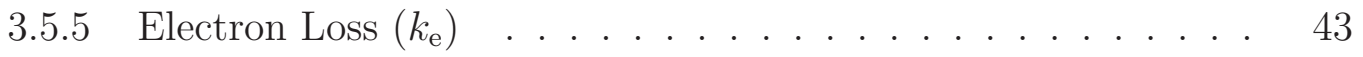

3.5.6 Internal Photon Scatter Correction $\left(k_{\text {in_scatt }}\right) \ldots . . . . . . . .44$

3.5.7 External Photon Scatter Correction $\left(k_{\text {ex_scatt }}\right) \ldots . . . . . .444$

3.5.8 Photon Scatter from Sample Holder $\left(k_{\text {stem }}\right)$. . . . . . . . . . 44

3.5.9 Aperture Penetration $\left(k_{\text {pen }}\right) \ldots \ldots . \ldots . . \ldots 45$

3.5.10 Aluminum Filter Attenuation $\left(k_{\text {foil }}\right) \ldots \ldots . . . . . . .45$

3.5.11 Displacement Correction $\left(k_{\mathrm{v}} \& k_{\mathrm{c}}\right) \ldots \ldots . \ldots$ 
4 Polarity Effect $\quad 51$

4.1 Observations . . . . . . . . . . . . . . . . . . . . 51

4.2 The Source of $Q_{\mathrm{p}}$ Causing the Polarity Effect . . . . . . . . . 55

4.2.1 \pm 9 V Battery DC Voltages Applied on Shield Foil . . . . . . . 56

4.2.2 Variable DC Applied on Shield Foil . . . . . . . . . . . . . . . 58

4.2.3 Electret Phenomenon on Mylar Surface of the Collecting Electrode of the WAFAC . . . . . . . . . . . . . 62

4.2.4 Elimination of the Polarity Effect with a Painted Conducting Layer on the Mylar Surface of the Collecting Electrode of the

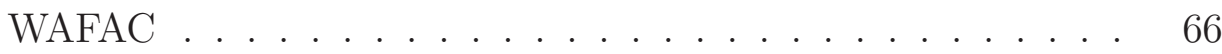

$\begin{array}{llr}5 & \text { Validation } & 68\end{array}$

5.1 Validation with Established National Primary Standard . . . . . . . . 68

5.1.1 Experiment ....................... 68

5.2 Aperture Size Effect . . . . . . . . . . . . . . . . . . 74

5.3 Validation with manufacturer's nominal $S_{\mathrm{k}}$ value. . . . . . . . . 78

5.4 Uncertainty Estimation . . . . . . . . . . . . . . . . . . 79

5.5 Long-term Stability with Check Source . . . . . . . . . . . . . . 82

6 Conclusions and Future Work $\quad 83$ 


\section{List of Tables}

2.1 Differences between NRC low energy exposure standard (LEES) and

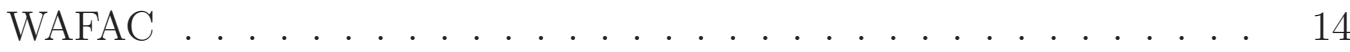

3.1 Validation of cylinders position . . . . . . . . . . . . . 29

3.2 Repeat measurement at different polarities . . . . . . . . . . . . . 37

3.3 Weighted average of table $3.2 \ldots \ldots . \ldots . \ldots$

3.4 Correction factors for ${ }^{125} \mathrm{I}$ seed measurement . . . . . . . . . . . . . 40

3.5 Test results for Al filter attenuation correction factor . . . . . . . . 48

4.1 Polarity effect measurements using ${ }^{125} \mathrm{I}$ and ${ }^{241} \mathrm{Am}$. . . . . . . . . . 52

4.2 The difference with and without the offset being applied to results from table $3.3 \ldots \ldots \ldots \ldots \ldots \ldots$

4.3 Electrometer reading with variation of volumes at position $2 \ldots 54$

4.4 Effect of applying $\pm 9 \mathrm{~V}$ DC on the shield foil . . . . . . . . 57

4.5 The effect on charge collection of the DC voltage applied to the shield

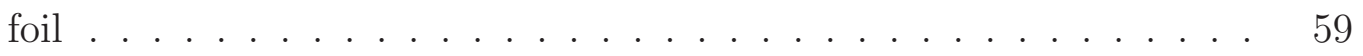


4.6 Effect of reversing the collecting electrode . . . . . . . . . . 65

4.7 Polarity measurements with graphite painted on the back of the collecting electrode . . . . . . . . . . . . . . . 67

4.8 $Q_{\mathrm{i}}$ and $Q_{\mathrm{p}}$ at position 1 and 2 after graphite painted on the back of the collecting electrode . . . . . . . . . . . . . . . . . 67

5.1 Correction factors used for WAFAC as the comparison measurement to LEES in Narrow Spectrum X-ray beam. . . . . . . . . . . . . . . . 72

5.2 The measurements of WAFAC in x-ray beam established by LEES . . 73

5.3 The measurements of the WAFAC with different size of aperture . . . 76

5.4 The Monte Carlo calculated aperture size effect . . . . . . . . . . . . 77

5.5 Air kerma measurement for ${ }^{125} \mathrm{I}$ seeds, model 6711 . . . . . . . . . . 78

5.6 Type B uncertainties listed in table 7 of NIST's work and as used here 81

5.7 Check source ${ }^{241} \mathrm{Am} \ldots \ldots \ldots$. . . . . . . . . . . . . . 82 


\section{List of Figures}

1.1 Low dose brachytherapy treatment of prostate cancer . . . . . . . . . 2

1.2 Schematic diagram of a conventional free air chamber used for $\mathrm{x}$ ray primary standard ........................ 4

1.3 Drawings of the brachytherapy seeds examined in the AAPM TG-43U

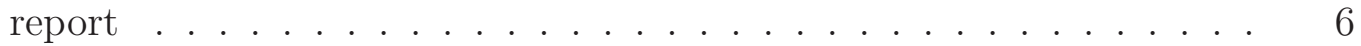

1.4 Low dose brachytherapy seeds . . . . . . . . . . . . . . . . . . . . 7

1.5 Coordinate system for a brachytherapy seed . . . . . . . . . . . 8

1.6 The well type ion chamber used as working standard traceable to the primary standard . . . . . . . . . . . . . . . . . . . . 10

2.1 The wide angle free air chamber at NRC . . . . . . . . . . . . . 13

2.2 Two cylinders form the chamber volume . . . . . . . . . . . . 16

2.3 The schematic of WAFAC . . . . . . . . . . . 17

2.4 The collecting electrode . . . . . . . . . . . . . . . 18

2.5 The measurement of charge collected . . . . . . . . . . . . . . 19 
2.6 The measurement point of kerma rate . . . . . . . . . . . . . . 20

2.7 The electrical field of air volume of WAFAC . . . . . . . . . . . 23

2.8 The filter wheel of the WAFAC . . . . . . . . . . . . . 24

2.9 The aperture of the WAFAC . . . . . . . . . . . . . 24

2.10 The seed holder . . . . . . . . . . . . . . . . 26

3.1 Sharp edges inside electrical field . . . . . . . . . . . . . . . . 32

3.2 Modified connector to collecting electrode . . . . . . . . . . 33

3.3 Schematic of the patch of the modification of connector to collecting electrode .......................... 34

3.4 30 measurement cycles of a single ${ }^{125}$ I seed after modifying the collect-

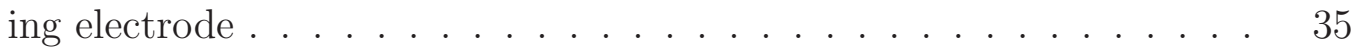

3.5 Eight ${ }^{125} \mathrm{I}$ seeds combined on a plane . . . . . . . . . . . . . . . 36

3.6 Inverse square correction for aperture . . . . . . . . . . . . . . . . . . 42

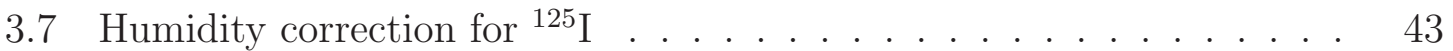

$3.8 \mathrm{Ti}$ x rays effect of air kerma rate . . . . . . . . . . . . . . 46

3.9 Aluminum filter attenuation . . . . . . . . . . . . . . . . . . 49

4.1 Electrometer reading vs. collecting volume in different polarity . . . . 55

4.2 The saturation curves of charge collected in the region between collecting electrode and shield foil . . . . . . . . . . . . . . . . . 61 
4.3 A schematic figure for the mechanism of charge collected in the region between collecting electrode and shield foil . . . . . . . . . . 63

5.1 The setup of $\mathrm{x}$ ray standard at NRC $\ldots \ldots \ldots \ldots$

5.2 Different measures of the relative $\mathrm{x}$ ray tube output as function of the tube current. . . . . . . . . . . . . . . . . . . . 70

5.3 The ratio of measured results from WAFAC and LEES . . . . . 75 


\section{Chapter 1}

\section{Introduction}

Brachytherapy has been used for a long time, since the discovery of radium [1]. It is a type of internal radiotherapy that involves implanting multiple small, encapsulated radioactive sources inside, or close to, the cancer tumor. In contrast to external beam radiation therapy, typically delivered using linear accelerators, a key feature of brachytherapy is the localized treatment, resulting in reduced dose to healthy tissues. It also limits the effects of tumor movement during treatment and reduces the chance of surviving cancer cells dividing and growing in the intervals between each radiotherapy dose [2]. In addition it costs much less and requires fewer patient visits. Currently, the use of brachytherapy is becoming more popular after decreasing during the middle of the last century, due to concerns about operator safety. Now it is an essential part of the treatment for almost all cancer centers.

Brachytherapy techniques can be divided to high and low dose rate (LDR) brachytherapy. LDR therapy aims to implant low energy and low dose rate encapsulated seeds inside the patient's body for a long period of time or even permanently. It has been used in a variety of anatomical sites. The most frequent use for LDR is 


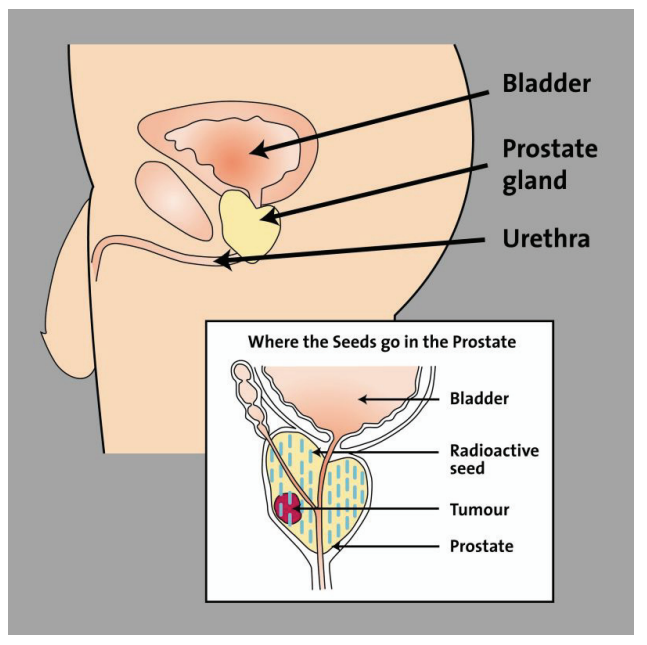

Figure 1.1: Multiple LDR radioactive seeds were implanted into a patient's prostate permanently to treat prostate cancer. (wikipedia, licensed under the Creative Commons Attribution-ShareAlike [3])

in the treatment of prostate cancer as shown in figure 1.1, but it can also be used in eye plaque therapy for choroidal melanoma, and lung implants. In particular, low dose brachytherapy for prostate cancer treatment increased rapidly in recent decades due to the improvements in diagnosis and case selection due to the introduction of the prostate specific antigen (PSA) screening test. The improved ultrasound-guided delivery techniques make the treatment easier and more precise. The radioactive sources used most often in current practice are ${ }^{125} \mathrm{I}$ and ${ }^{103} \mathrm{Pd}$. They are short halflife low-energy emitting sources, which have less penetration and therefore their dose is more localized.

An accurate measurement of the radiation strength of seeds is a crucial part of quality assurance for brachytherapy. AAPM TG-56 recommended that the accuracy of seed calibration should be within $3 \%$ [4] [5]. Currently there is no primary standard or calibration service for LDR brachytherapy in Canada, and Canadian cancer centers 
are required to access calibration laboratories in the US (with the associated problems of cross-border shipping of equipment). The National Research Council of Canada therefore initiated a program to develop a primary standard for calibrating LDR sources and to disseminate this to Canadian users by calibrating well type ion chamber used in cancer centers. The starting point is a commercial version of the wide-angle free air chamber (WAFAC) pioneered by NIST. It was designed as a primary standard to measure the air kerma strength of low dose brachytherapy seeds, which would be used to calibrate well chamber. The purpose of this project is to investigate the performance of the NRC WAFAC and commission it as a primary standard. Work is ongoing to refine operations of the primary standard and develop the calibration protocol for clinical users, with an anticipated launch of a calibration service in 2016 or 2017.

\subsection{Primary Standard for low energy photons}

There are three fundamental quantities that are used to describe photon interactions with matter [6]. They are kerma, exposure and dose. Kerma (K) was introduced by the ICRU to describe the initial interaction between indirectly ionizing radiation and the medium. Kerma stands for Kinetic Energy Released in the Medium [7] and is defined as:

$$
K=\frac{d E_{t r}}{d m}
$$

where $d E_{t r}$ is the kinetic energy transfered from indirectly ionizing radiations (photons and neutrons) to electrons in a volume element whose mass is $\mathrm{dm}$ in a finite volume during some time interval [6] [7]. 
The free air chamber is the most commonly used standard instrument for air kerma. Figure 1.2 is a schematic diagram of a conventional free air chamber, which is currently used as the primary standard of air kerma of low and medium energy x ray at NRC. Detail descriptions of this instrument can be found in the report of Henry and Garrett [8].

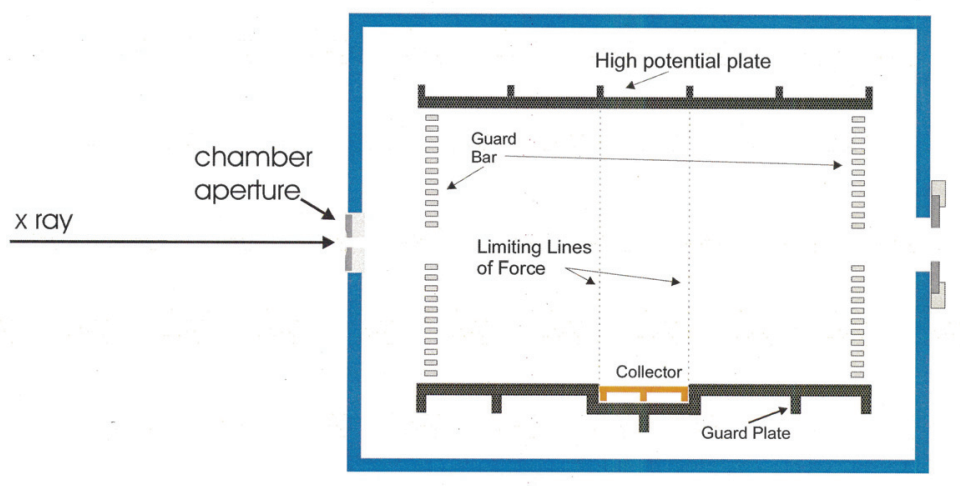

Figure 1.2: Schematic diagram of a conventional free air chamber used for $\mathrm{x}$ ray primary standard.

The free air chamber actually measures the charge liberated in a defined air volume. To transfer the measurement from charge (or exposure) to air kerma, a parameter $\left(W_{\text {air }} / e\right)$ is used, which is the mean energy expended in dry air per ion pair formed [6]. $\left(W_{\text {air }} / e\right)$ can be expressed in units of $\mathrm{eV}$ per ion pair or $\mathrm{J} / \mathrm{C}$. The value currently used is $33.97 \mathrm{~J} / \mathrm{C}$ [6]. In this way kerma can be measured using a free-air chamber as:

$$
K=\frac{Q}{v \rho_{\text {air }}}\left(\frac{W_{\text {air }}}{e}\right) \prod_{i} k_{i},
$$

where $\mathrm{Q}$ is charge collected by free-air chamber; $v$ is the defined volume where $\mathrm{Q}$ is produced; $\rho_{\text {air }}$ is the density of air in dry and standard conditions; $\prod_{i} k_{i}$ is the product of various correction factors. 


\subsection{Brachytherapy Seeds}

Brachytherapy seeds are encapsulated radioactive sources. The sources that have been used include ${ }^{226} \mathrm{Ra},{ }^{222} \mathrm{Rn},{ }^{137} \mathrm{Cs},{ }^{60} \mathrm{Co},{ }^{192} \mathrm{Ir},{ }^{103} \mathrm{Pd},{ }^{131} \mathrm{Cs},{ }^{169} \mathrm{Yb}$ and ${ }^{125} \mathrm{I}$. Gold used to be used for encapsulation. Currently ${ }^{125} \mathrm{I}$ and ${ }^{103} \mathrm{Pd}$ are common LDR radioactive sources and titanium is the most common encapsulation material.

The low energy of the photons emitted, self-absorption and filtration effects are big factors to determine the overall dosimetric characteristics for the seeds. They are very sensitive to the details of encapsulation geometry and internal structure. Seeds containing the same radioisotope and encapsulation, but minor differences in design or manufacturing processes can have significant dosimetric differences. That is also why air kerma rate constant or apparent activity are not good parameters to describe the radioactive strength of a seed. Regardless of the characteristics of the seeds, the energy of these gamma- and x rays $(10-30 \mathrm{keV})$ and the low activity also means that standardization is a challenge.

Figure 1.3 shows the schematics of a variety of brachytherapy seeds. [9] Their geometry and internal structure are obviously very different, but their external dimension do not vary as much as the internal structure. They are all encapsulated in titanium with $0.8 \mathrm{~mm}$ diameter and 4.5-5.0 $\mathrm{mm}$ length.

Figure 1.4 is a photograph of the brachytherapy seeds used in this project. These are model 6711 seeds made by Medi-Physics Inc [10]. ${ }^{125} \mathrm{I}$ is adsorbed onto a silver rod within welded titanium capsules, which is the same as the Amersham Health model 6711 source illustrated in figure 1.3. The radionuclide purity is higher than $99.9 \%{ }^{125} \mathrm{I}$ and less than $0.005 \%{ }^{126} \mathrm{I}$. Each seed has nominal air kerma strength $0.618 \mu \mathrm{Gy} \mathrm{m}^{2} / \mathrm{h}$ at the specified reference date. ${ }^{125} \mathrm{I}$ decays via electron capture. The 


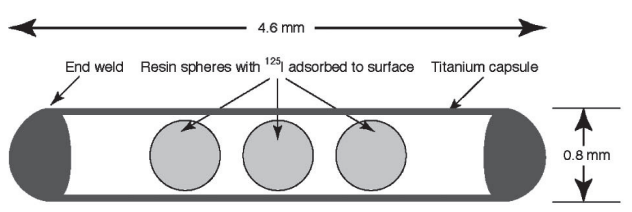

Amersham Health model 6702 source

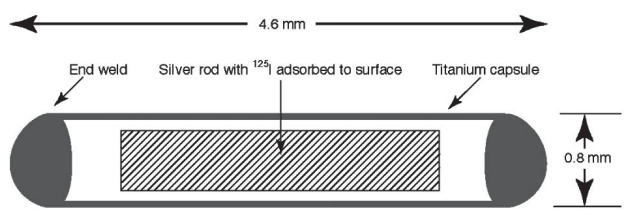

Amersham Health model 6711 source

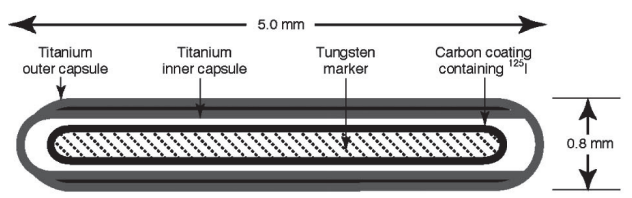

Best model 2301 source

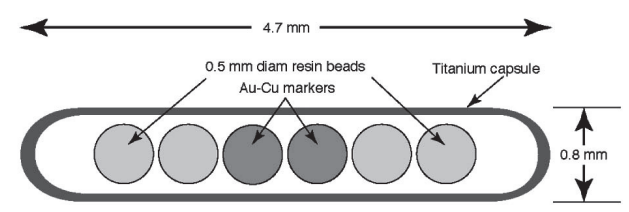

NASI model MED3631-A/M or MED3633 source

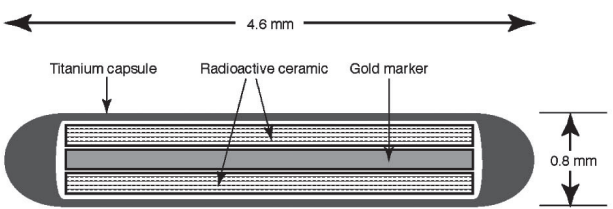

Bebig model I25.S06 source

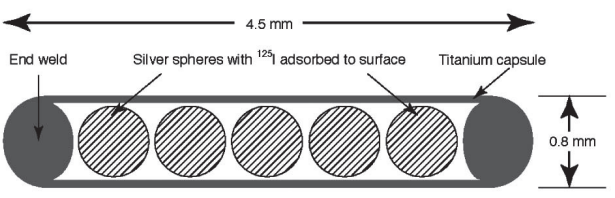

Imagyn model IS-I2501 source

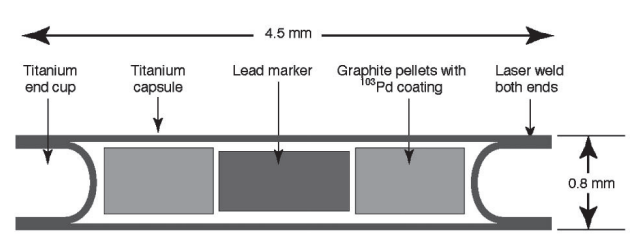

Theragenics model 200 source

Figure 1.3: Drawings of the internal structure of brachytherapy seeds examined in the AAPM TG-43U report [9]. Image reproduced with permission of AAPM.

seed emits photons in the energy level of: 27.2, 27.5, 31.0, 31.7 and $35.5 \mathrm{keV}$ from

${ }^{125} \mathrm{I} ; 22.0,22.2,24.9$ and $25.5 \mathrm{keV}$ fluorescence from the silver rod and about $4.5 \mathrm{keV}$ from the Ti encapsulation [2].

\subsection{Brachytherapy Seed Calibration}

Brachytherapy seeds used for brachytherapy treatment have to be verified on site using calibrated ion chambers, which are traceable to a primary standard dosimetry 


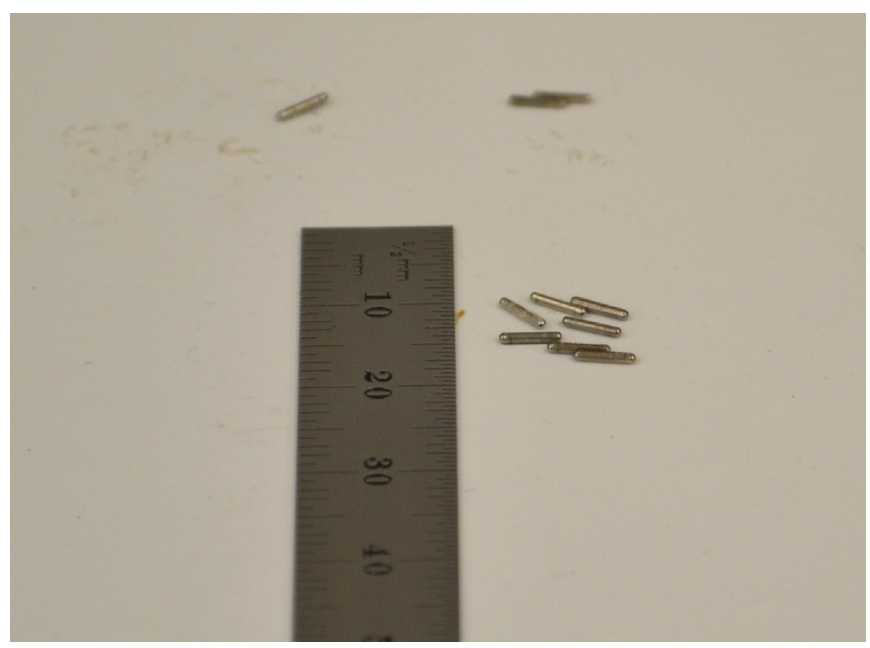

Figure 1.4: External dimension and appearance of ${ }^{125}$ I LDR Brachytherapy seeds.

laboratory. Accidents have been caused due to a lack of calibration [1]. The IAEA has a technical report as a guideline on standardized procedures for the calibration of brachytherapy source, IAEA-TECDOC-1274, "Calibrations of photon and beta ray sources used in brachytherapy" [1].

The current recommended quantities for the specification of the gamma brachytherapy sources are the reference air kerma rate and the air-kerma strength. The reference air kerma rate is defined by the International Commission on Radiation Units and Measurements (ICRU). The air-kerma strength $S_{\mathrm{k}}$ was introduced by the AAPM TG-32 report in 1987, and revised with minor changes by AAPM TG-43, and defined as [9]:

$$
S_{\mathrm{k}}=\dot{K}_{\delta}(d) \cdot d^{2},
$$

where $\dot{K}_{\delta}(d)$ is the air-kerma rate in vacuo due to photon energies greater than $\delta$ located at a distance $d$ from the center of the seed.

Figure 1.5 is a coordinate system for a brachytherapy seed [9]. $\dot{K}_{\delta}(d)$ must be measured on the plane of $z=0$, and $\theta_{0}$. "in vacuo" refers to kerma measured in a 
non-vacuum situation, and then corrected for air attenuation and all kinds of scatter including in air, objects between source and detector, as well as nearby objects [9]. The cutoff energy $\delta$ is used to exclude low energy photons, which do not contribute to the dose significantly at distances larger than $1 \mathrm{~mm}$ in tissue. Such photons are not significant in biology but increase the air kerma rate measured. More discussion can be found in section 3.5.10.1. $\delta$ is usually equal to $5 \mathrm{keV}$. The distance $d$ must also be on the transverse plane $\left(\mathrm{z}=0, \theta=90^{\circ}\right)$ and it can be any distance that is large relative to the maximum linear dimension of the detector and source. $S_{\mathrm{k}}$ is independent of $d$.

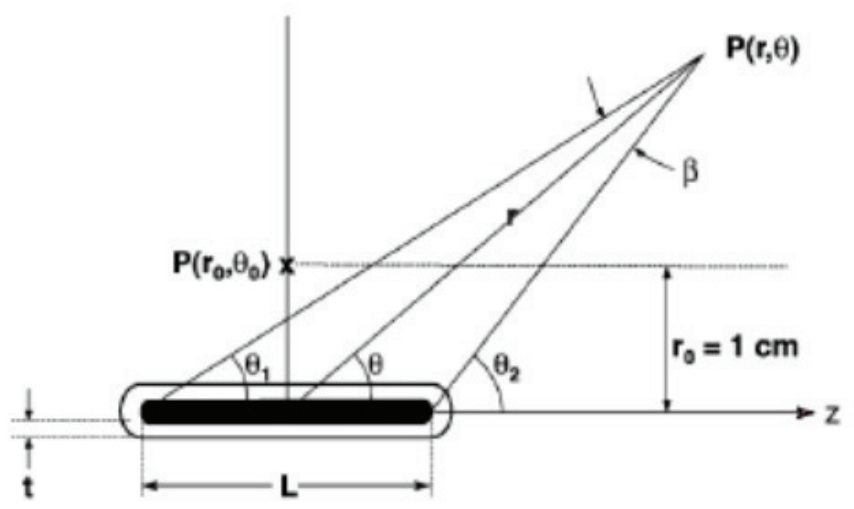

Figure 1.5: Coordinate system for a brachytherapy seed [9]. $S_{\mathrm{k}}$ must be measured on the plane of $\mathrm{z}=0$, and $\theta=90^{\circ}$. Image reproduced with permission of AAPM.

The reference air kerma rate defined by ICRU is that of the kerma rate to air at a reference distance of one meter, corrected for air attenuation and scattering [1]. Thus it is numerically equivalent to air-kerma strength at that specific distance. Air-kerma strength will be used in this thesis for the specification of low dose brachytherapy seeds.

Air kerma strength for brachytherapy seeds has to be traceable to the primary standard. The National Institute of Standards and Technology (NIST), formerly the National Bureau of Standards (NBS), started brachytherapy seed calibration as a 
pioneer with a parallel free air chamber in the early 1980s, and has been using a wide angle free air chamber (WAFAC) since 1993, which officially became a primary standard for low energy photon sources in 1999 [2].

In addtion to the WAFAC there are a number of standards used for calibration of low dose brachytherapy seeds. The University of Wisconsin uses the variable aperture free air chamber (VAFAC) for calibrations of ${ }^{125} \mathrm{I}$ and ${ }^{103} \mathrm{Pd}$ [11]. The PhysikalischTechnische Bundesanstalt (PTB) developed the Grossvolumen Extrapolationskammer (GROVEX) [12]. The National Physical Laboratory (NPL) calibrate ${ }^{125}$ I seeds using a well-type secondary standard that is traceable to the NPL primary standard for air kerma [13]. The Laboratoire National Henri Becquerel has designed a circular free-air chamber [14].

The frequently used working standard for routine calibration of radioactive brachytherapy seeds is a well-type ion chamber as shown in figure 1.6, which is traceable to the primary standard.

The primary standard is used to establish air kerma rate for seeds and then the calibrated seeds are used to calibrate well type ion chambers transferring the primary standard to the working standard [15].

Figure 1.6 shows what the working standard well chamber looks like. It is a unsealed ion chamber and has the same principle as other ion chambers used in a radiation lab. It is designed for both LDR and HDR measurements. NRC has already established an HDR primary standard [16]. The intent of this project is to establish a primary standard for LDR sources and therefore, calibration services would be provided for well chambers used in both HDR and LDR brachytherapy.

The following chapters will describe some details about instruments, commission- 


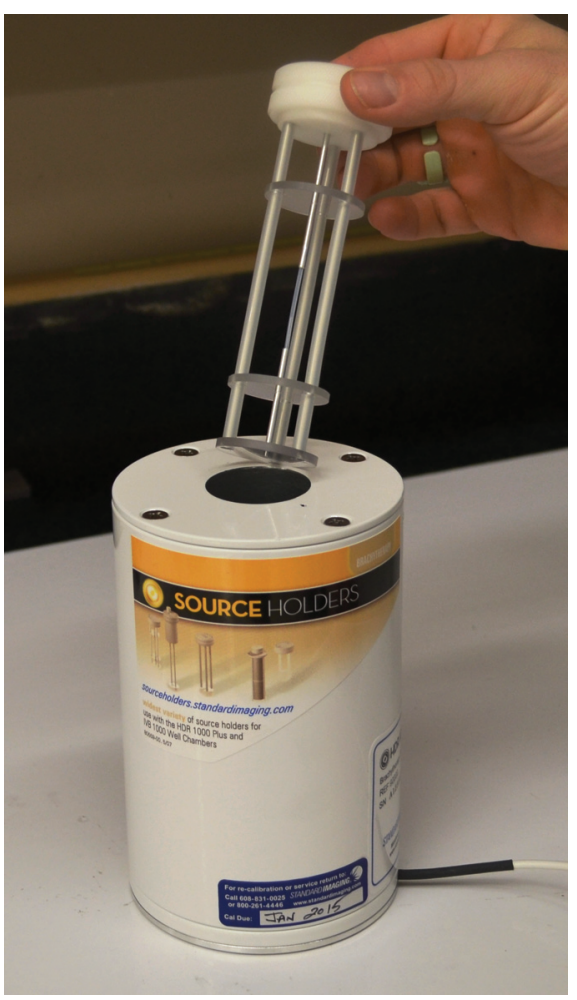

Figure 1.6: The well type ion chamber used as working standard traceable to the primary standard. The specific type used at NRC is the SI HDR-1000.

ing processes, important effects and the validation of the new primary standard.

Chapter 2 includes the structure of the wide angle free air chamber (WAFAC), the working principle of the WAFAC and functions of each main parts.

Chapter 3 describes problems solved during commissioning, and the determination of correction factors.

Chapter 4 describes studies on the polarity effect including the observation, the mechanism of the effect and the way to eliminate it.

Chapter 5 mainly describes the validation of the accuracy and precision of the WAFAC. 
Chapter 6 gives the summary of the work and the further work needed to be done before starting the calibration service. 


\section{Chapter 2}

\section{Wide Angle Free Air Chamber}

\subsection{General}

The Wide-Angle Free-Air Chamber (WAFAC) was pioneered by NIST in the early 1990's and formally introduced on January 1, 1999. It is a special version of a free air chamber. The general principle is the same as other versions of the free air chamber. The electrons are set in motion by photon interactions. Then, the electrons produce ionization as they slow down. The free air chamber measures all the ionization produced in air by radiation including all collisional interactions in air. To collect all the electrons liberated in air of mass $m$ they must be completely stopped in air. Thus the chamber size will depend on the free path of electrons that are related to the photon energy it measures. The WAFAC was designed to measure photon energies up to $40 \mathrm{keV}$.

Figure 2.1 is the external view of the WAFAC at the NRC laboratory, which was originally designed by NIST, and manufactured by Hopewell Designs Inc. (Al- 


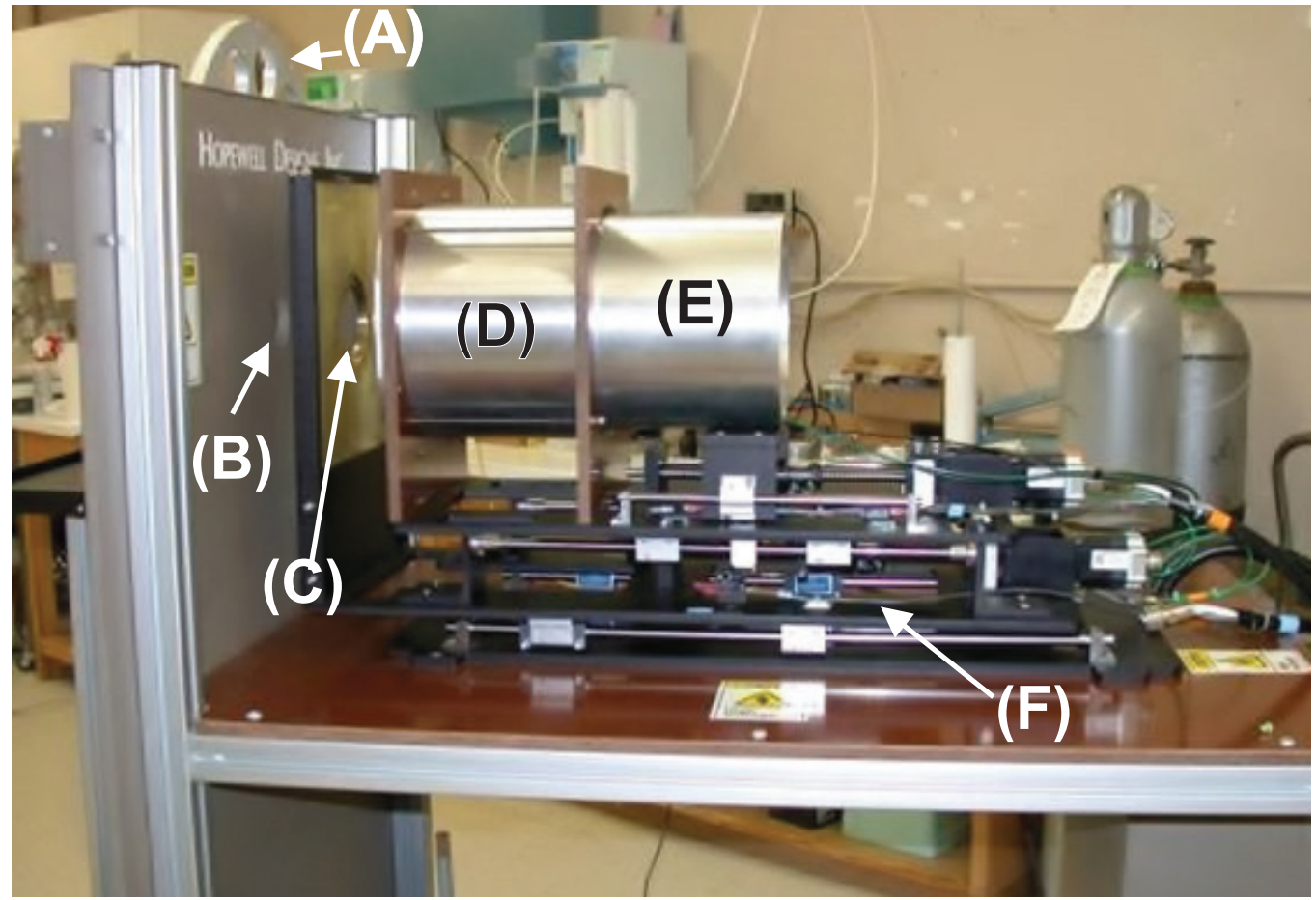

Figure 2.1: The commercial auto wide angle free air chamber at NRC. (A) is the filter wheel. (B) is the preliminary limit aperture. (C) is the chamber aperture. (D) is the outer cylinder. (E) is the inner cylinder. (F) is the automatic cylinder-moving system controlled by the computer to close or separate outer and inner cylinders.

pharetta, GA). Major components include the following: (A) is the filter wheel there are ten holes each of $7 \mathrm{~cm}$ diameter. Eight of the holes hold different filters, and one is a blank, and another one holds a piece of lead. The piece of lead on the filter wheel act as a shutter. The wheel's rotation is controlled by the computer to switch between different filters and to open or close the source beam. (B) is a large piece of lead covered with aluminum playing a role as the preliminary limit aperture to block unnecessary radiation scatter and to only allow a cone shaped beam to go 


\begin{tabular}{|l|l|l|}
\hline Free Air Chamber & LEES & WAFAC \\
\hline Distance From Source & $100 \mathrm{~cm}$ & $30 \mathrm{~cm}$ \\
\hline Aperture Size & $5 \mathrm{~mm}$ & $80 \mathrm{~mm}$ \\
\hline Defined Volume & $0.9069 \mathrm{~cm}^{3}$ & $403.7 \mathrm{~cm}^{3}$ \\
\hline Half Angle & $0.14^{\circ}$ & $8^{\circ}$ \\
\hline
\end{tabular}

Table 2.1: Differences between NRC low energy exposure standard (LEES) and WAFAC

through. $(\mathrm{C})$ is the chamber aperture that limits the number of photons, and defines the area part of the air volume, where charge produced by photons within the air volume is collected. It also defines the measurement location $d$ in equation 1.3. (D) is the outer cylinder. It physically holds the high voltage electrode. At the same time, it is isolated from the electrode and plays a role as the middle electrode and holds half of the voltage of the high voltage electrode to maintain the electrical field. (E) is the inner cylinder, used for holding the collecting electrode. (F) is the automatic cylinder-moving system controlled by the computer to close or separate outer and inner cylinders.

Table 2.1 lists the major differences between the NRC low energy exposure standard (LEES) and the WAFAC. Compared to the "standard" free air chamber that is currently used as a low energy exposure standard, the wide-angle free air chamber has a large aperture to admit the photon beam, with a shorter distance from the radiation source. Therefore the cone shaped beam has a wide solid angle. It makes the WAFAC much more sensitive than the low energy primary standard. It was specially designed to measure low dose and low energy photon brachytherapy seeds, particularly for ${ }^{125} \mathrm{I}$ and ${ }^{103} \mathrm{Pd}$, which are the most commonly used LDR photon sources. Because of the 
larger defined volume and shorter distance, the WAFAC is about 400 times more sensitive than the LEES.

\subsection{The Working Principles of the WAFAC}

The WAFAC consists of two aluminum cylinders concentrically set with each other as shown in figure 2.2. Both have aluminized Mylar electrodes on the end, which are isolated from the cylinders as shown in figure 2.3. The gap between the two electrodes forms an air volume. Each cylinder can move in coordinated but opposite directions for the same distance, which keeps the center plane of the chamber persistent. The distance of the separation defines the length of air volume used to calculate the air mass.

Figure 2.3 is a schematic of the working principle of the WAFAC. The front electrode is a piece of aluminized Mylar biased with high voltage to maintain the electrical field at $110 \mathrm{~V} / \mathrm{cm}$. The outer cylinder not only physically supports the front electrode, but at the same time is charged with half of the voltage of the high voltage electrode in order to maintain the electric field shape. The rear electrode is also a piece of aluminized Mylar but etched in a circle around the center to divide it into central circular collector and a grounded annular guard ring as shown in figure 2.4. The volume between these two electrodes is the region where ionization is collected. The charges produced by photons and electrons in the volume are collected on the $100 \mathrm{pF}$ capacitor as shown in figure 2.5. The volume of air where the charge is produced and collected is the area of the aperture times the length of separation of the high voltage and collecting electrodes.

When photons pass through the aperture ionization happens not only in the air 


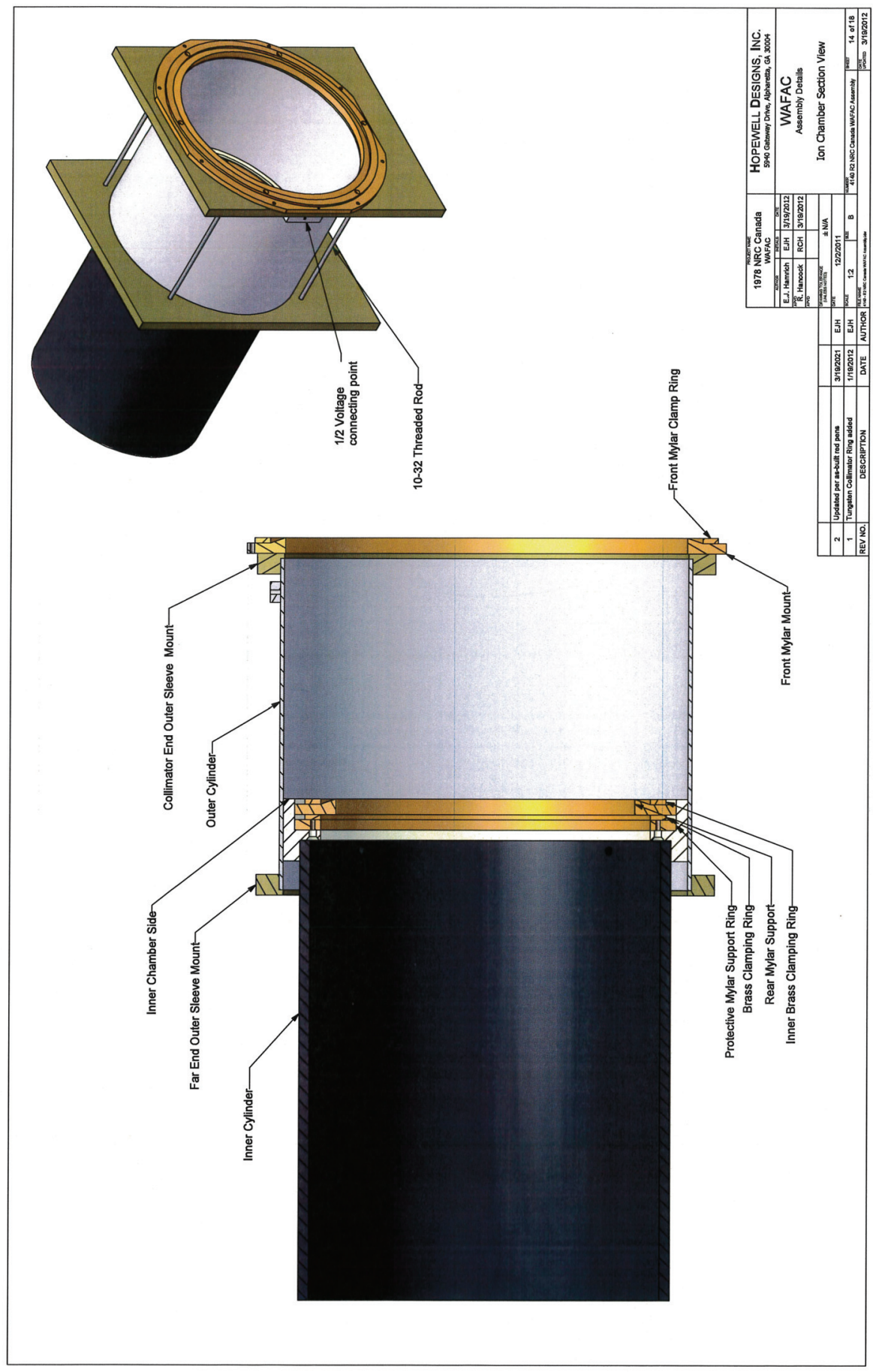

Figure 2.2: The design drawing of the two cylinders form the chamber volume of the WAFAC. 


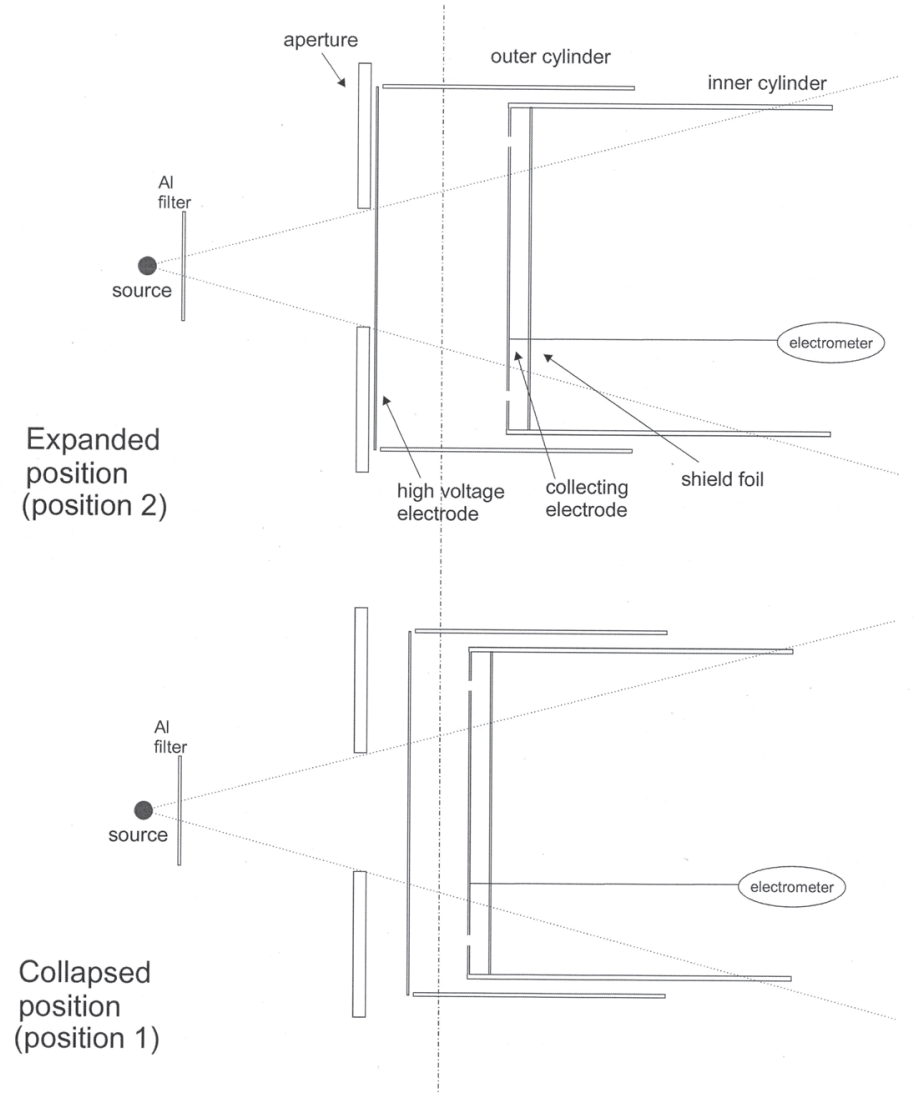

Figure 2.3: Schematic of the NRC WAFAC.

inside and outside the collecting volume but also at the front Mylar electrode and back electrode. In contrast to conventional free air chambers, these photon interactions in the electrodes disturb charge particle equilibrium in the air near their surface. To remove the perturbation, a complete measurement cycle includes measuring the charge collected and length of the collecting volume twice with different chamber lengths. The maximum continuous slowing down approximation (CSDA) range for electrons set in motion by ${ }^{125} \mathrm{I}$ and ${ }^{103} \mathrm{Pd}$ is $1.48 \mathrm{~cm}$ and $0.89 \mathrm{~cm}$, respectively. The 


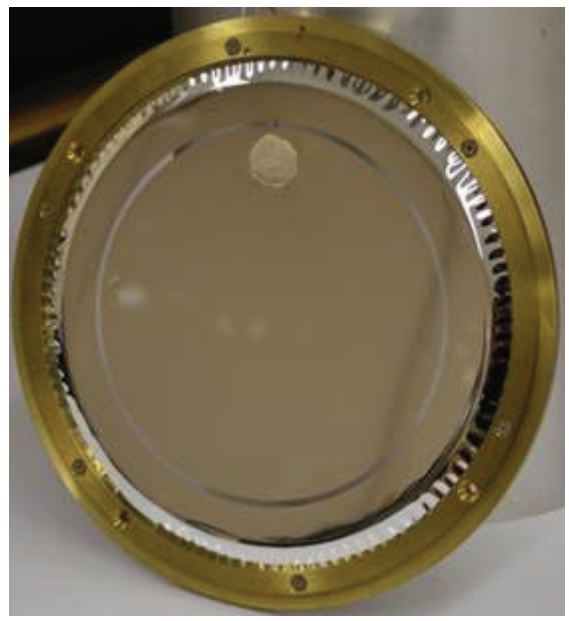

Figure 2.4: The rear electrode is etched in a circle around the center to divide it into central circular collector and a grounded annular guard ring.

smallest electrode separation must be greater than twice the CSDA to eliminate the effect of the electrode foil. $6 \mathrm{~cm}$ was used for smaller length, which is labeled as position 1, for air kerma strength measurement for the ${ }^{125} \mathrm{I}$ seeds in this project. The charge difference $\triangle Q$ is the charge produced in the effective air volume, which is the difference of air volume between two chamber positions. The dry air quantity, m, in which the charge produced equals to the air volume times the dry air density. The exposure, $\mathrm{X}$, can therefore be calculated from the definition: $\mathrm{X}=\triangle Q / m$.

The collecting electrode connects to a setup shown in figure 2.5, which use a Keithley 642 remote head and meter for charge measurement [17]. Collected charge, $Q$, is the Voltage measured using the Keithley 2002 multimeter times the capacitance $(100 \mathrm{pF})$, i. e. $Q=C V$. Equation 2.1 can be applied to the situation of the WAFAC to calculate $S_{\mathrm{k}}$ :

$$
S_{\mathrm{k}}=\frac{\left(V_{\mathrm{p}_{1}}-V_{\mathrm{p}_{2}}\right) C d^{2}}{\left.\left(L_{\mathrm{p}_{1}}-L_{\mathrm{p}_{2}}\right) A \rho_{\mathrm{air}} t(1-\bar{g})\right)}\left(\frac{W}{e}\right) \prod_{i} k_{i},
$$

where $\left(V_{\mathrm{p}_{1}}-V_{\mathrm{p}_{2}}\right)$ is the voltage difference measured by the voltmeter in figure 2.5 for the cylinders in collapsed position (position 1) and expanded position (position 2) in 


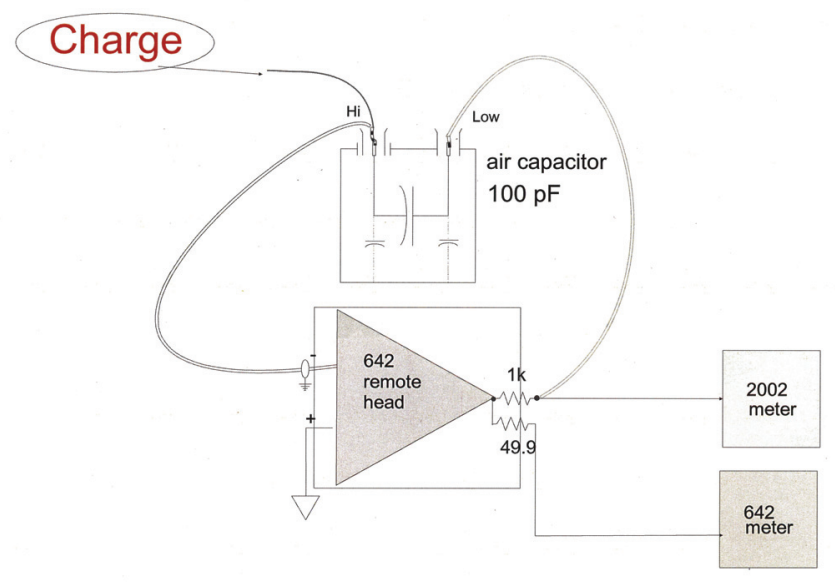

Figure 2.5: The setup of measurement of charge collected on a $100 \mathrm{pF}$ capacitor. Charge collected from WAFAF is deposited to the standard air capacitor and connect to the input on Keithley remote head. The voltage on the air capacitor measured by the Keithley 2002 multichannel multimeter and the Keithley 642 multimeter [17].

figure 2.3 respectively. $C$ is the capacitance in figure 2.5. $\left(V_{\mathrm{p}_{1}}-V_{\mathrm{p}_{2}}\right) \times C=Q$ is the charge collected in the effective volume. Subtraction of the two terms shows the cancelling out of the charge perturbation at the front and rear electrodes. $\left(L_{\mathrm{p}_{1}}-L_{\mathrm{p}_{2}}\right)$ is the difference of the chamber lengths of the two cylinder positions as illustrated in figure 2.3. $A$ is the area of the aperture. $\left(L_{\mathrm{p}_{1}}-L_{\mathrm{p}_{2}}\right) \times A$ is the effective volume where charge $Q$ is collected. $\bar{g}$ is the fraction of the electron kinetic energy radiated as photons. $t$ is the time period of charge collection. $\frac{\left(V_{\mathrm{p}_{1}}-V_{\mathrm{p}_{2}}\right) C}{\left(L_{\mathrm{p}_{1}}-L_{\mathrm{P}_{2}}\right) A \rho_{\text {air }} t}$ is the exposure rate of the source. This converts to air kerma rate after multiplying $\frac{1}{(1-\bar{g})}\left(\frac{W}{e}\right)$, which is $\dot{K}_{\delta}(d)$ in equation 1.3. $\prod_{i} k_{i}$ is the product of correction factors.

The air kerma rate, $\dot{K}$, measured in the setup demonstrated in figure 2.3 is at the mid-point of the center plane. It is $\mathrm{P} 0$ in figure 2.6 at distance $d 0$. The effective volume of air, which is represented as a conical shape between front and back electrodes in figure 2.6, is equal to the length of the cylinder times the area which has a diameter 


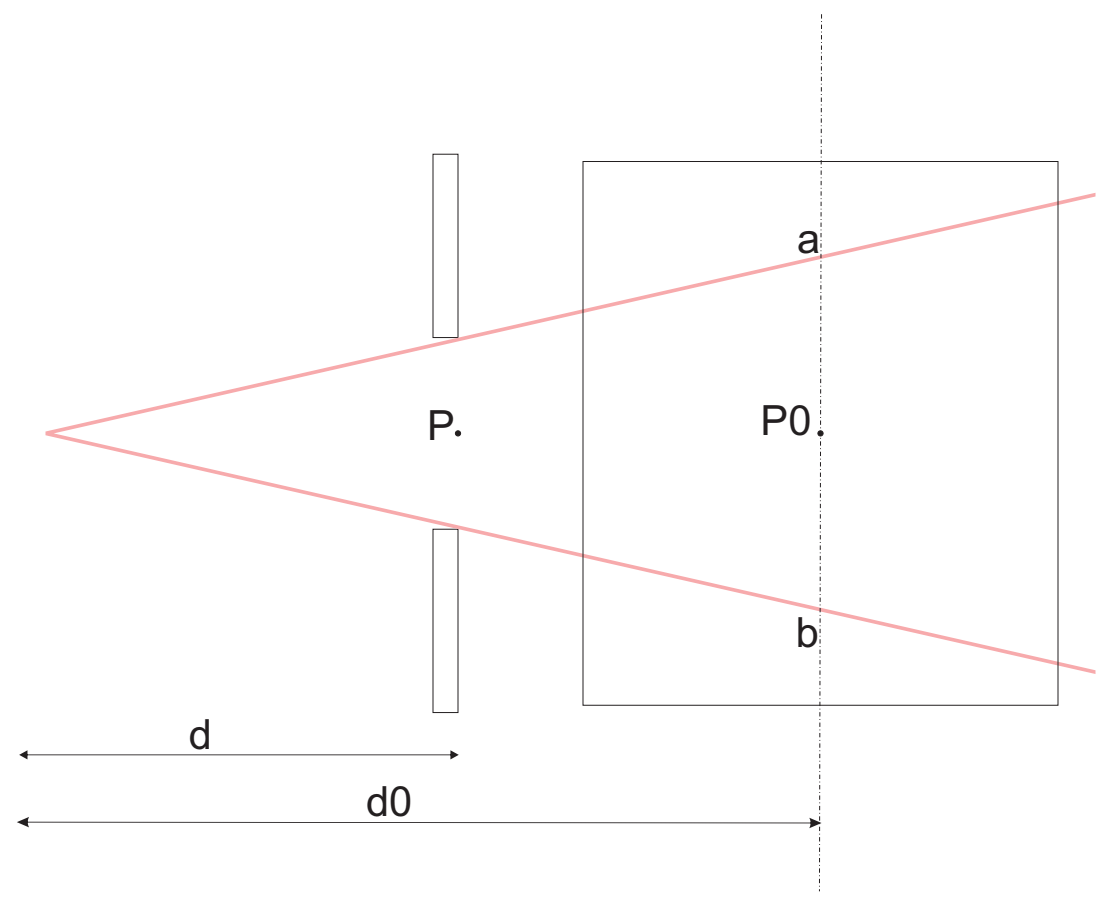

Figure 2.6: The measurement point of kerma rate. The box represents the imagined cylinder after subtraction of two cylinder positions. A cone shape is the radiation beam defined by aperture and location of source. The effective volume of air, which is represented as a conical shape between front and back electrodes is equal to the length of the box times the area which has a diameter of $a b$, in which the length of the box is the difference of length of position 1 and position 2. P0 is the center of the effective chamber. $\mathrm{P}$ is the point at the center of the aperture plane at down stream side. $\mathrm{d}$ is the distance from center of the source to the point $\mathrm{P}$, and $\mathrm{d} 0$ is the distance from center of the source to the point P0. 
of $a b$, in which the length of the cylinder is the difference of length of position 1 and position 2. The box shown in figure 2.6 represents the imaging cylinder as a effective chamber after subtraction of two cylinders position. a cone shape is the radiation beam defined by aperture and location of source.

In practice, it is more convenient to know the kerma rate at the point $\mathrm{P}$, where beam size and shape are limited by the aperture. The following proves that the kerma rate at point $\mathrm{P}$ is the same expression as above but using diameter of the aperture instead of $a b$ (ignoring the effect of air attenuation):

$$
\dot{K}_{P 0}=\frac{\triangle Q}{\rho_{\text {air }} \pi\left(\frac{a b}{2}\right)^{2} \triangle L t} \frac{1}{(1-\bar{g})}\left(\frac{W_{a i r}}{e}\right) .
$$

At point $\mathrm{P}$ the kerma rate will be $\left(\frac{d 0}{d}\right)^{2}$ times higher than that at $P 0$ according to the inverse square law.

$$
\begin{gathered}
\dot{K}_{\mathrm{p}}=\left(\frac{d 0}{d}\right)^{2} \dot{K}_{P 0}=\left(\frac{d 0}{d}\right)^{2} \frac{\triangle Q}{\rho_{\text {air }} \pi\left(\frac{a b}{2}\right)^{2} \triangle L t} \frac{1}{(1-\bar{g})}\left(\frac{W_{\text {air }}}{e}\right) \\
=\frac{\triangle Q}{\rho_{\text {air }} \pi\left(\left(\frac{a b}{2}\right)\left(\frac{d}{d 0}\right)\right)^{2} \triangle L t} \frac{1}{(1-\bar{g})}\left(\frac{W_{\text {air }}}{e}\right) .
\end{gathered}
$$

The radius of the aperture, $r$, is:

$$
r=\frac{a b}{2} \times \frac{d}{d 0} .
$$

Replace equation 2.4 in equation 2.3 and $\pi r^{2}=\mathrm{A}$ (area of aperture). Then equation 2.3 gives the kerma rate at point $\mathrm{P}$ becomes: 


$$
\dot{K}_{\mathrm{p}}=\frac{\triangle Q}{\rho_{\text {air }} A \triangle L t} \frac{1}{(1-\bar{g})}\left(\frac{W_{\text {air }}}{e}\right)
$$

Comparing equation 2.5 with equation 2.1 , it can be seen that, after applying other terms include attenuation corrections from $\mathrm{P}$ to $\mathrm{P} 0$ and the other correction factors $\prod_{i} k_{i}$ then, equation 2.5 and equation 2.1 are equivalent. Equation 2.1 is suitable for calculating the air kerma rate at point $\mathrm{P}$. Therefore $d$ should be used in equation 2.1 for calculating $S_{\mathrm{k}}$.

\subsection{Major Parts and Features of the WAFAC}

The major parts of the NRC WAFAC have been briefly mentioned before in sections 2.1 and 2.2. This section focuses in more detail on those parts.

\subsubsection{Middle Electrode}

The middle electrode is actually the outer cylinder, which plays its role in not only physically holding the high voltage mylar electrode at its end, but also to carry half of the high voltage on it as well. It helps to maintain the electrical field inside the air volume properly (see figure 2.7).

Figure 2.7 shows the electrical field lines that have been calculated by NIST at the expanded position of the chamber. At collapsed position, the electrical field line are nearly parallel. [2]. 


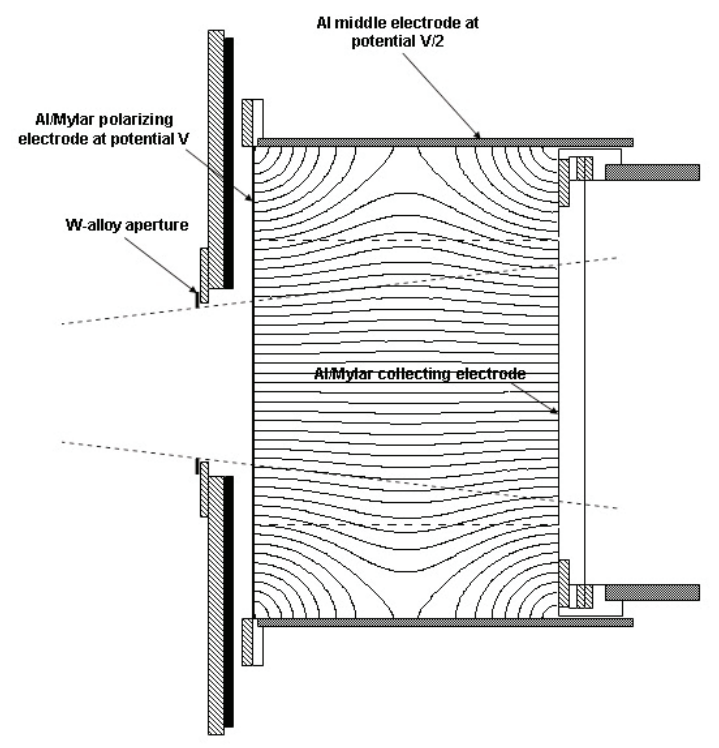

Figure 2.7: The electrical field of air volume of WAFAC calculated by NIST [2]. Permission not required to reproduce image.

\subsubsection{Filter Wheel}

Figure 2.8 shows the filter wheel. It contains 10 holes of $7 \mathrm{~cm}$ diameter each. It holds filters located between the seed and preliminary limiting aperture. The filter is mainly used to remove photons that have energy below $\delta$, which is approximately $5 \mathrm{keV}$. In addition to filters, one of them holds a piece of $6 \mathrm{~mm}$ thick lead and another is kept empty. These two are used for stopping the radiation for leakage measurements and opening for kerma measurement without filter. The movement of the filter wheel is fully controlled by a computer which is coordinated with the measurement steps.

\subsubsection{Aperture}

Figure 2.9 is a photo of the aperture, which is a critical part, not only for limiting photons entrance but also for defining the effective volume and the reference distance 


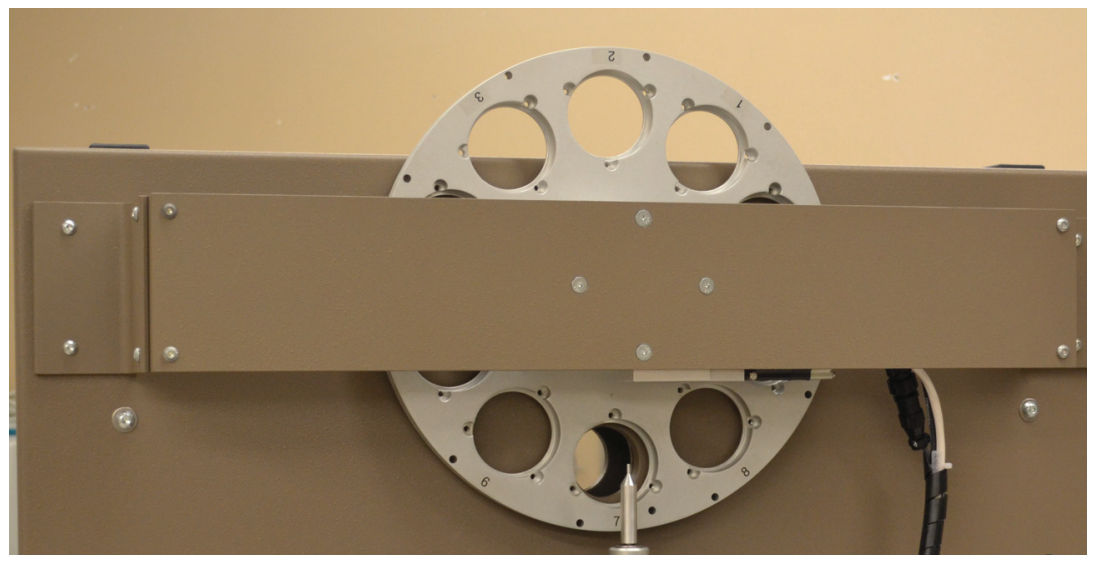

Figure 2.8: The filter wheel of the WAFAC.

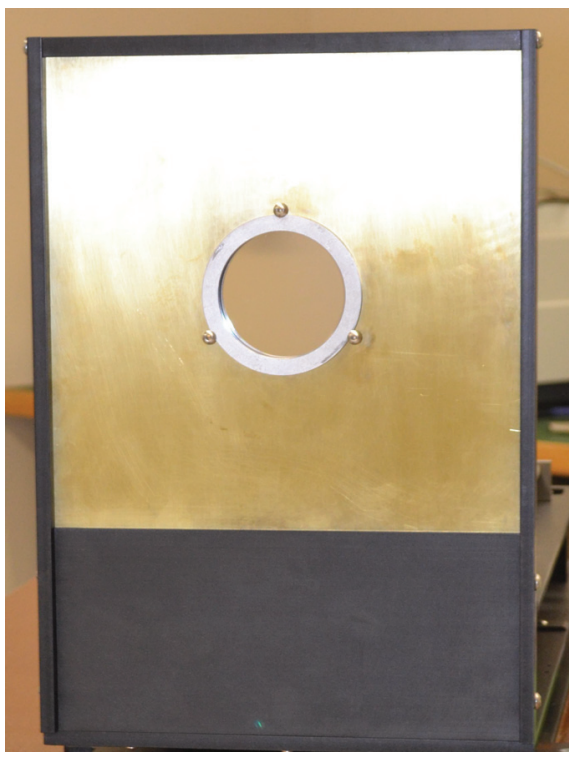

Figure 2.9: The aperture of the WAFAC. 
from the radioactive source. As described in section 2.2, it defines the area $A$ of effective volume in equation 2.1. The distance between the aperture plane on the down stream side and the center line of brachytherapy seed has to be measured precisely and kept consistent, which is the distance $d$ in equation 2.1 (see figure 2.6). The aperture is a tungsten annulus, with dimensions of $80.00 \mathrm{~mm}$ inner diameter and $101.6 \mathrm{~mm}$ outer diameter and $4 \mathrm{~mm}$ thickness. The inner diameter has been verified by calipers.

In the original design, the aperture was held by a piece of $3 \mathrm{~mm}$ thick brass. A layer of $3 \mathrm{~mm}$ thick lead has been added behind the brass layer to reduce the penetration of photons.

\subsubsection{Seed Holder}

The seed holder used in this project is shown in figure 2.10. It is made of nylon. The holder is $12.8 \mathrm{~mm}$ in diameter and $59.1 \mathrm{~mm}$ high. The height of the cone is $10.7 \mathrm{~mm}$. There is a hole on the vertex $2 \mathrm{~mm}$ depth for accommodating a seed. The holder connects to a rotating motor on its bottom. It can rotate the seed to average over the seed anisotropy during measurement and it is controlled by a computer. The correction of scatter for this seed holder is used as 0.9985, taken from NIST's work, but will be verified in future work.

\subsubsection{Cylinder Movement Control}

The cylinders are installed on two separate slide plates powered by stepper motors and their movement is controlled by a computer program. No matter what volume is preset in the program their movement is controlled to move in both directions to keep 


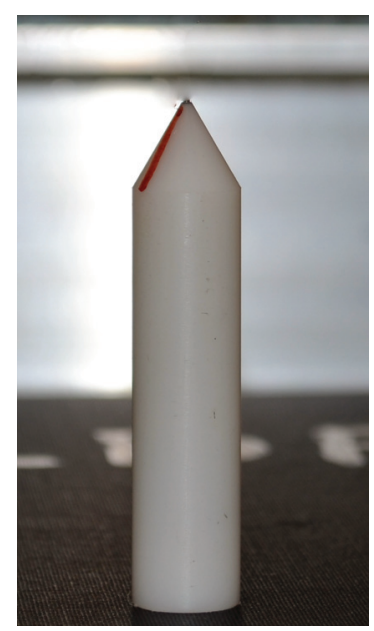

Figure 2.10: The seed holder.

the center of volume at the same distance from the source. The cylinder movement position was verified using slide micrometers.

\subsubsection{Electrical Equipment}

Figure 2.5 shows the setup of charge measurement using the Keithley 642 remote head and multimeter [17]. To improve reading precision, the multimeter Keithley 2002 (Cleveland, OH) is added paralleling with the Keithley 642. The readings used for final calculation are read from the Keithley 2002. The Keithley 642 multimeter is mainly used for zero check controlling.

The capacitor used as shown in 2.5 is a standard air capacitor Model 1404-B manufactured by IET Labs Inc. (Long island, NY). The specification [18] of the air capacitor show it has an accuracy of $\pm 5 \mathrm{ppm}$ and stability (Long term drift) of less than $20 \mathrm{ppm} /$ year. Maximum change with orientation is $10 \mathrm{ppm}$. Temperature coefficient of capacitance is $2 \pm 2 \mathrm{ppm} /{ }^{\circ} \mathrm{C}$ from $-20{ }^{\circ} \mathrm{C}$ to $+65{ }^{\circ} \mathrm{C}$. For temperature cycling over range from $-20{ }^{\circ} \mathrm{C}$ to $+65^{\circ} \mathrm{C}$, the hysteresis is less than $20 \mathrm{ppm}$ at $23{ }^{\circ} \mathrm{C}$. 
The dissipation factor is less than $10^{-5}$ at $1 \mathrm{kHz}$.

A PS 325/2500V-25W high voltage power supply from Stanford Research Systems Inc. (Sunnyvale, CA) is used to apply the high voltage on the front electrode and middle electrode.

A set of NRC-built sensors read environment conditions including temperature, air pressure and humidity. These sensors are traceable to national standards.

All of the equipments communicate with the computer by GPIB or Ethernet interfaces. 


\section{Chapter 3}

\section{Commissioning}

\subsection{General}

Preliminary measurements showed that this instrument was in an unstable condition when this project first started. The measured leakage had the same level as the signal and the readings were not repeatable.

The software performed well for instrument control and read out raw data, but was not adequate for data analysis and applying correction factors.

\subsection{Troubleshooting}

Troubleshooting was the first step to start this project, which included checking the movement positions of two cylinders, grounding, connectors, and voltage applied on each electrode. Additionally, leakage of the capacitor, wires, the remote head and multimeters, i.e., all components that would affect the operation and reading, were 
checked.

\subsubsection{Cylinder Movement}

Two micrometers were installed for monitoring movement of each cylinder during measurements. The nominal volume at position 1 is $300 \mathrm{~cm}^{3}$ and $703.7 \mathrm{~cm}^{3}$ at position 2, which corresponds to lengths of $5.968 \mathrm{~cm}$ and $14.000 \mathrm{~cm}$ at position 1 and position 2 respectively. The nominal $\Delta L$ is $8.032 \mathrm{~cm}$. The measured results for the volume change from position 1 to position 2 are listed in table 3.1. The measured results

\begin{tabular}{|c|c|c|c|}
\hline No. & Front $(\mathrm{cm})$ & Rear $(\mathrm{cm})$ & Total Change $(\mathrm{cm})$ \\
\hline 1 & 4.015 & 3.976 & 7.991 \\
\hline 2 & 4.014 & 3.973 & 7.987 \\
\hline 3 & 4.014 & 3.975 & 7.989 \\
\hline ave & 4.014 & 3.975 & 7.989 \\
\hline st. dev & 0.0005 & 0.0012 & 0.0016 \\
\hline
\end{tabular}

Table 3.1: Cylinders moved from position 1 (volume $300 \mathrm{~cm}^{3}$ ) to position 2 (volume $\left.703.7 \mathrm{~cm}^{3}\right)$. Results showed that front electrode moved $0.039 \mathrm{~cm}$ more than rear electrode, which caused a centre displacement between the two positions. And the length difference $\Delta L$ was $0.54 \%$ less than the nominal length, which is $8.032 \mathrm{~cm}$.

show that movement of the outer cylinder is slightly more than the inner cylinder, which means the center of the air chamber plane actually shifted $0.0195 \mathrm{~cm}$ forward to the source when the air volume moved from $300 \mathrm{~cm}^{3}$ to $703.7 \mathrm{~cm}^{3}$. Also, the volume difference is not $703.7 \mathrm{~cm}^{3}-300 \mathrm{~cm}^{3}=403.7 \mathrm{~cm}^{3}$ but $\pi \times\left(\frac{8.000}{2} \mathrm{~cm}\right)^{2} \times 7.989 \mathrm{~cm}=$ $401.6 \mathrm{~cm}^{3}$, because the length change $\Delta L$ is $7.989 \mathrm{~cm}$. The results also demonstrate 
that the position movement controlled by computer has good reproducibility.

The displacement causes the actual volume to be $0.54 \%$ smaller than the nominal volume. It should lead to a correction of 1.0054 for volume as using $300 \mathrm{~cm}^{3}$ and $703.7 \mathrm{~cm}^{3}$ for position 1 (collapse) and position 2 (extend) respectively. Regarding the displacement of $0.0195 \mathrm{~cm}$ from source to the centre plane of the collecting volume when the air volume moved from $300 \mathrm{~cm}^{3}$ to $703.7 \mathrm{~cm}^{3}$, it does not affect measurement results significantly. As described in section 2.2, the aperture defines the size of the beam and the chamber is designed to intercept all of the beam. Thus, it does not matter where the centre is or if it is different for the two positions, except that one wants to keep the air attenuation the same for both settings. As per the distance from source to the centre of collecting volume is $30+9 \mathrm{~cm}$ at position 1 , the centre displacement at position 2 would only lead to less than $0.01 \%$ difference in air attenuation. Therefore the correction for centre displacement should be negligible. If we denote these two correction as $k_{v}$ for volume correction and $k_{c}$ for volume centre misplace then:

$k_{v}=1.0054$

and

$k_{c}=1.0000$.

The results listed in table 3.1 shows that WAFAC's unstable reading was not caused by the cylinder's movement, although the volume difference needs to be corrected. 


\subsubsection{Leakage of Capacitor, Multimeter and Remote Head}

The IET 1404-B standard air capacitor, Keithley 2002 multimeter and the remote head Keithley 642 electrometer were checked for leakage by replacing them individually with components from the current NRC low-energy primary standard system. The observations showed that there was no significant effect on the WAFAC system.

All connectors were cleaned and reconnected. The Voltage applied on front and middle electrodes were also checked and the results showed no significant leakage or deviation from expected values.

\subsubsection{Electric Field in the Collecting Volume}

The electric field in the collecting volume plays a big role in charge collection. It is maintained to be approximately $110 \mathrm{~V} / \mathrm{cm}$ in the collecting volume by: (1) the high voltage on the front electrode, (2) half of the high voltage on the middle electrode, (3) the grounded guard, and (4) the collecting electrode. The electrical field for the WAFAC's collecting volume was described in NIST's paper [2] as shown in figure 2.7. The figure shows a simulation of the electrical field lines at the expanded position of $16.0 \mathrm{~cm}$ collecting length. If the collecting length is $4.12 \mathrm{~cm}$, the electric field lines will be essentially straight. In such a set up designed by NIST, charges produced in the effective volume will be collected properly. If this set up is not followed properly and the electric field lines are distorted, one may obtain unstable results. For example, since the electrical field strength is inversely proportional to the radius of a surface, if any sharp edges exist, the electrical field would be distorted and this distortion might not be stable if the sharp component is loose or connected to a flexible part.

The cylinders were opened up for inspection. Sharp edges were observed on the 
wire connecting the collecting electrode, as shown in figure 3.1. To prove this was the reason causing the unstable reading, the sharp edge on the wire was removed and RTV103 adhesive was applied to cover the bare wire. Test results showed this process improved the signal quality significantly.

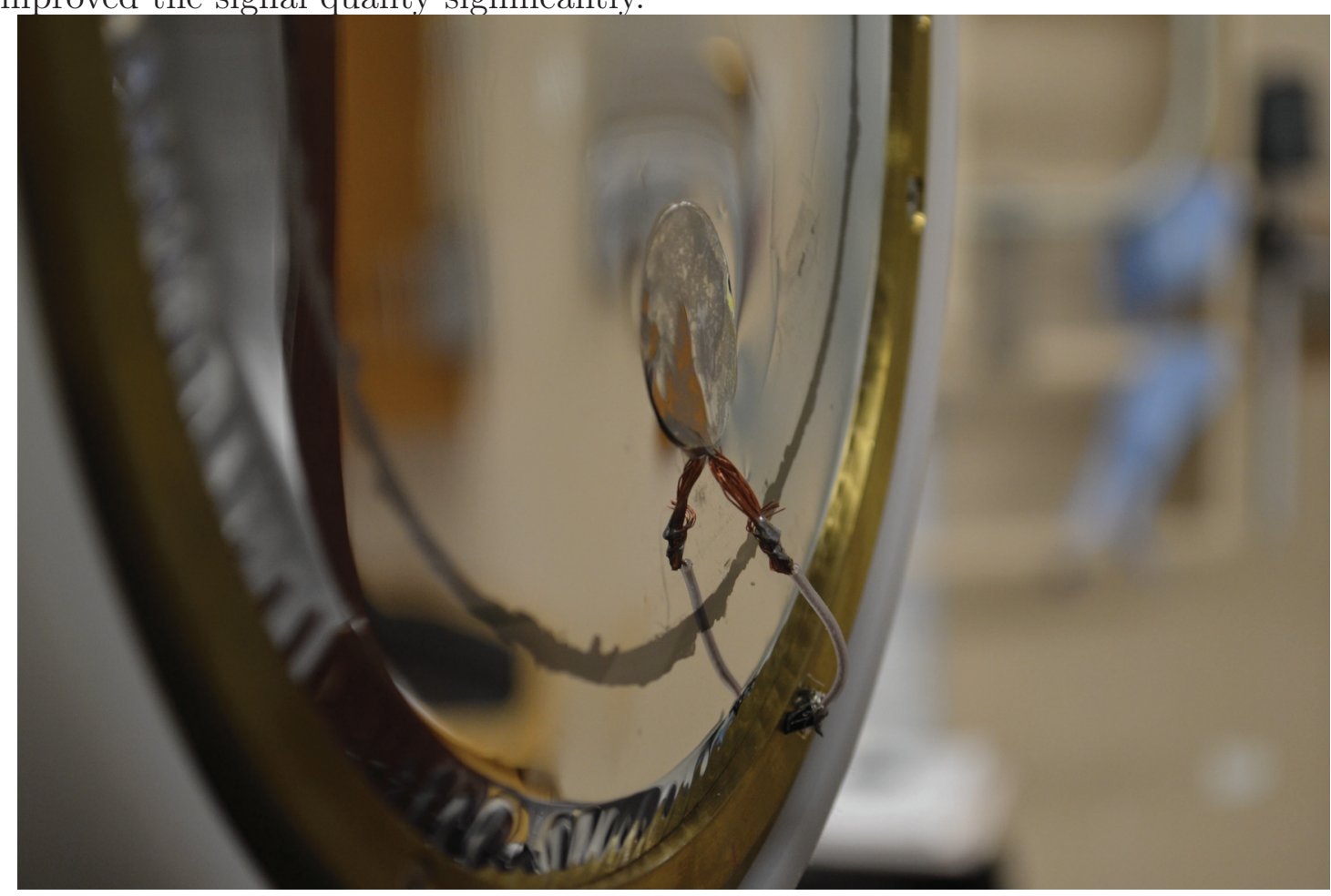

Figure 3.1: A picture of the original collecting electrode. Rough cuts on wires were found inside of the collecting volume. The sharp edges likely caused electric field distortions.

\subsection{Redesigning the Collecting Electrode}

The purpose of redesigning the collecting electrode was to make all the surfaces inside the collecting volume as smooth as possible. In the modified design, the connecting wire is taken through the back of the collecting electrode. Figure 3.2 shows what the 


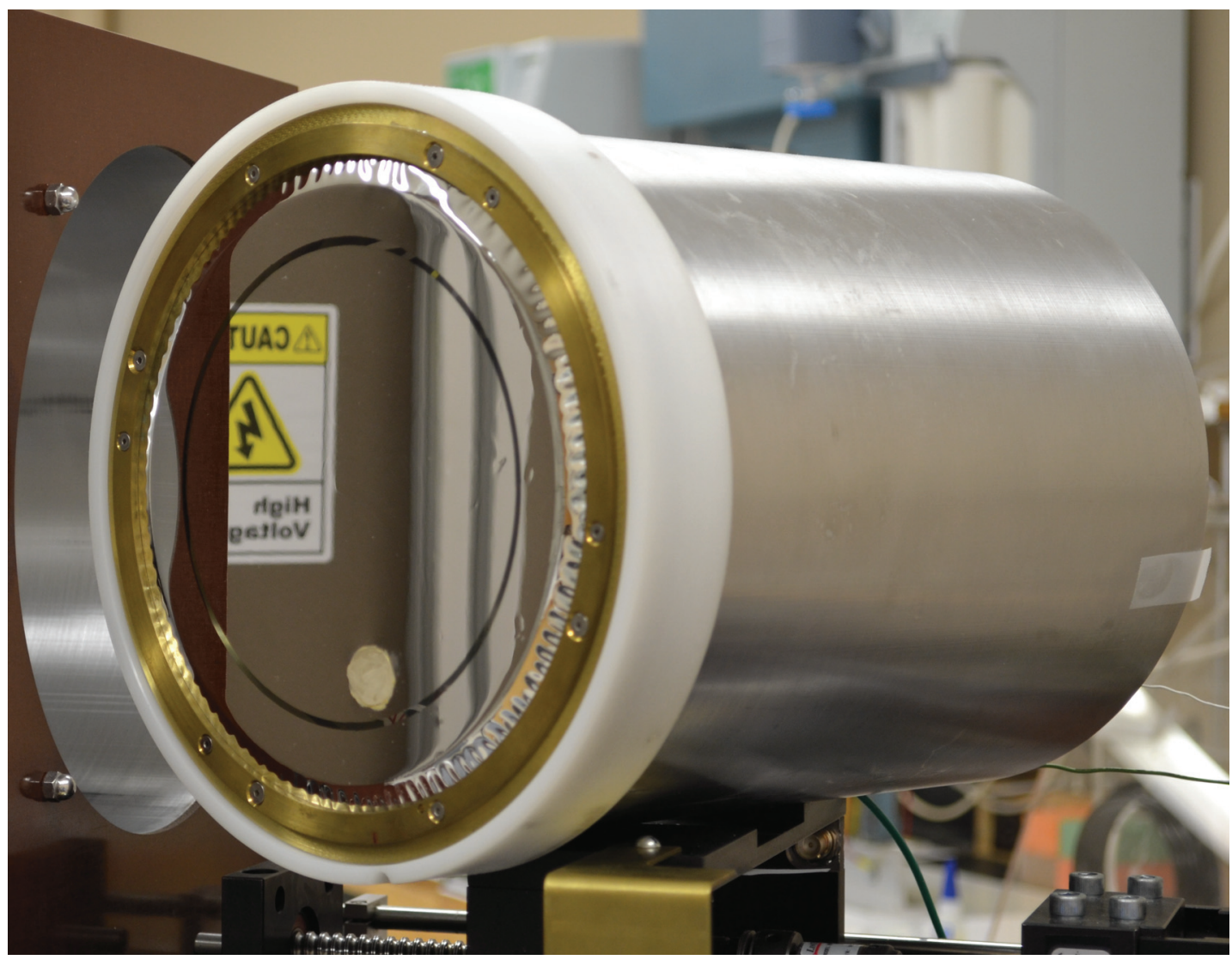

Figure 3.2: Modified connector of collecting electrode on the inner cylinder has a smooth surface, eliminating distortion of the electric field.

modified collecting electrode looks like. The old connector was removed by cutting it off and patching it with combined pieces of aluminized Mylar. The signal wire connection was made behind the patch. Three pieces of aluminized Mylar were used to make this connection as shown in figure 3.3. A hole about $1 \mathrm{~cm}$ diameter was punched in the collecting electrode and then a piece of aluminized Mylar was patched on the hole with the aluminum side face to the aluminum side of the electrode using conductive adhesive. A small gauge wire, insulated 39 AWG $\times 6$ stranded wire, was glued on the aluminum side of the patch with conducting adhesive, which is epoxy mixed with silver (tiga silver 920h made by Resin Technology Group, LLC, 


\section{conductive paint}

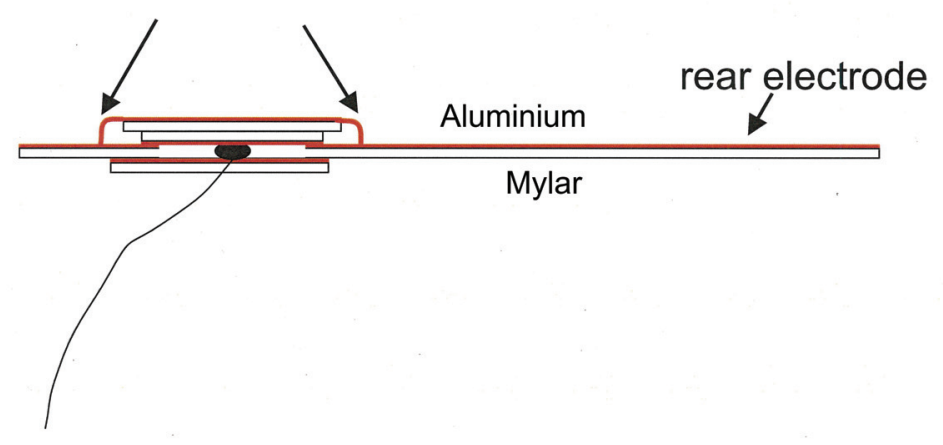

Figure 3.3: Schematic of the patches for the modified connector. Red (labeled as Aluminium) pieces are conductive

Easton, MA). A second larger piece of aluminized Mylar was used to cover the first patch with Mylar side to Mylar that means the aluminum side faces towards the source. Conducting paint was used to keep the connection of this piece of patch to the rest of electrode, so charge collected on the patch will be also connected to the signal wire. A third piece of Mylar was used to cover the back of the connector making the back surface the same as rest of the electrode, which is Mylar on the back. The resistance of the patch set up and new signal wire combination was measured to be a few ohms. The wire is threaded carefully through a hole in the shield foil avoiding touching any parts and connected to a standard RG174 BNC cable.

A test was carried out after the collecting electrode was modified. A single ${ }^{125} \mathrm{I}$ seed with nominal $0.618 \mu \mathrm{Gy} \mathrm{m} / \mathrm{h}$ air kerma strength was used for this test with 30 measurement cycles to observe the repeatability of the instrument. At position 1, which had a volume of $300 \mathrm{~cm}^{3}$, an average one min reading of $0.0134 \mathrm{~V}$ was read by the Keithley 2002 voltmeter with standard deviation $0.0006 \mathrm{~V}$. An average one min reading of $0.0285 \mathrm{~V}$ with standard deviation $0.0006 \mathrm{~V}$ was obtained at position 2, 


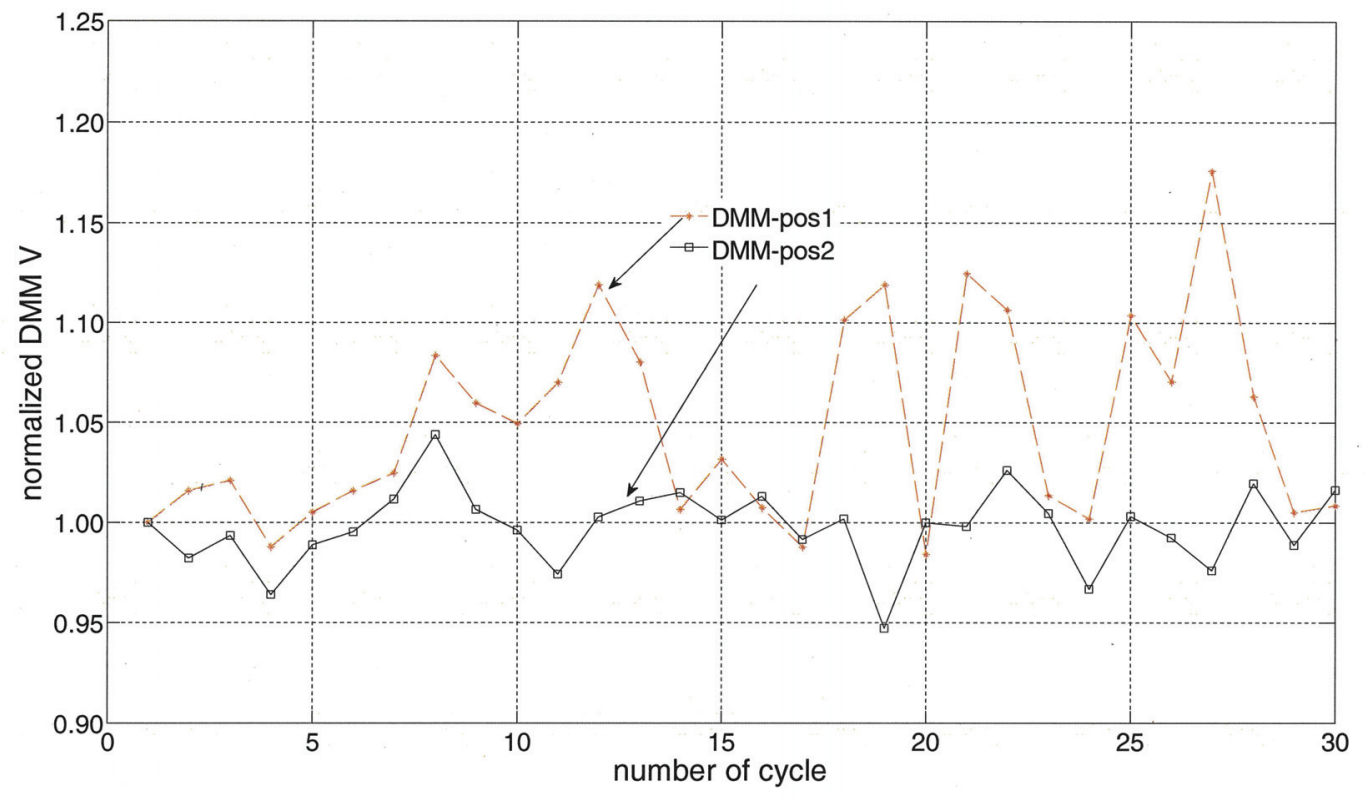

Figure 3.4: 30 measurement cycles of a single ${ }^{125}$ I seed after modifying the collecting electrode. The $\mathrm{x}$ axis shows the cycle number, and $\mathrm{y}$ axis shows the normalized digital multimeter readings. The readings for the chamber at position 1 (collapse) is plotted in red dash line and position 2 (expanded) in black solid line. Normalization is to first point.

which had a volume of $703.7 \mathrm{~cm}^{3}$. The measured air kerma strength was determined to be $0.606 \mu \mathrm{Gy} \mathrm{m}^{2} / \mathrm{h}$. The average leakage was $2.3 \mathrm{fA}$ and $-0.9 \mathrm{fA}$ corresponding to one min reading of $1.4 \times 10^{-3}$ and $-5.4 \times 10^{-4} \mathrm{~V}$ at position 1 and at position 2 respectively. The results are plotted in figure 3.4. Overall the WAFAC was judged to be in a satisfactory working condition after modification of the collecting electrode. 


\subsection{Reproducibility and Effect of Polarity on High Voltage Electrode}

Repeat measurements were carried out over 5 days with positive and negative polarity to observe reproducibility. The source was 7 seeds combined on a plane similar to that in figure 3.5. The plane of combination faces towards the aperture without rotation during measurements. Each test took 10-50 measurement cycles as shown in table 3.2. Each measurement cycle includes four steps for one position: settling time, which is for all parts, including the Mylar electrode to settle down after movement; pre-leakage that measures reading drift without radiation (lead block in place) with the capacitor uncharged; exposure measurement; and post-leakage with the capacitor charged. After the measurements are performed at position 1, the cylinders move to position 2 and the four steps are repeated. In the measurements listed in table 3.2, settling time was set to be 300 seconds and 60 seconds was set for pre- and postleakage and the exposure test for each position. The percentage standard deviation was about $2 \%$ for position 1 and about $1 \%$ for position 2 for each test.

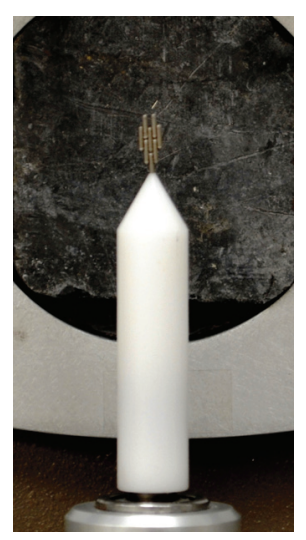

Figure 3.5: Eight ${ }^{125} \mathrm{I}$ seeds combined on a plane to increase signal strength. The plane of the combination faces towards the aperture without rotation. 
Positive Polarity

\begin{tabular}{|c|cc|cc|c|c|}
\hline Repeat & \multicolumn{2}{|c|}{ Position 1 } & \multicolumn{2}{|c|}{ Position 2 } & Ratio & Difference \\
Cycles & DMM1 & st dev & DMM2 & st dev & DMM2/DMM1 & DMM2-DMM1 \\
& $\mathrm{V}$ & $\mathrm{V}$ & $\mathrm{V}$ & $\mathrm{V}$ & & $\mathrm{V}$ \\
\hline 50 & 0.0965 & 0.0018 & 0.2055 & 0.0022 & 2.13 & 0.109 \\
50 & 0.0960 & 0.0016 & 0.2055 & 0.0020 & 2.14 & 0.110 \\
50 & 0.0958 & 0.0018 & 0.2051 & 0.0016 & 2.14 & 0.109 \\
\hline
\end{tabular}

Negative Polarity

\begin{tabular}{|c|cc|cc|c|c|}
\hline Repeat & \multicolumn{2}{|c|}{ Position 1 } & \multicolumn{2}{c|}{ Position 2 } & Ratio & Difference \\
Cycles & DMM1 & st dev & DMM2 & st dev & DMM2/DMM1 & DMM2-DMM1 \\
& $\mathrm{V}$ & $\mathrm{V}$ & $\mathrm{V}$ & $\mathrm{V}$ & & $\mathrm{V}$ \\
\hline 10 & -0.0673 & 0.0020 & -0.1771 & 0.0026 & 2.63 & -0.110 \\
50 & -0.0666 & 0.0014 & -0.1759 & 0.0020 & 2.64 & -0.109 \\
15 & -0.0666 & 0.0015 & -0.1768 & 0.0026 & 2.65 & -0.110 \\
\hline
\end{tabular}

Table 3.2: Repeat measurement at different polarities using seven ${ }^{125} \mathrm{I}$ seeds over 5 days. Column 1 is the repeat cycles in one test. DMM1 and DMM2 are digital multimeter readings in Volts at position 1 and position 2 respectively. st dev is standard deviation of the reading.

Table 3.2 gives the averages and standard deviation from each test under different high voltage electrode polarities. The percentage standard deviation of the three tests with each polarity condition in five days was around $0.5 \%$. The difference between the two positions, which is used for calculation of kerma strength of seeds listed in column 7 , has a variation of $0.4 \%$ on positive polarity and $0.7 \%$ on negative polarity as indicated in table 3.3. 


\begin{tabular}{|c|cc|cc|c|cc|}
\hline Polarity & \multicolumn{2}{|c|}{ Position 1 } & \multicolumn{2}{c|}{ Position 2 } & Ratio & \multicolumn{2}{|c|}{ Subtract } \\
& DMM1 & st dev & DMM2 & st dev & DMM2/ & DMM2-DMM1 & st dev \\
& $\mathrm{V}$ & $\mathrm{V}$ & $\mathrm{V}$ & $\mathrm{V}$ & DMM1 & $\mathrm{V}$ & $\mathrm{V}$ \\
\hline positive & 0.0961 & 0.0004 & 0.2054 & 0.0002 & 2.14 & 0.109 & 0.0004 \\
\hline negative & -0.0667 & 0.0004 & -0.1762 & 0.0006 & 2.64 & 0.110 & 0.0007 \\
\hline
\end{tabular}

Table 3.3: Weighted average of table 3.2. DMM1 and DMM2 are digital multimeter readings in Volts at position 1 and position 2 respectively and st dev is the standard deviation of the reading.

Another important observation is that the ratio of signals at position 1 and 2 is not equal to the ratio of volumes, that was $703.7 / 300=2.35$, and it depends on the polarity of the bias. It seems there is some extra current present with the signal from the air cavity. It affects the reading consistently by approximately $-0.0144 \mathrm{~V}$. The ratio of signal will be equal to volume ratio, which is 2.35 , if we apply -0.0144 to all DMM readings. Details about this extra charge reading and polarity effect will be discussed in chapter 4 .

\subsection{Correction Factors}

The correction factors are crucial terms in equation 2.1 for air kerma strength measurement of brachytherapy seeds, which is denoted as $\prod_{i} k_{i}$ and are listed in table 3.4. In addition, there are several other corrections to be applied to each individual reading before taking the product for use in equation 2.1. They are:

- Decay correction $k_{\text {decay }}$ : correction of the air kerma strength to a certain refer- 
ence time due to decay.

$$
k_{\text {decay }}=e^{\left(\frac{\ln 2}{85579}\right) t}
$$

where: $t$ is the time from the moment of measurement to reference time which is assumed to be prior to the measurement. The number 85579 is the half life of ${ }^{125} \mathrm{I}$ in minutes [2].

- PT correction $k_{\mathrm{pt}}$ : correction of air temperature and pressure to the standard condition as $22^{\circ} \mathrm{C}$ and $101.325 \mathrm{kPa}[2]$.

$$
k_{\mathrm{pt}}=\left(\frac{273.15+T}{295.15}\right)\left(\frac{101.325}{P}\right)
$$

where: $T$ and $P$ are temperature $\left({ }^{\circ} \mathrm{C}\right)$ and pressure $(\mathrm{kPa})$ when the measurement is taken.

- Leakage correction: correction of background and drift signal when the shutter is closed. The leakage applied is the average of pre- and post-leakage.

As listed in table $3.4, \prod_{i} k_{i}$ includes 11 correction factors. Most correction factors used in this project are, at present, based on the NIST WAFAC and will be evaluated in future works.

\subsubsection{Air Attenuation $\left(k_{\text {att }}\right)$}

Air attenuation is a large component in $\prod_{i} k_{i}$. Photons are transmitted through air as:

$$
N / N_{0}=e^{-\left(\frac{\mu}{\rho} \cdot d \cdot \rho\right)} .
$$

So the air transmission factor should be:

$$
k_{\text {air }}=e^{\left(\frac{\mu}{\rho} \cdot d \cdot \rho\right)},
$$




\begin{tabular}{l|l} 
correction factors & value \\
\hline recombination inside WAFAC & 1.004 \\
\hline Al filter attenuation & 1.032 \\
\hline air attenuation from aperture to center of chamber & 1.0048 \\
\hline air attenuation from source to aperture & 1.0143 \\
\hline inverse square correction for aperture & 1.0089 \\
\hline humidity & 0.9979 \\
\hline in chamber photon scatter & 0.9968 \\
\hline scatter from source holder stem & 0.9985 \\
\hline electron loss inside chamber & 1.0000 \\
\hline aperture penetration & 0.9999 \\
\hline external photon scatter & 0.9947 \\
\hline
\end{tabular}

Table 3.4: Correction factors for ${ }^{125} \mathrm{I}$ seed measurement based on the NIST WAFAC [2].

where $\frac{\mu}{\rho}$ is the mass attenuation coefficient of air, which is $0.1537 \mathrm{~cm}^{2} / \mathrm{g}$ for $30 \mathrm{keV}$ photons and 0.5389 for $20 \mathrm{keV}$ photons [7]. $\rho$ is air density, which is $0.001205 \mathrm{~g} / \mathrm{cm}^{3}$ at NTP. $\mathrm{d}$ is the distance of the air path, which is $30 \mathrm{~cm}$ from seed to aperture and 9 $\mathrm{cm}$ from aperture to chamber center plane. Thus the attenuation correction factor of ${ }^{125} \mathrm{I}$ from seed to aperture should be between 1.0197 and 1.0056, and from aperture to center plane it should be between 1.0059 and 1.0017, depending on the photon energy. The practical value can be determined by experiments measuring signals at different distances to get an effective $\frac{\mu}{\rho}$ and then obtaining the $k_{\text {air }}$, or it can be calculated using a Monte Carlo method. Values for $k_{\text {air }}$ of 1.0143 and 1.0048 have been used in this project for air attenuation from source to aperture and from aperture to the 
centre of the chamber respectively, based on NIST's work [2].

\subsubsection{Ion Recombination Inside WAFAC ( $\left.k_{\text {sat }}\right)$}

Recombination inside WAFAC needs to be corrected for, taking account of ions with opposite signs that recombine together before they are collected. The way to determine this factor was described in Seltzer et al. [2] based on the work of Scott and Greening [19]. According to their work the recombination correction factor is determined by the equation:

$$
k_{\text {sat }}=1.0+3.12 \times 10^{8} \times I \quad,
$$

where $I$ is the current measured by the WAFAC in Amperes. One single ${ }^{125}$ I seed used in this project typically give current $I$ about $50 \mathrm{fA}$ at position 2 (expanded position).

\subsubsection{Inverse Square Correction for Aperture $\left(k_{\text {invsq }}\right)$}

Figure 3.6 shows that photon fluence is not uniform across the aperture plane from a point source. The fluence on the plane of the aperture at points $a$ and $b$ is lower than that at point $P$. This non-equalization of the photon fluence at any point on the aperture plane needs to be corrected to point $P$. The correction can be obtained from an integration to get the average fluence on the plane of aperture and then correcting to point $P$. Details of this process have been described clearly in NIST's paper [2], which has the equation:

$$
k_{\text {invsq }}=\frac{\Phi(D)}{\bar{\Phi}(D)}=\frac{(R / D)^{2}}{\ln \left[1+(R / D)^{2}\right]},
$$

where $R$ is the radius of aperture, and $D$ is the distance from axis of seed to the aperture plane. 


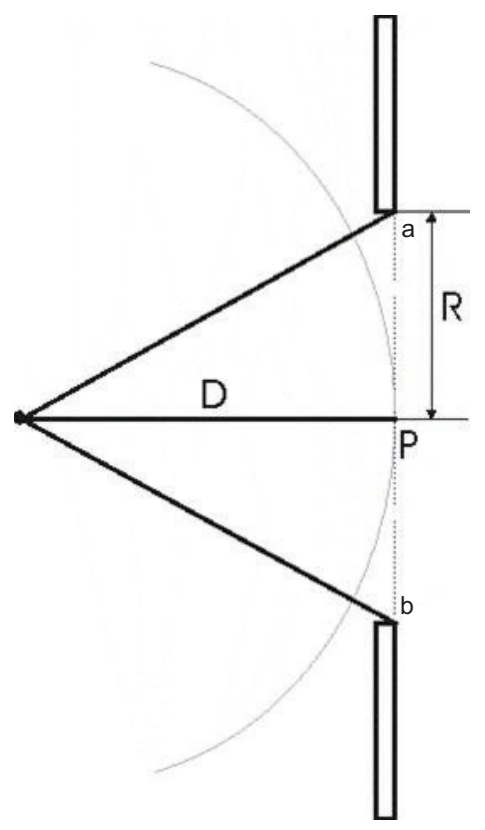

Figure 3.6: Inverse square correction for aperture to correct the non-uniformity of photon fluence on the aperture plane

From equation 3.6 it can be easily observed that this correction is only significant for small $D$ and large $R$. This is therefore a correction for chambers having a big entrance aperture. As $R=4 \mathrm{~cm}$ and $D=30 \mathrm{~cm}$ for the NRC WAFAC, which is our normal setup, this correction is 1.0089 .

\subsubsection{Humidity Correction $\left(k_{\text {humi }}\right)$}

Air kerma is defined for dry air, so a correction is required for humidity.

Figure 3.7 shows the humidity correction factor versus humidity for ${ }^{125} \mathrm{I}$, which is figure 10 in NIST's paper [2]. It shows plots in conditions varying in temperature from 22 to $23{ }^{\circ} \mathrm{C}$ and pressure from 99 to $103 \mathrm{kPa}$, which are typical laboratory conditions. It demonstrates that the humidity correction in typical laboratory conditions is in the range 0.9975 to 0.9995 . It is taken to be 0.9979 in this work, which is for relative 


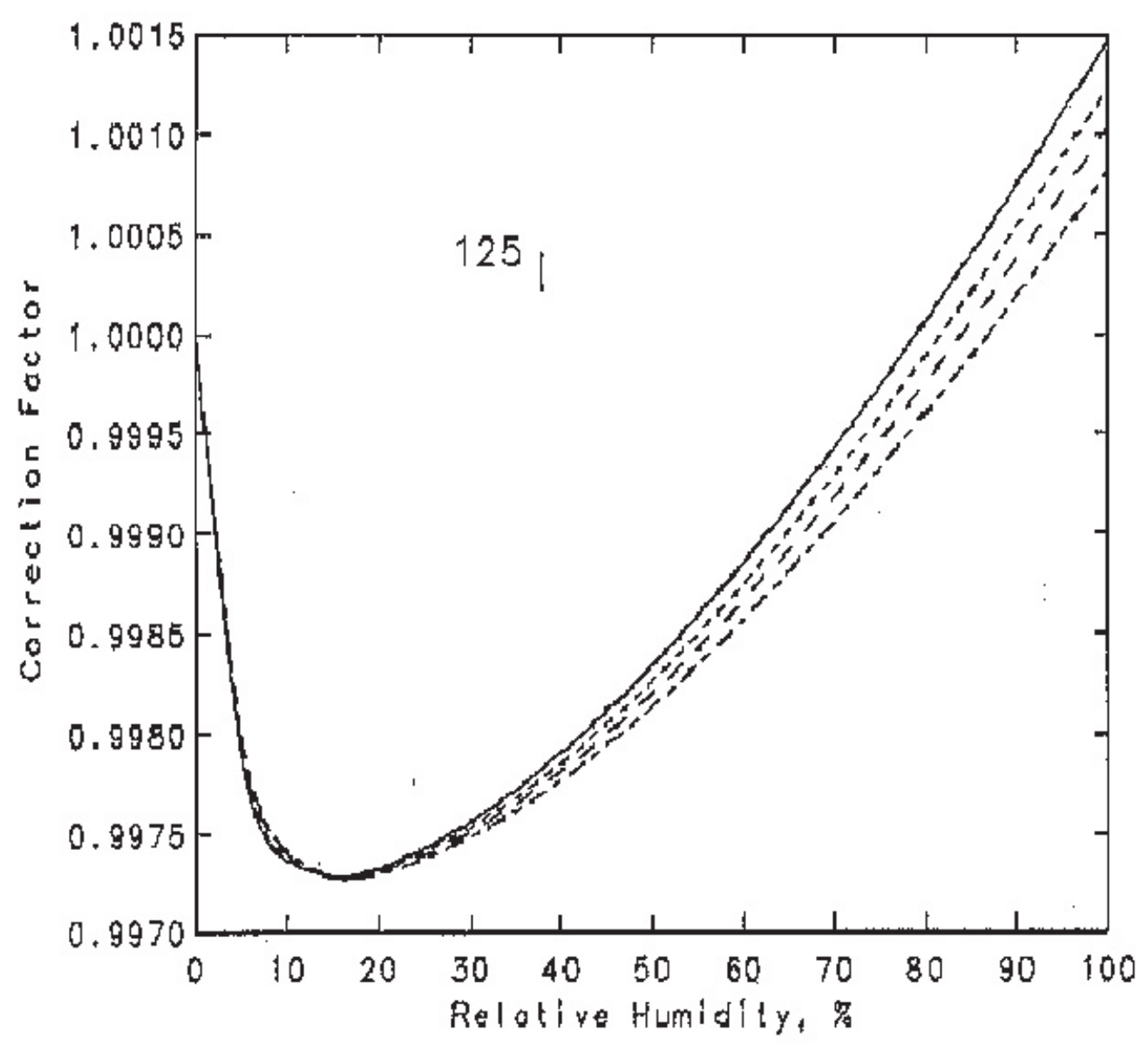

Figure 3.7: Humidity correction for ${ }^{125}$ I. It is the figure 10 in NIST paper [2]. Solid curve: $\mathrm{T}=23{ }^{\circ} \mathrm{C} \quad \mathrm{P}=99 \mathrm{kPa}$. Short-dash curve: $\mathrm{T}=23{ }^{\circ} \mathrm{C} \mathrm{P}=103 \mathrm{kPa}$. Long-dash curve: $\mathrm{T}=22{ }^{\circ} \mathrm{C} \quad \mathrm{P}=99 \mathrm{kPa}$. Long-short-long dash curve: $\mathrm{T}=22{ }^{\circ} \mathrm{C}$ and $\mathrm{P}=103 \mathrm{kPa}$. Permission to reproduce image not required.

humidity of about $50 \%$ which is typical laboratory condition.

\subsubsection{Electron Loss $\left(k_{\mathrm{e}}\right)$}

This is a correction to account for secondary electrons not collected. It was indicated to be unity in NIST's paper [2] 


\subsubsection{Internal Photon Scatter Correction ( $\left.k_{\text {in_scatt }}\right)$}

The definition of $S_{k}$ is in vacuo. Any ionization current from scatter needs to be corrected for. The scatter can come from air, collimators, filter, aperture and other objects inside or outside of the chamber. The internal photon scatter correction is a factor to remove the portion of charge produced by photons scattered inside the chamber. The correction is obtained from Monte Carlo simulation and taken to be 0.9968 for this project [2].

\subsubsection{External Photon Scatter Correction ( $\left.k_{\text {ex_scatt }}\right)$}

Similar to $k_{\text {in_scatt }}$, this is used to correct for scatter from external objects except for the sample holder, which is accounted for separately. This correction includes scatter from Al filter, air from seed to aperture, seed enclosure and any objects outside of the collecting volume [2]. It may slightly related to laboratory environmental conditions.

A value of $k_{\text {ex_scatt }}=0.9947$ is used here, taken from NIST for ${ }^{125} \mathrm{I}$. This is a correction factor that must be derived for the NRC WAFAC.

\subsubsection{Photon Scatter from Sample Holder $\left(k_{\text {stem }}\right)$}

This correction is listed separately from external scatter because it can be different shape or material. The seed holder used in this project is shown in figure 2.10. This correction can be derived by putting another of the same holder symmetrically on the top of seed and then comparing the measured results of with and without it. The effect includes scatter and attenuation caused from the holder. It is taken as 0.9985 at present based on NIST's work [2] and needs further assessment. 


\subsubsection{Aperture Penetration $\left(k_{\text {pen }}\right)$}

As described in section 2.3.3, the aperture is made of tungsten with $4 \mathrm{~mm}$ thickness. The surrounding front panel is a combination of three layers of metal: brass, lead, and aluminum, each of which are $3 \mathrm{~mm}$ in thickness. The aperture penetration correction is used to correct for incident photons that penetrate the aperture itself and the surrounding front panel. This correction is considered unity for now. It will be verified by Monte Carlo calculations in future work.

\subsubsection{Aluminum Filter Attenuation $\left(k_{\text {foil }}\right)$}

The intrinsic radiation from ${ }^{125} \mathrm{I}$ includes three photon peaks, which are $27.4 \mathrm{keV}$ tellurium $K_{\alpha}, 31.0 \mathrm{keV} K_{\beta}$, and $35.5 \mathrm{keV}$ gamma-ray. There are additional photon peaks at $22.1 \mathrm{keV}$ and $25.2 \mathrm{keV}$ corresponding to silver $K_{\alpha}$ and $K_{\beta}$ for some models that contain ${ }^{125} \mathrm{I}$ adsorbed onto a silver wire. Those photons would interact with $\mathrm{Ti}$ atoms in the seed capsule to produce $4.7 \mathrm{keV} \times$ ray fluorescence, which is not clinically important because these low-energy photons would be absorbed in about 1 mm water [2]. Previously, the air kerma rate for LDR seeds was measured at NIST without removing the low-energy photons, until Hideo Kubo found out that lowenergy fluorescence x rays produced from the Ti capsule would significantly affect the measured results for $\mathrm{S}_{\mathrm{k}}[20]$.

Figure 3.8 illustrates the air attenuation for the beam with and without Ti K x rays by Monte Carlo simulation described in NIST's paper [2]. The number of Ti K x rays is almost comparable to that of $35.5 \mathrm{keV} \gamma$ rays [20]. Due to the higher absorption coefficients, the contribution of these low-energy photons to the measurement of the air kerma strength of the seed can be very significant. 


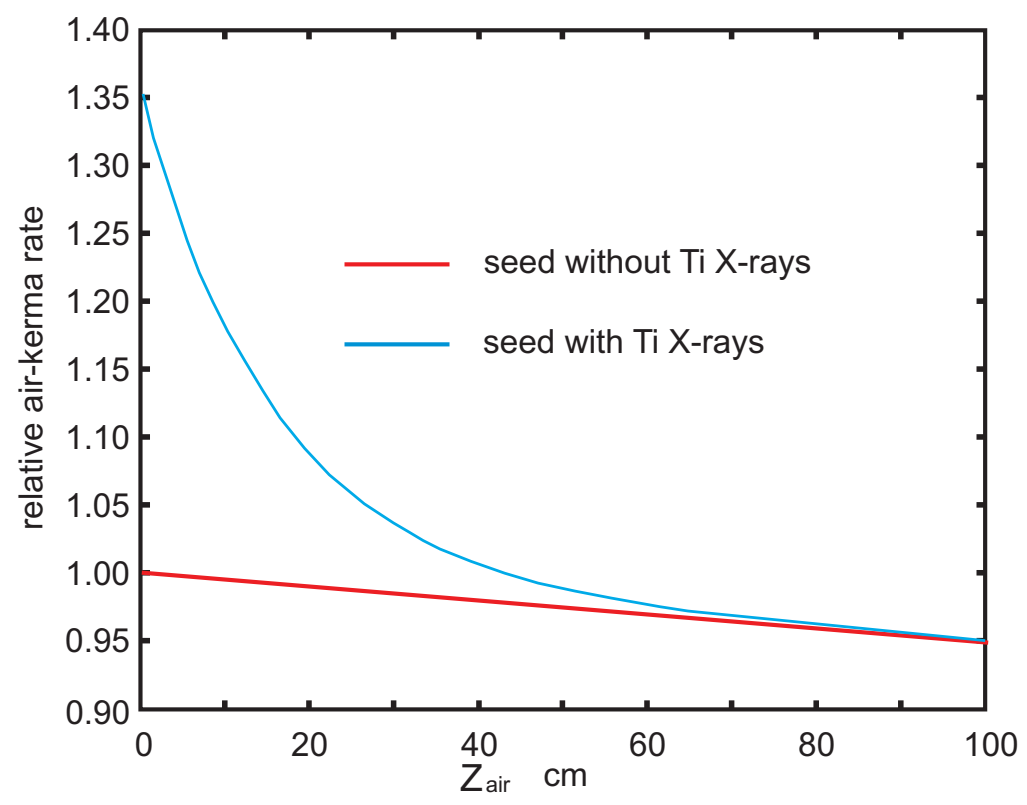

Figure 3.8: Air attenuation for the beam with and without Ti $\mathrm{K} x$ rays by Monte Carlo simulation described in NIST's paper [2] for the model 6711 seed. The number of $\mathrm{Ti} \mathrm{x}$ rays is almost comparable to that of $35.5 \mathrm{keV} \gamma$ rays. It would affect the air kerma rate measurement significantly, but is not clinically important in-phantom.

Since the 2004 update of AAPM Task Group No. 43 Report, there has been a revised AAPM protocol for brachytherapy dose calculations which recommended a cutoff energy $\delta$ to remove contaminant photons, which is typically $5 \mathrm{keV}$ but is dependent on the application.

To measure the exposure rate above $5 \mathrm{keV}$ radiation, a $0.0829 \mathrm{~mm}$ Al filter was put between the seed and the aperture of WAFAC for this work. As shown in figure 2.8 multiple thickness of $\mathrm{Al}$ filters, which depend on the requirements, can be set up on the filter wheel to exclude different values of cut off energy, $\delta$. This filter would not only filter out the Ti K x rays, but also attenuate higher energy photons as well. A correction factor needs to be introduced to correct for this effect on photons that have 
energy higher than $\delta$. This factor can be determined by either experiments or the Monte Carlo method.

\subsubsection{Experiment for Measuring Filter Attenuation Correction}

The sources used to measure the attenuation of the aluminum filter were clinical ${ }^{125}$ I seeds, model 6711 from RapidStrand. They are within welded titanium capsules containing the ${ }^{125} \mathrm{I}$ absorbed onto a silver rod. To increase the strength of the signal and therefore obtain more accurate measurements, 10 single seeds were combined together, which is similar to that arrangement shown in figure 3.5. The seed holder stem does not rotate in this case. The plane of the 10 seeds faces the aperture of the WAFAC to avoid blocking each other and it was set $30 \mathrm{~cm}$ away from the aperture. The WAFAC was set as:

$\begin{array}{lll}\text { Position 1 } & 300 \mathrm{~cm}^{3} \text { volume } & 660 \mathrm{~V} \text { bias } \\ \text { Position 2 } & 703.7 \mathrm{~cm}^{3} \text { volume } & 1540 \mathrm{~V} \text { bias } \\ \text { Settling time } & 300 \mathrm{sec} & \\ \text { Measurement time for exposure } & 120 \mathrm{sec} & \\ \text { Measurement time for leakage } & 120 \mathrm{sec} & \\ \text { Cycles } & 5\end{array}$

The filter thickness for each individual filter was determined using the measured attenuation in an $\mathrm{x}$ ray beam compared to an established NRC aluminum absorber set.

The plot of filter thickness vs normalized position 2 results (listed in table 3.5) is illustrated in figure 3.9 in "*" (blue) dots. The "o" dots (red) are Monte Carlo calculated results. A TableCurve 2D v5.01 software was used to determine a fitting 
Chapter 3. Commissioning of the Wide Angle Free Air Chamber

\begin{tabular}{|c|ccc|ccc|}
\hline Filter Thickness & \multicolumn{3}{|c|}{ Position $1\left(300 \mathrm{~cm}^{3}\right)$} & \multicolumn{3}{|c|}{ Position $2\left(703.7 \mathrm{~cm}^{3}\right)$} \\
$\mathrm{mm}$ & Reading & Norm & $U_{\mathrm{A}}$ & Reading & Norm & $U_{\mathrm{A}}$ \\
\hline 0 & 0.1487 & 1.0024 & 0.0018 & 0.3151 & 0.9962 & 0.0013 \\
0.00646 & 0.1466 & 0.9882 & 0.0022 & 0.3120 & 0.9864 & 0.0013 \\
0.02579 & 0.1431 & 0.9646 & 0.0017 & 0.3043 & 0.9621 & 0.0030 \\
0.05146 & 0.1421 & 0.9579 & 0.0021 & 0.3024 & 0.9561 & 0.0009 \\
0.08288 & 0.1398 & 0.9424 & 0.0030 & 0.2970 & 0.9390 & 0.0017 \\
0.10319 & 0.1389 & 0.9363 & 0.0033 & 0.2957 & 0.9349 & 0.0025 \\
0.12783 & 0.1364 & 0.9194 & 0.0026 & 0.2928 & 0.9257 & 0.0017 \\
0.15375 & 0.1351 & 0.9107 & 0.0029 & 0.2887 & 0.9127 & 0.0012 \\
0 & 0.1480 & 0.9976 & 0.0009 & 0.3175 & 1.0038 & 0.0009 \\
\hline
\end{tabular}

Table 3.5: Test results for Al filter attenuation correction factor. Norm is the reading normalized to the average of two readings without filter, which were measured at beginning and end of the test. $U_{\mathrm{A}}$ is the standard uncertainty of normalized results. equation with average residual 0.002 :

$$
\text { attenuation }=0.02708 e^{-99.89 t}+0.9732 e^{-0.40507 t},
$$

where $\mathrm{t}$ is the thickness $(\mathrm{mm})$ of $\mathrm{Al}$ filter.

Equation 3.7 indicates a two-part exponential attenuation with fast and slow components. The fast term with a high attenuation coefficient corresponds to an average of $4.3 \mathrm{keV}$ photons attenuating in aluminum. It can be reasonably assumed that it is the attenuation from $4.7 \mathrm{keV}$ Ti x ray fluorescence and $3.5 \mathrm{keV}$ photons from ${ }^{125} \mathrm{I}$. The slow term corresponds to $28 \mathrm{keV}$ and combines the attenuation of higher energy photons, which includes photons from intrinsic ${ }^{125}$ I decay and silver $K_{\alpha}, K_{\beta}$ x rays. 


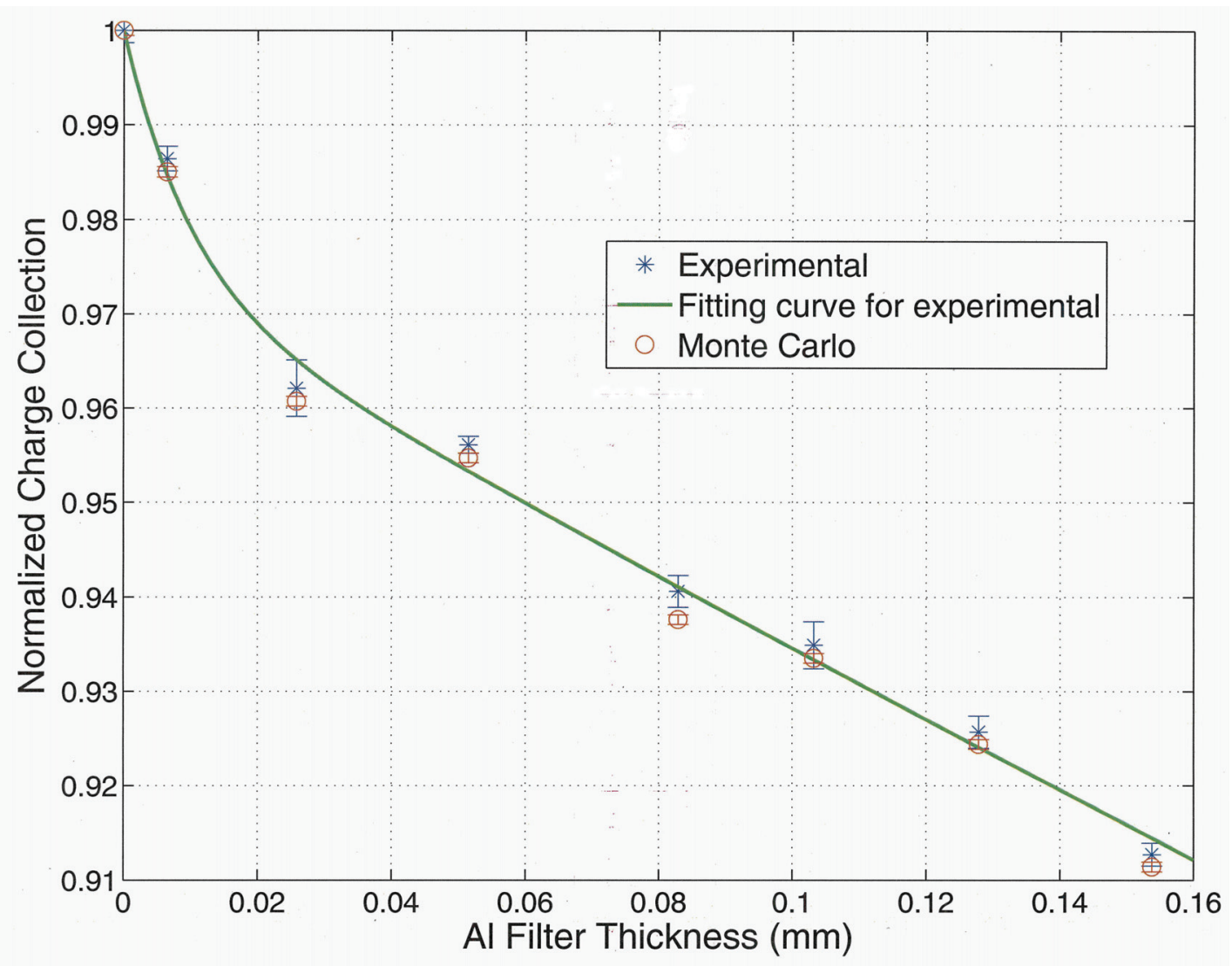

Figure 3.9: Aluminum filter attenuation. The "o" dots (red) are Monte Carlo calculated results provided by Dr. Mainegra-Hing. The "*” (blue) dots are experimental results. The line is the curve fit of equation 3.7.

The use of a piece of $\mathrm{Al}$ filter $(\mathrm{t}=0.083 \mathrm{~mm})$ causes the first term in equation 3.7 to reduce to 0.00025 . The higher energy beam component, which needs to be calibrated, was attenuated to be 0.967 of original beam. Thus the correction factor for the attenuation in $\mathrm{Al}$ filter is:

$$
k_{\text {foil }}=e^{0.40507 \times 0.08288}=1.034 \pm 0.002 \quad,
$$

where the uncertainty of 0.002 is from the average fitting residual.

Monte Carlo simulation gives each attenuation value as compared to the experi- 
mental results, illustrated in figure 3.9. The attenuation of the filter is 0.96843 with uncertainty of $0.036 \%$, that gives $k_{\text {foil }}=1.0326$ from Monte Carlo with statistical uncertainty of 0.0004 .

\subsubsection{Displacement Correction $\left(k_{\mathrm{v}} \& k_{\mathbf{c}}\right)$}

As described in subsection 3.2.1, the displacement of the cylinder movement will lead two corrections, which are volume correction and center plan correction. In the case of position 1 being $300 \mathrm{~cm}^{3}$ and position 2 being $703.7 \mathrm{~cm}^{3}$, the displacement correction for volume $\left(k_{\mathrm{v}}\right)$ and center plan $\left(k_{\mathrm{c}}\right)$ are:

$k_{v}=1.0054$,

and

$k_{c}=1.0000$. 


\section{Chapter 4}

\section{Polarity Effect}

\subsection{Observations}

As shown in columns 2 and 4 of Table 3.2, the readings from the electrometer had a substantial difference when opposite polarities were applied to the electrode. However the subtraction of readings at the two positions (listed in column 7) were consistent. Therefore the measured ionization, which is proportional to the air kerma strength of the source is independent of polarity.

A polarity effect has not been reported by any other laboratories using this kind of free air chamber. Additional measurements were carried out using ${ }^{125} \mathrm{I}$ and ${ }^{241} \mathrm{Am}$ sources to test the reproducibility of the polarity effect and to show that the results did not depend on the type of seed. The results are listed in Table 4.1. The polarity effect was observed with both ${ }^{125} \mathrm{I}$ and ${ }^{241} \mathrm{Am}$ sources.

As mentioned in Section 3.4, the observation showed that the polarity effect acted as if applying a constant value to each reading. For example, if one subtracts 0.0144 


125 I source
\begin{tabular}{|c|cc|cc|c|}
\hline Polarity & \multicolumn{2}{|c|}{ Position 1 } & \multicolumn{2}{|c|}{ Position 2} & Difference \\
& DMM1 (V) & st dev & DMM2 (V) & st dev & DMM2-DMM1 \\
\hline Positive & 0.1127 & 0.002 & 0.2374 & 0.002 & 0.125 \\
Negative & -0.0786 & -0.0006 & 0.2066 & 0.0004 & -0.128 \\
\hline
\end{tabular}

${ }^{241} \mathrm{Am}$ source

\begin{tabular}{|c|cc|cc|c|}
\hline \multirow{2}{*}{ Polarity } & \multicolumn{2}{|c|}{ Position 1 } & \multicolumn{2}{c|}{ Position 2 } & Difference \\
& DMM1 (V) & st dev & DMM2 (V) & st dev & DMM2-DMM1 \\
\hline Positive & 0.0442 & 0.00004 & 0.0969 & 0.0007 & 0.0527 \\
Negative & -0.0320 & 0.0002 & -0.0854 & -0.0003 & -0.0534 \\
\hline
\end{tabular}

Table 4.1: Repeat measurements of Table 3.2 at different polarities using ${ }^{125} \mathrm{I}$ and ${ }^{241} \mathrm{Am}$. DMM1 and DMM2 are digital multimeter readings in Volts at position 1 and position 2 respectively and st dev is the standard deviation for the followed reading. The polarity effect was observed with both radioactive sources. Even the offset quantity was reproducible after normalization to the source strength of ${ }^{125} \mathrm{I}$ seeds used in table 3.2.

from all digital multimeter readings in table 3.3, both at position 1 and position 2 and both in positive and negative polarity, there is no difference between different polarities, and the ratio of the readings from position 1 and 2 equals the volume ratio, which is $703.7 / 300=2.35$. These results are demonstrated in table 4.2 . The average offset, 0.0144 in table 3.2 , is $15 \%$ of the average reading at position 1 in positive polarity. A certain offset on all readings for ${ }^{125} \mathrm{I}$ is also observed in table 4.1 and it is found to be $15 \%$ as well. 


\begin{tabular}{|l|c|cc|cc|c|cc|}
\hline \multirow{2}{*}{ offset } & Polarity & \multicolumn{2}{|c|}{ Position 1 } & \multicolumn{2}{|c|}{ Position 2 } & \multicolumn{2}{c|}{ Ratio } & \multicolumn{2}{|c|}{$\begin{array}{c}\text { Difference } \\
\text { DMM1 }\end{array}$} & st dev & DMM2 & st dev & DMM2/ & DMM2- & st dev \\
& & $\mathrm{V}$ & $\mathrm{V}$ & $\mathrm{V}$ & $\mathrm{V}$ & DMM1 & DMM1 & $\mathrm{V}$ \\
\hline \multirow{2}{*}{ not } & positive & 0.0961 & 0.0036 & 0.2054 & 0.00023 & 2.14 & 0.109 & 0.0004 \\
\cline { 2 - 10 } applied & negative & -0.0667 & 0.0004 & -0.1762 & 0.00062 & 2.64 & -0.110 & 0.0007 \\
\hline \multirow{2}{*}{ applied } & positive & 0.0817 & 0.0036 & 0.1910 & 0.00023 & 2.34 & 0.109 & 0.0004 \\
\cline { 2 - 9 } & negative & -0.0811 & 0.0004 & -0.1906 & 0.00062 & 2.35 & -0.110 & 0.0007 \\
\hline
\end{tabular}

Table 4.2: The difference with and without the offset being applied to results from table 3.3. Data without offset applied (first two rows) are from table 3.3. DMM1 and DMM2 are digital multimeter readings in Volts at position 1 and position 2 respectively, and st dev is the standard deviation of the reading.

It seems that readings obtained from the ion chamber include two parts, which are the charge collected in the collecting region and an additional offset value. To express this idea, let us denote $Q_{\mathrm{m}}^{+}$and $Q_{\mathrm{m}}^{-}$to be the total readings of the electrometer with positive and negative polarity respectively. We denote $Q_{i}^{+}$and $Q_{i}^{-}$to be the charge collected from only the collecting volume with positive polarity and negative polarity respectively. Denote $Q_{\mathrm{p}}$ to be the offset charge causing the polarity effect. Then the relationship between those values according to the measurement listed in table 3.2 and table 4.1 are:

$$
\begin{gathered}
Q_{i}^{+}=-Q_{i}^{-}, \\
Q_{\mathrm{m}}^{+}=Q_{i}+Q_{\mathrm{p}}
\end{gathered}
$$




$$
\begin{gathered}
Q_{\mathrm{m}}^{-}=-Q_{i}+Q_{\mathrm{p}}, \\
Q_{i}=\left(Q_{\mathrm{m}}^{+}-Q_{\mathrm{m}}^{-}\right) / 2 \\
Q_{\mathrm{p}}=\left(Q_{\mathrm{m}}^{+}+Q_{\mathrm{m}}^{-}\right) / 2
\end{gathered}
$$

\begin{tabular}{|c|c|c|c|c|c|c|c|c|}
\hline \multicolumn{3}{|c|}{ Position 1} & \multicolumn{6}{|c|}{ Position 2} \\
\hline \multirow{3}{*}{$\begin{array}{c}\text { Volume } 1 \\
\mathrm{~cm}^{3}\end{array}$} & \multicolumn{2}{|c|}{ Electrometer } & \multirow{3}{*}{$\begin{array}{c}\text { Volume } 2 \\
\mathrm{~cm}^{3}\end{array}$} & \multicolumn{4}{|c|}{ Electrometer } & \multirow{3}{*}{$\begin{array}{c}Q_{\mathrm{p}} \\
10^{-10} \mathrm{C}\end{array}$} \\
\hline & $Q_{\mathrm{m}}^{-}$ & $Q_{\mathrm{m}}^{+}$ & & $Q_{\mathrm{m}}^{-}$ & $U_{\mathrm{A}}$ & $Q_{\mathrm{m}}^{+}$ & $U_{\mathrm{A}}$ & \\
\hline & $10^{-10} \mathrm{C}$ & $10^{-10} \mathrm{C}$ & & $10^{-10} \mathrm{C}$ & $10^{-10} \mathrm{C}$ & $10^{-10} \mathrm{C}$ & $10^{-10} \mathrm{C}$ & \\
\hline 200 & -0.0472 & 0.0782 & 200 & -0.0471 & 0.0003 & 0.0778 & 0.0002 & 0.0154 \\
\hline 200 & -0.0468 & 0.0778 & 300 & -0.0781 & 0.0003 & 0.1088 & 0.0002 & 0.0154 \\
\hline 200 & -0.0468 & 0.0779 & 400 & -0.1099 & 0.0002 & 0.1401 & 0.0001 & 0.0151 \\
\hline 200 & -0.0466 & 0.0780 & 600 & -0.1722 & 0.0008 & 0.2034 & 0.0005 & 0.0156 \\
\hline 200 & -0.0469 & 0.0775 & 703.7 & -0.2057 & 0.0003 & 0.2329 & 0.0005 & 0.0136 \\
\hline
\end{tabular}

Table 4.3: Electrometer reading with variation of volumes at position 2. This is another way to verify an offset value applied to all readings independent of the volume. Position 1 was a fixed volume of $200 \mathrm{~cm}^{3}$. Data with this volume are not used for further calculations. $U_{\mathrm{A}}$ is the type A standard uncertainty of the reading.

Table 4.3 lists data measured using fixed volume at position 1 as $200 \mathrm{~cm}^{3}$ and varying the volume of position 2 from $200 \mathrm{~cm}^{3}$ to $703.7 \mathrm{~cm}^{3}$. The cylinder movements 


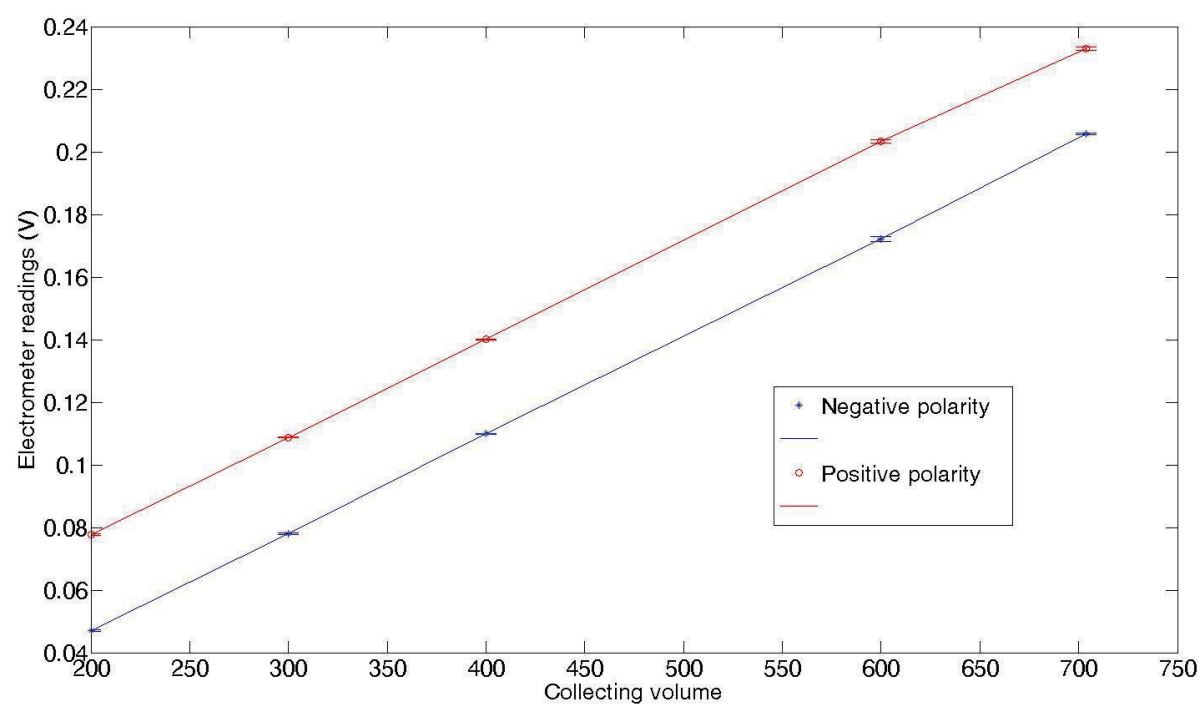

Figure 4.1: Electrometer reading vs. collecting volume in different polarity. Plot of table 4.3 absolute value of fifth column and seventh column versus volume.

for the NRC WAFAC, which decide the volume of the ion chamber, are designed to be controlled by a computer program. It is able to change the volume continuously from 200 to $703.7 \mathrm{~cm}^{3}$ for volume 1 and volume 2 . The results of this experiment further proved that $Q_{i}$ was proportional to the collecting volume as shown in figure 4.1. The offset $Q_{\mathrm{p}}$ is independent of the chamber volume.

\subsection{The Source of $Q_{\mathrm{p}}$ Causing the Polarity Effect}

The polarity effect in a parallel chamber as it is exposed to radiation is caused by a number of effects [6] [21]. As indicated by Attix [6], when an electrode is placed in an ionizing radiation beam, electrons are knocked out from the electrode causing a positive current. When a positive polarity is applied on the front $\mathrm{HV}$ electrode this extra current will add to the signal, while it will be subtracted when the HV electrode 
is negative. Also, as indicated by [21], it may be caused by the electric field distortion when the polarity is changed. Those effects generally are on the level of a few tenths of a percent. In the case of the WAFAC the electrode is $7.1 \mathrm{mg} / \mathrm{cm}^{2}$ aluminized Mylar with $12 \mu \mathrm{g} / \mathrm{cm}^{2}$ aluminum, and the volume is $300 \mathrm{~cm}^{3}$ in the collapsed position. Monte Carlo method can be used to show that the total effects, which were indicated by Attix and Boag, are as small as $0.007 \%$ [22]. The effect of about $40 \%$ observed in table 3.2, 4.1 and 4.3 does not seem to be caused by the knocked out charge as Attix indicated [6] or by electric field distortion indicated by Boag [21].

The magnitude of $Q_{\mathrm{p}}$ in table 4.3 implied that it corresponded to the charge produced in about a $1 \mathrm{~cm}$ length of collecting volume. Further observations implied that the charge that caused the polarity effect comes from the region behind the collecting electrode, between the collecting electrode and the shield foil (see figure 2.3).

\subsection{1 \pm 9 V Battery DC Voltages Applied on Shield Foil}

The shield foil located downstream of the collecting foil is used to shield and protect the collecting foil as shown in figure 2.3. It is a piece of uniform one side aluminized Mylar, the same as the material used for the front HV and collecting electrode. The aluminum side of the shield foil is upstream. The length of the gap between collecting electrode and the shield foil is $11 \mathrm{~mm}$. To observe if the offset charge $Q_{\mathrm{p}}$ was collected in this region between the shield foil and collecting electrode, a second collecting electrode-like foil was used to replace the shield foil. In other words this new shield foil had exactly the same structure as the collecting electrode, so that it was possible to apply voltage on the centre area of the shield foil. A $9 \mathrm{~V}$ battery was 
used to apply a \pm DC voltage on the shield foil to observe how this voltage affected the chamber reading. The measured results are listed in Table 4.4.

\begin{tabular}{|c|c|cc|cc|}
\hline Voltage on & Polarity & \multicolumn{2}{|c|}{ Position 1 } & \multicolumn{2}{c|}{ Position 2 } \\
Protective Foil & & $\begin{array}{c}\text { Volume } \\
\mathrm{cm}^{3}\end{array}$ & $\begin{array}{c}\text { DMM1 } \\
\text { Volume }\end{array}$ & DMM2 \\
& & $\mathrm{cm}^{3}$ & $\mathrm{~V}$ \\
\hline \multirow{2}{*}{0} & negative & 300 & -0.081 & 703.7 & -0.207 \\
& positive & 300 & 0.106 & 703.7 & 0.233 \\
\hline \multirow{2}{*}{9} & negative & 300 & -0.070 & 703.7 & -0.195 \\
& positive & 300 & 0.119 & 703.7 & 0.246 \\
\hline \multirow{2}{*}{-9} & negative & 300 & -0.115 & 703.7 & -0.243 \\
& positive & 300 & 0.071 & 703.7 & 0.197 \\
\hline
\end{tabular}

Table 4.4: Effect of applying $\pm 9 \mathrm{~V}$ DC on the shield foil. When applied voltage was 0 the results repeated the polarity effect as measured before. When $+9 \mathrm{~V}$ applied on the shield foil it enhanced the polarity effect. When $-9 \mathrm{~V}$ applied on the shield foil it reversed the polarity effect. DMM1 and DMM2 are digital multimeter readings in Volts at position 1 and position 2 respectively.

When $0 \mathrm{~V}$ was applied on the shield foil the results showed that polarity effect was the same as previous tests, like those in table 3.2 and table 4.3. This result was expected due to no change in the geometry or electric field. The extra collected charge current in the polarity effect was always positive in table 3.2 and table 4.3, which suggested that the collecting electrode seems to have a negative bias voltage. So, when a positive $9 \mathrm{~V}$ voltage is applied to the shield foil, the electric field between collecting electrode and shield foil had been enhanced and when $-9 \mathrm{~V}$ voltage is applied to the shield foil, it reversed the polarity of the electric field behind the collecting 
electrode. Therefore the absolute value was larger on positive polarity, as observed in table 3.2 and table 4.3 and it was smaller when $-9 \mathrm{~V}$ was applied on the shield foil. This experiment gives evidence that the charge from the region between collecting electrode and shield foil dominated the polarity effect in the WAFAC. It also implies that there is an electric field in this region with direction from the collecting electrode to shield foil with a bias voltage less than $9 \mathrm{~V}$.

\subsubsection{Variable DC Applied on Shield Foil}

As indicated in section 4.2.1 there is an electric field between the collecting electrode and shield foil in the normal setup and charge produced in this region can be collected by the collecting electrode as $Q_{\mathrm{p}}$. This electric field has a direction towards the collecting electrode and is less than $9 \mathrm{~V}$. So $Q_{\mathrm{p}}$ was always positive in previous tests. Data listed in table 4.5 were obtained to observe the charge collecting behavior until reaching saturation by varying the electric field between collecting electrode and shield foil. It also was used to determine the bias voltage on the Mylar surface of the collecting electrode. The experimental setup was the same as that described in section 4.2.1, except the voltage applied on the shield foil was varied from 16.32 to $-27.70 \mathrm{~V}$. The polarity on the front HV electrode was kept to be positive. Thus there is no $Q_{\mathrm{m}}^{-}$in table 4.5 ; and $Q_{\mathrm{p}}$ is a variable, which varies from positive saturated value to negative saturated value. Charge collection was measured at both position 1 and position 2, which were the two cylinder positions with collecting volume $300 \mathrm{~cm}^{3}$ and $703.7 \mathrm{~cm}^{3}$ respectively. Column 1 is the voltage applied on the center area of the shield foil, which was the same area as the collecting electrode. Column 2 and column 5 were the electrometer readings at position 1 and 2 respectively, which were $Q_{\mathrm{m}}^{+}$as defined in equation 4.2. When the voltage applied on the shield foil center area was 


\begin{tabular}{|c|ccc|ccc|}
\hline Voltage on & \multicolumn{3}{|c|}{ Position 1 $\left(300 \mathrm{~cm}^{3}\right)$} & \multicolumn{3}{c|}{ Position $2\left(703.7 \mathrm{~cm}^{3}\right)$} \\
Shield Foil & $Q_{\mathrm{m}}^{+} / 10^{-10} \mathrm{C}$ & $Q_{\mathrm{p}} / Q_{\mathrm{p}}(\mathrm{sat})_{p o 1}$ & $U_{\mathrm{A}}$ & $Q_{\mathrm{m}}^{+} / 10^{-10} \mathrm{C}$ & $Q_{\mathrm{p}} / Q_{\mathrm{p}}(\mathrm{sat})_{p o 2}$ & $U_{\mathrm{A}}$ \\
\hline 16.32 & 0.1166 & 1.0000 & 0.0147 & 0.2405 & 1.0000 & 0.0311 \\
12.96 & 0.1170 & 1.0195 & 0.0526 & 0.2409 & 1.0201 & 0.0301 \\
9.60 & 0.1153 & 0.9360 & 0.0145 & 0.2397 & 0,9539 & 0.0319 \\
6.24 & 0.1145 & 0.8970 & 0.0118 & 0.2391 & 0.9248 & 0.0376 \\
5.13 & 0.1125 & 0.7945 & 0.1067 & 0.2411 & 1.0275 & 0.0127 \\
2.88 & 0.1144 & 0.8920 & 0.0310 & 0.2418 & 1.0667 & 0.0712 \\
0 & 0.1133 & 0.8355 & 0.0199 & 0.2376 & 0.8459 & 0.0336 \\
-2.86 & 0.1120 & 0.7699 & 0.0504 & 0.2369 & 0.8067 & 0.1328 \\
-4.00 & 0.1117 & 0.7539 & 0.0196 & 0.2334 & 0.6214 & 0.0207 \\
-5.11 & 0.1056 & 0.4524 & 0.0181 & 0.2283 & 0.3540 & 0.0193 \\
-6.26 & 0.1000 & 0.1728 & 0.0092 & 0.2235 & 0.0966 & 0.0216 \\
-9.64 & 0.0877 & -0.4459 & 0.0164 & 0.2135 & -0.4339 & 0.0362 \\
-13.03 & 0.0811 & -0.7744 & 0.0516 & 0.2073 & -0.7654 & 0.0243 \\
-16.41 & 0.0781 & -0.9230 & 0.0390 & 0.2053 & -0.8655 & 0.0232 \\
-19.81 & 0.0773 & -0.9630 & 0.0324 & 0.2036 & -0.9576 & 0.0140 \\
-27.70 & 0.0766 & -1.0000 & 0.0286 & 0.2028 & -1.0000 & 0.0303 \\
\hline
\end{tabular}

Table 4.5: The effect on charge collection of the DC voltage applied to the shield foil. The voltage applied to high voltage electrode was kept positive, so $Q_{\mathrm{m}}$ was always positive. $Q_{\mathrm{p}} / Q_{\mathrm{p}}(\mathrm{sat})$ is the charge collection efficiency. $U_{\mathrm{A}}$ is the type A standard uncertainty of the charge collection efficiency. 
$+16.3 \mathrm{~V}$ and $-27.7 \mathrm{~V}$ the charge collection achieved saturation as shown in figure 4.2.

Although there is no $Q_{\mathrm{m}}^{-}$in table 4.5 , the equations from 4.1 to 4.5 can still be applied to describe the relationship of $Q_{\mathrm{m}}^{+}, Q_{\mathrm{p}}$ and $Q_{\mathrm{i}}$. $Q_{\mathrm{p}}(\mathrm{sat})$, which is the charge produced in the region between collecting electrode and shield foil in saturated condition

$$
Q_{\mathrm{p}}(\text { sat })=\left(Q_{\mathrm{m}}^{+}(16.3 V)-Q_{\mathrm{m}}^{+}(-27.7 V)\right) / 2 \quad
$$

and the $Q_{i}$, which is the charge collected at the collecting volume between HV electrode and collecting electrode

$$
Q_{i}=Q_{\mathrm{m}}^{+}(16.3 V)-Q_{\mathrm{p}}(\mathrm{sat})
$$

Therefore, the saturated $Q_{\mathrm{p}}$ at position 1 and 2 according to equation 4.6 is $Q_{\mathrm{p}}($ sat $)($ position 1$)=(0.1166-0.0766) / 2=0.0200 \quad$, $Q_{\mathrm{p}}($ sat $)($ position 2$)=(0.2405-0.2028) / 2=0.0189 \quad$, and $Q_{i}$ at position 1 and 2 according equation 4.7 is $Q_{i}($ position 1$)=0.1166-0.0200=0.0966 \quad$, $Q_{i}($ position 2$)=0.2405-0.0189=0.2217 \quad$.

As mentioned before $Q_{\mathrm{p}}$ is a variable in this experiment. It is the charge collected in the region between the collecting electrode and shield foil corresponding to various voltages applied on the shield foil from $+16.3 \mathrm{~V}$ to $-27.7 \mathrm{~V}$. It can be calculated as:

$$
Q_{\mathrm{p}}=Q_{\mathrm{m}}^{+}-Q_{i}
$$

where $Q_{\mathrm{m}}^{+}$is the reading from the electrometer listed in column 2 or column 5 in table 4.5 for position 1 and position 2 respectively. 


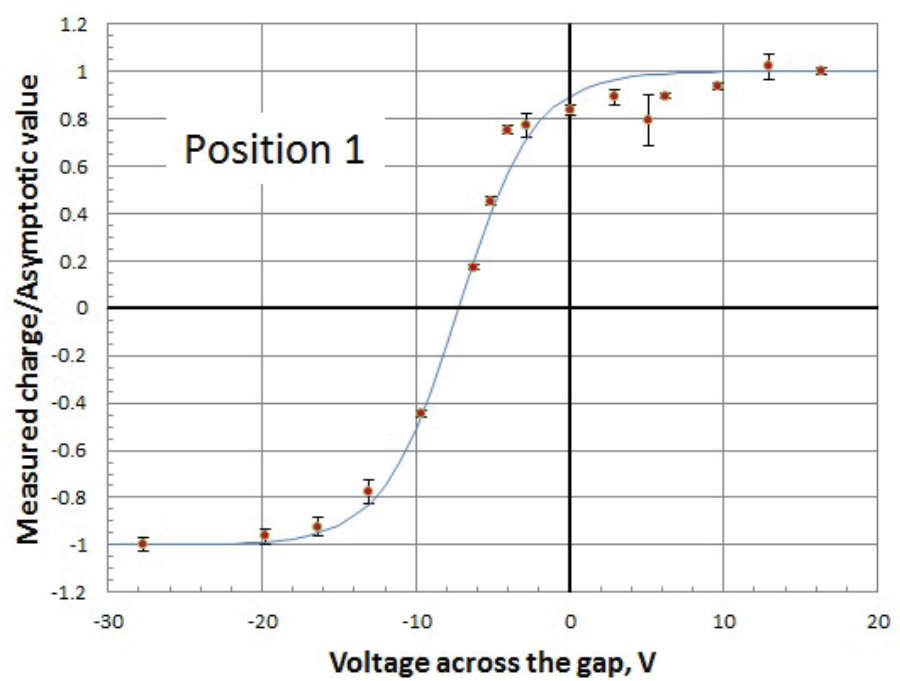

(a) position 1

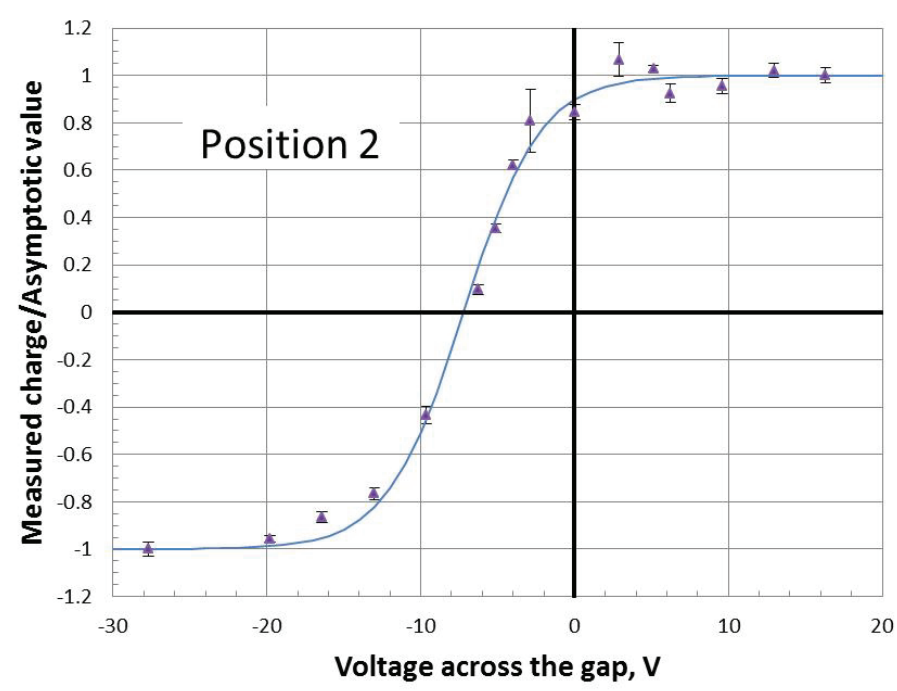

(b) position 2

Figure 4.2: The saturation curves for the charge produced in the region between the collecting electrode and the shield foil. The smooth curve is a weighted, least-squares fit of the expression proposed by Fallone and Podgorsak [23]. Data were collected in two effective collecting volumes, which are $300 \mathrm{~cm}^{3}$ as position 1 and $703.7 \mathrm{~cm}^{3}$ as position 2. Data plotted were $Q_{\mathrm{p}} / Q_{\mathrm{p}}$ (sat) from columns 3 and 6 vs $\mathrm{V}$ from column 1 , in table 4.5 . 
The charge collection efficiency was denoted as $f=Q_{/} Q$ (sat) by Fallone and Podgorsak [23] for a parallel plate ion chamber, where $Q$ is charge collected and $Q$ (sat) is charge collected at saturation. $f$ is a function of the voltage applied to the parallel plate chamber. In this case, $f=Q_{\mathrm{p}} / Q_{\mathrm{p}}$ (sat). The geometry and setup in this experiment is the same as a parallel plate ion chamber. The voltage applied on the shield foil is listed in column 1 of table 4.5, and the collection efficiencies are listed in columns 3 and 6 . Columns 4 and 7 are the uncertainties of collection efficiencies for position 1 and position 2 respectively. $f=Q_{\mathrm{p}} / Q_{\mathrm{p}}$ (sat) verses $\mathrm{V}$ are plotted in figure 4.2 at both position 1 and 2 . The results fit well to a hyperbolic function:

$$
f_{N R C}=Q_{\mathrm{p}} / Q_{\mathrm{p}}(\mathrm{sat})=\tanh \left(\left(V+V_{0}\right) / V^{*}\right) .
$$

This hyperbolic function was proposed by Fallone and Podgorsak [23] to measure saturation for a regular parallel plate chamber, which was given as:

$$
f=\tanh \left(E / E^{*}\right)
$$

where $E$ is electric field and $E^{*}$ is a free parameter. Comparing equation 4.9 and equation 4.10 and looking at figure 4.2 there is a shift of $V_{0}$ in this experiment compared to a regular parallel plate chamber. $V_{0}$ is the existing voltage between collecting electrode and shield foil. $V_{0}$ and $V^{*}$ can be obtained as $V_{0}=7.23 \mathrm{~V}$ and $V^{*}=4.96 \mathrm{~V}$ using a weighted, least-squares procedure. In other words, the downstream side of the collecting electrode has a potential of $-7.23 \mathrm{~V}$ with respect to the shield foil.

\subsubsection{Electret Phenomenon on Mylar Surface of the Collect- ing Electrode of the WAFAC}

As concluded in section 4.2.2 there is an electric field in the region between the

collecting electrode and the shield foil. The collecting electrode is connected to the 
feedback of the remote head of the Keithley 642 electrometer and causes a negative bias less than $1 \mathrm{mV}$. The difference of the work function between Mylar and $\mathrm{Al}$ is also a possible source of the electric field in the gap. The work function for Mylar is 4.25 $\mathrm{V}$ and $4.08 \mathrm{~V}$ for aluminum. Both of these effects are not the major source of the -7.2 $\mathrm{V}$ bias on the Mylar surface. The negative charge accumulated on the Mylar surface may be caused by handling [22]. As indicated by Fallone and Podgorsak, Mylar can retain a surface charge for months as an electret [24].

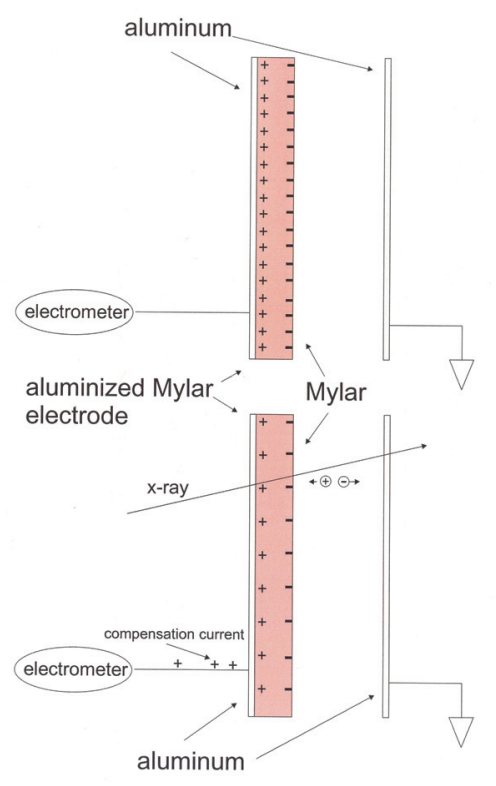

Figure 4.3: A schematic figure for the mechanism of charge collected in the region between collecting electrode and shield foil. Ion pairs are produced when radiation from the brachytherapy seed crosses it. Positive charge drifts to the Mylar surface of the collecting electrode and reduce the negative charge on it, inducing a positive compensating charge current signal.

The electret phenomenon plays a role in charge collection from the back region of the collecting electrode. The assemble of the back region of the collecting electrode 
is similar to the electret produced by ionizing radiation described by Fallone and Podgorsak [24]. In their work, the electret was produced on a piece of one sided metallized Mylar sheet with a thickness of a few $\mu \mathrm{m}$. The metal side was used as the measuring electrode and the Mylar side was facing a polarizing electrode a few $\mathrm{cm}$ away. As this device was exposed in an ionizing radiation field, charge would drift and accumulate on the Mylar surface to produce the electret. A compensation charge would be created on the measuring electrode.

Inadvertently, this is the same situation as in the back region of the WAFAC as shown in figure 4.3. Ion pairs are produced when radiation from the brachytherapy seed crosses this region. Positive charge drifts to the Mylar surface of the collecting electrode and reduces the negative charge on it, inducing a positive compensating charge current in the aluminum side. These processes can result in a signal that corresponds to charge produced by radiation at the back region.

To verify such a mechanism of charge collection, where charge appears to pass from Mylar to aluminum collector, a test was done with a reversed collecting electrode. In this experiment the Mylar side of the collecting electrode was put on the upstream side to collect charge from the normal collecting volume. The results are listed in table 4.6.

The measurement setup was the same as a normal measurement, with volumes $300 \mathrm{~cm}^{3}$ and $703.7 \mathrm{~cm}^{3}$ for position 1 and position 2 respectively. The front high voltage electrode was set as positive polarity. For the reversed collecting electrode setup (Mylar side upstream) there was still $87 \%$ and $94 \%$ of the charge being collected. This verified the hypothesis in the previous paragraph.

As charge accumulates on the surface of the Mylar, the electric field will get 


\begin{tabular}{|c|ccc|ccc|}
\hline \multirow{2}{*}{ Electrode setup } & \multicolumn{3}{|c|}{ Position 1 } & \multicolumn{3}{c|}{ Position 2 } \\
& $\begin{array}{c}\text { Volume } \\
\mathrm{cm}^{3}\end{array}$ & Reading & st dev & Volume & Reading & st dev \\
\hline normal & 300 & 0.0925 & 0.006 & 703.7 & 0.2205 & 0.007 \\
\hline reversed & 300 & 0.0803 & 0.006 & 703.7 & 0.2067 & 0.007 \\
\hline
\end{tabular}

Table 4.6: Effect of reversing the collecting electrode. For the reversed collecting electrode setup (Mylar side upstream) there was still $87 \%$ and $94 \%$ of the charge being collected.

weaker, so the polarity effect above should disappear when charge is saturated on the Mylar surface. This is a possible reason why some laboratories have not observed this effect, especially if their WAFAC or similar instrument was exposed to radiation for one polarity only. In this project the radiation source is a LDR brachytherapy seed. The ion current in the back region for a typical seed was about $4 \mathrm{fA}$ and the current was collected over an area of about $100 \mathrm{~cm}^{2}$. The collecting electrode acts like a capacitor with the aluminum as one plate and the free Mylar surface as the other. The capacitance per unit area of collecting electrode is:

$$
C_{A}=k \varepsilon_{0} / d \quad,
$$

where: $\mathrm{k}$ is the relative permittivity, $\varepsilon_{0}$ is the permittivity of free space, which is $8.854 \times 10^{-12} \mathrm{~F} / \mathrm{m}$ and $d$ is the thickness of the Mylar foil. In this case $d=51 \mu \mathrm{m}$, $\mathrm{k}=3$, so $C_{A}=52.1 \mathrm{pF} / \mathrm{cm}^{2}$ and the capacitance of the collecting electrode is $5.2 \mathrm{nF}$. Therefore the time to reach saturation on the electrode is approximately:

$$
T_{\text {sat }}=Q_{\text {sat }} / I=C_{A} V / I \quad,
$$


where $Q_{\text {sat }}$ is the charge needed to cancel out the exist $7.2 \mathrm{~V}$ bias voltage on the electrode, which equals $C_{A} \times V$. I is the charge current in back region which is

typically $4 \mathrm{fA}$ for a brachythrapy seed used in this experiment. $T_{\text {sat }}$ is $9.4 \times 10^{6}$ seconds, or 2600 hours.

\subsubsection{Elimination of the Polarity Effect with a Painted Con- ducting Layer on the Mylar Surface of the Collecting Electrode of the WAFAC}

As described above, the polarity effect is caused by the charge produced in the region between the collecting electrode and shield foil. The charge produced in this region is collected by the mechanism of electrets. Intuitively, this effect can be eliminated by coating the back of the collecting electrode with a grounded conductive layer, or using double sided aluminized Mylar. Tests were carried out with the collecting electrode painted with colloidal graphite making the back side electrically conductive. To verify this idea, measurements with the painted collecting electrode were performed using ${ }^{125} \mathrm{I}$ and ${ }^{241} \mathrm{Am}$ radiation sources. The results are listed in table 4.7.

Using equations 4.4 and 4.5 we obtained the charge from the collecting volume $Q_{i}$ and the charge from the back region $Q_{\mathrm{p}}$ after painting a conductive coating on the back of the collecting electrode.

The results shown in table 4.8 give $Q_{\mathrm{p}}$ values which are all less than $0.6 \%$ of $Q_{i}$ and the average value of $Q_{\mathrm{p}} / Q_{i}$ is $0.36 \%$. In two cases, $Q_{\mathrm{p}}$ is equivalent to the standard uncertainty and all cases it is less than three times the standard uncertainty. Comparing to results in table 4.1, which had $Q_{\mathrm{p}}=17 \%$ of $Q_{i}$ for the ${ }^{125}$ I source and $15 \%$ for the ${ }^{241} \mathrm{Am}$ source, and considering the uncertainty on $Q_{\mathrm{p}}$, the conductive 


\begin{tabular}{|c|c|cc|cc|}
\hline \multirow{2}{*}{ source } & Polarity & \multicolumn{2}{|c|}{ Position 1} & \multicolumn{2}{c|}{ Position 2} \\
& & $Q_{\mathrm{m}}$ & $U_{\mathrm{A}} \%$ & $Q_{\mathrm{m}}$ & $U_{\mathrm{A}} \%$ \\
\hline${ }^{125} \mathrm{I}$ & Positive & 0.0925 & 0.36 & 0.2177 & 0.26 \\
& Negative & -0.0934 & 0.35 & -0.2182 & 0.14 \\
\hline \multirow{2}{*}{${ }^{241} \mathrm{Am}$} & Positive & 0.0377 & 0.52 & 0.0904 & 0.27 \\
& Negative & -0.0382 & 0.33 & -0.0908 & -0.46 \\
\hline
\end{tabular}

Table 4.7: Polarity measurements with graphite painted on the back of the collecting electrode using ${ }^{125} \mathrm{I}$ or ${ }^{241} \mathrm{Am}$ as the radiation source.

\begin{tabular}{|l|cc|cc|cc|cc|}
\hline \multirow{2}{*}{ source } & \multicolumn{4}{|c|}{ Position 1 } & \multicolumn{4}{c|}{ Position 2 } \\
\cline { 2 - 9 } & $Q_{\mathrm{i}}$ & $U_{\mathrm{A}} \%$ & $Q_{\mathrm{p}}$ & $U_{\mathrm{A}}$ & $Q_{\mathrm{i}}$ & $U_{\mathrm{A}}$ & $Q_{\mathrm{p}}$ & $U_{\mathrm{A}}$ \\
\hline${ }^{125} \mathrm{I}$ & 0.0930 & 0.0002 & -0.0005 & 0.0002 & 0.2179 & 0.0003 & -0.0003 & 0.0003 \\
${ }^{241} \mathrm{Am}$ & 0.0379 & 0.0001 & -0.0002 & 0.0001 & 0.0906 & 0.0002 & -0.0002 & 0.0002 \\
\hline
\end{tabular}

Table 4.8: $Q_{\mathrm{i}}$ and $Q_{\mathrm{p}}$ at position 1 and 2 after graphite painted on the back of the collecting electrode using ${ }^{125} \mathrm{I}$ and ${ }^{241} \mathrm{Am}$ as the radiation source.

coating on the collecting electrode has eliminated the polarity effect. 


\section{Chapter 5}

\section{Validation}

\subsection{Validation with Established National Primary Standard}

To verify the accuracy of the WAFAC, a comparison with the NRC Low Energy Exposure Standard (LEES) was performed by aligning the WAFAC to a narrow spectrum $\mathrm{x}$ ray beam with tube voltage $40 \mathrm{kV}$ and effective photon energy $31 \mathrm{keV}$ as described in ISO 4037-1 [25]. The WAFAC measured the kerma rate that had been established by the LEES.

\subsubsection{Experiment}

The $\mathrm{x}$ ray beam is generated with a Comet MXR-320 x ray tube (Liebefeld, Swizerland). The $\mathrm{x}$ ray tube is control by a system with current and voltage stabilizer [8]. The filtration used was $0.23 \mathrm{~mm}$ of $\mathrm{Cu}$ and $1 \mathrm{~mm}$ of $\mathrm{Al}$. The resulting x ray spectrum 
has an effective energy of $31.1 \mathrm{keV}$ and an HVL of $2.59 \mathrm{~mm}$ of Al.

The NRC $\mathrm{x}$ ray standard facility consists of an $\mathrm{x}$ ray tube, a monitor chamber, a limiting aperture and the LEES as shown in figure 5.1. The LEES was in line to measure kerma rate of the $\mathrm{x}$ ray beam and calibrate the monitor chamber. The WAFAC would replace the position of the LEES in figure 5.1 during the comparison measurement.

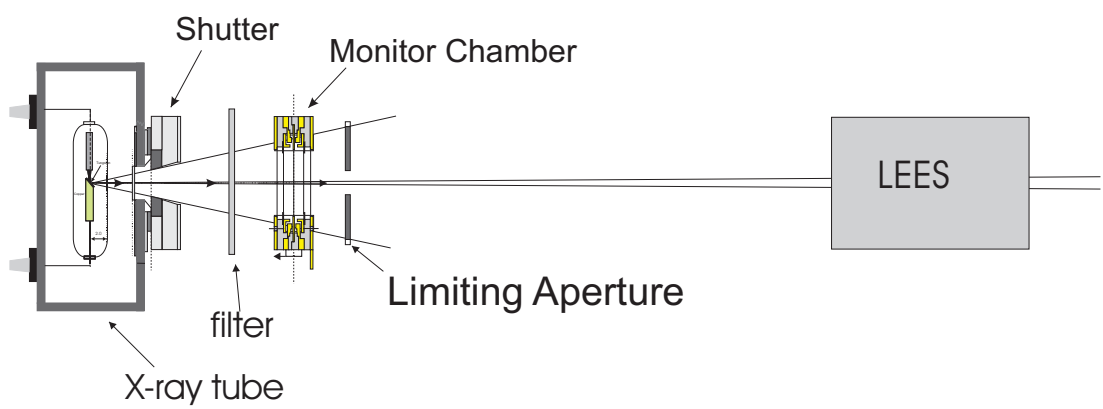

Figure 5.1: The setup of $\mathrm{x}$ ray standard at NRC

The monitor chamber intercepts the $\mathrm{x}$ ray beam during the measurement. The software used for data acquisition define the monitor reading as the voltage on the capacitor which collects charge in units of Volts, and the monitor rate as the monitor reading divided by time elapsed in seconds and $\mathrm{x}$ ray tube current in milliampere, so the monitor rate reads are in units $\mathrm{V} \mathrm{s}^{-1} \mathrm{~mA}^{-1}$. Meanwhile the LEES measures kerma rate of the $\mathrm{x}$ ray beam in units of Gy $\mathrm{min}^{-1} \mathrm{~mA}^{-1}$, where Gy is the unit of 


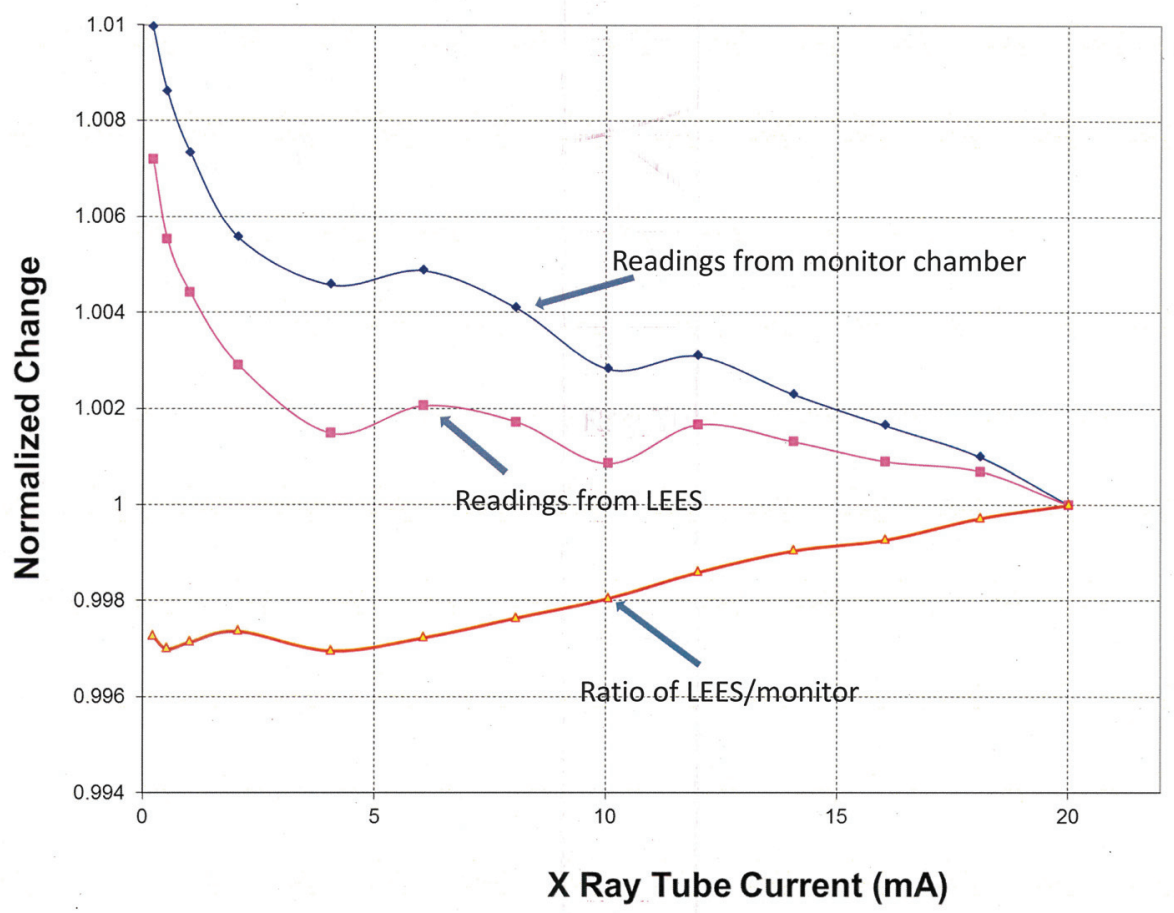

Figure 5.2: Different measures of the relative $\mathrm{x}$ ray tube output as function of the tube current. All readings are normalized to the reading when tube current is $20 \mathrm{~mA}$. Both LEES and monitor measure the $\mathrm{x}$ ray tube output per unit of $\mathrm{x}$ ray tube current. The measurements have bigger variation when the tube current is low. To disseminate the air kerma of the $\mathrm{x}$ ray beam measured by the LEES to the situation when the WAFAC is used with a much smaller $\mathrm{x}$ ray tube current, the ratio of LEES/monitor should be used.

kerma, $\mathrm{mA}$ is $\mathrm{x}$ ray tube current, and min is time elapsed in minutes. The ratio of LEES/monitor would be used to disseminate the kerma rate when the WAFAC replaces the LEES for $\mathrm{x}$ ray beam measurement. That means the monitor reading times the ratio of LEES/monitor would be used to define the air kerma rate during the measurement of the WAFAC.

Since the LEES aperture is $5.009 \mathrm{~mm}$ and the WAFAC aperture is $80 \mathrm{~mm}$, the 
intensity of the $\mathrm{x}$ ray beam had to be adjusted to provide a suitable signal for the two chambers. The $\mathrm{x}$ ray tube current is the parameter used to control beam intensity. The $\mathrm{x}$ ray tube current used for the LEES measurement was about $4 \mathrm{~mA}$ or above and a range from 0.02 to $0.08 \mathrm{~mA}$ was used during WAFAC measurements.

Figure 5.2 shows the different measures of the $\mathrm{x}$ ray tube output when the tube current varies, with all readings being normalized to the reading when tube current is $20 \mathrm{~mA}$. As described in previous paragraphs, both LEES and monitor measure the $\mathrm{x}$ ray tube output per unit of $\mathrm{x}$ ray tube current, but these measurements show a bigger variation when the tube current is low, as shown in figure 5.2. That means that the results from WAFAC measurement cannot directly compare to the results measured by LEES. To disseminate the air kerma or exposure of the $\mathrm{x}$ ray beam measured by the LEES to the situation when the WAFAC is used, the ratio of LEES/monitor reading should be used. The ratio LEES/monitor varied less than $0.1 \%$ when tube current changed from $4 \mathrm{~mA}$ to $0.1 \mathrm{~mA}$ as shown in figure 5.2.

The correction factors for the WAFAC in this experiment were as in table 5.1 which were taken from NIST's work [2] except for the following corrections which were set to unity for this measurement:

* The transmission in the filter was set to 1 because the filter was not in use for this experiment.

* The source to aperture air attenuation was set to 1 because the WAFAC was set at the same position as the LEES

* The holder stem scatter was set to 1 because the holder was not in use.

* The inverse square correction for aperture was set to 1 because the aperture of the WAFAC was $1 \mathrm{~m}$ away from the source. The inverse square correction was not 


\begin{tabular}{l|l} 
Correction Factors & value \\
\hline recombination inside WAFAC & 1.000 \\
\hline Al filter attenuation & 1.000 \\
\hline air attenuation from aperture to center of chamber & 1.0042 \\
\hline air attenuation from source to aperture & 1.000 \\
\hline inverse square correction for aperture & 1.0008 \\
\hline humidity & 0.9979 \\
\hline in chamber photon scatter & 0.9966 \\
\hline scatter from source holder stem & 1.000 \\
\hline electron loss inside chamber & 1.000 \\
\hline aperture penetration & 1.000 \\
\hline external photon scatter & 1.000 \\
\hline
\end{tabular}

Table 5.1: Correction factors used for WAFAC as the comparison measurement to LEES in Narrow Spectrum X-ray beam.

significant in this experiment, according to equation 3.6. The correction factor would be 1.0008 for an aperture with radius of $4 \mathrm{~cm}$.

* External photon scatter was set to 1 because it was observed that this correction was aperture size related. Setting this correction to be unity would allow information about the aperture size effect on signal reading to be obtained.

* Recombination inside the WAFAC was set to unity according to equation 3.5. The ionization current was typically around $1 \mathrm{pA}$ and the correction should be less than $0.05 \%$.

Irradiation of the LEES and the monitor chamber with a tube current of $4 \mathrm{~mA}$ 


\begin{tabular}{|c|c|c|cc|c|c|}
\hline Date & Tube & Monitor & \multicolumn{2}{|c|}{ Air kerma $(\mu \mathrm{Gy} / \mathrm{h})$} & WAFAC & $U_{\mathrm{A}}$ \\
& Current $(\mathrm{mA})$ & $\mathrm{V} / 10 \mathrm{~min}$ & LEES & WAFAC & LEES & \\
\hline $02 / 26 / 14$ & 0.01646 & 0.03652 & 83.38 & 83.58 & 1.002 & 0.001 \\
\hline $02 / 27 / 14$ & 0.01581 & 0.03491 & 79.70 & 79.84 & 1.002 & 0.002 \\
\hline $03 / 02 / 14$ & 0.08120 & 0.17895 & 408.6 & 408.5 & 1.005 & 0.001 \\
\hline $03 / 03 / 14$ & 0.07800 & 0.17227 & 393.3 & 390.7 & 0.998 & 0.002 \\
\hline
\end{tabular}

Table 5.2: Comparison of the WAFAC and the LEES measurements at $1 \mathrm{~m}$ from a effective energy $31 \mathrm{keV}$ x ray source. $U_{\mathrm{A}}$ is the standard type A uncertainty of the WAFAC/LEES ratio. $U_{\mathrm{A}}$ is dominated by the uncertainty of the WAFAC readings and the type A uncertainty of LEES measurement is typically $0.04 \%$.

obtained a measured result of a kerma rate of $82.305 \mu \mathrm{Gy} \mathrm{min}{ }^{-1} \mathrm{~mA}^{-1}$ and a monitor rate of $3.60471 \mathrm{mV} \mathrm{s}^{-1} \mathrm{~mA}^{-1}$. The ratio of these two reading can be used to obtain kerma rate from a monitor reading during WAFAC measurement according to equation 5.1

$$
\dot{K}=\frac{(\dot{k})_{\text {ref }}}{(\dot{M})_{\text {ref }}} \times \dot{M}_{\text {monitor }}
$$

where $(\dot{k})_{\text {ref }}$ and $(\dot{M})_{\text {ref }}$ are the kerma rate and monitor rate measured by the LEES and the monitor chamber respectively, during the LEES measurement. The ratio $\frac{(\dot{k})_{\text {ref }}}{(\dot{M})_{\text {ref }}}=0.3805 \mathrm{mGy} / \mathrm{V}$ in this case. $\dot{M}_{\text {monitor }}$ is the monitor reading $(\mathrm{V})$ per minute during the WAFAC measurement.

The results for the LEES-WAFAC comparison are listed in table 5.2. Column 2 gives the tube currents used for each measurement when the WAFAC was in the beam line. In this range of tube currents the linearity correction of the output is not 
necessary. Column 5 gives the measurement results by the WAFAC when it replaced the position of the LEES in figure 5.1. the LEES has a total uncertainty $0.3 \%$ as $\mathrm{k}=1$ including type A and B. The type A uncertainty of the LEES measuement is $0.04 \%$ including that for positioning and correction factors, so the uncertainty of the ratio of WAFAC/LEES is dominated by the uncertainty of WAFAC measurements. The uncertainty in column 7 was calculated from the electrometer readings at position 1 and 2 of the WAFAC measurements and it dominated the uncertainty of the ratio.

The results listed in table 5.2 demonstrate good agreement of the WAFAC measurements with the kerma rate established by the LEES.

\section{$5.2 \quad$ Aperture Size Effect}

Because the WAFAC uses a much larger aperture compared to the conventional free air chamber, different sized apertures were used in place of the $80 \mathrm{~mm}$ WAFAC's aperture. The measurement results are listed in table 5.3, and the Monte Carlo results provided by Dr. Mainegra-Hing are listed in table 5.4. Both the experimental and Monte Carlo results are plotted in figure 5.3.

The experimental results show the reading of the WAFAC increases with aperture size in the small aperture region and then decreases for the largest aperture. The Monte Carlo results show a similar trend to experimental results, but the variations are less. Research at NIST showed no aperture effect in the range of aperture diameter from 10 to $80 \mathrm{~mm}[2]$. 


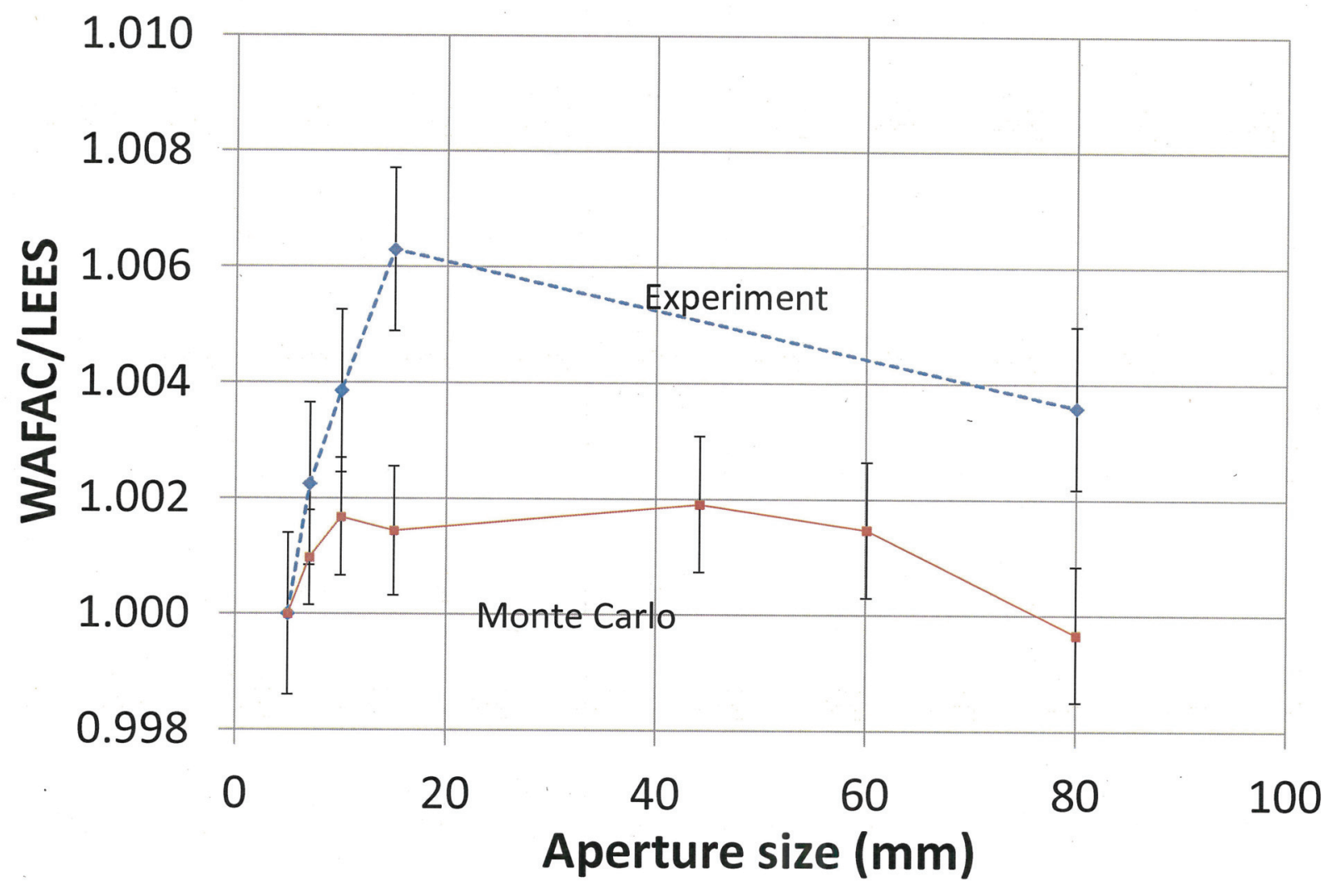

Figure 5.3: The experimental results which are listed in sixth column in table 5.3 for WAFAC versus aperture size, and Monte Carlo calculated results in table 5.4 provided by Dr. Mainegra-Hing versus aperture size. Readings were normalized to that with $5 \mathrm{~mm}$ aperture. 


\begin{tabular}{|c|c|c|cc|c|c|}
\hline $\begin{array}{c}\text { Aperture } \\
\text { Size } \\
(\mathrm{mm})\end{array}$ & $\begin{array}{c}\text { Tube } \\
\text { current } \\
(\mathrm{mA})\end{array}$ & $\begin{array}{c}\text { Monitor } \\
\text { Reading } \\
(\mathrm{V} / \mathrm{min})\end{array}$ & $\begin{array}{c}\text { air kerma } \\
\text { LEES }\end{array}$ & $\begin{array}{c}\text { WAFAC } \\
(\mathrm{mGy} / \mathrm{h})\end{array}$ & $\begin{array}{c}\text { WLEES } \\
\text { normalized }\end{array}$ & \\
\hline 5.009 & 9.995 & 2.1665 & 49.47 & 49.10 & 1.0000 & 0.0014 \\
\hline 7.013 & 9.995 & 2.1699 & 49.55 & 49.29 & 1.0022 & 0.0014 \\
\hline 10.00 & 5.002 & 1.0929 & 24.95 & 24.87 & 1.0039 & 0.0014 \\
\hline 15.03 & 2.200 & 0.4799 & 10.96 & 10.95 & 1.0063 & 0.0014 \\
\hline 80.00 & 0.078 & 0.0172 & 0.393 & 0.392 & 1.0036 & 0.0014 \\
\hline
\end{tabular}

Table 5.3: The measurements of the WAFAC in $\mathrm{x}$ ray beam with different size of aperture. The tube current non-linear correction has been applied to the first two readings, which were measured using higher current. Inverse square correction has been applied for WAFAC readings in the fifth column, which is a small factor at 1 $\mathrm{m}$, but it is considered for aperture size effect. Normalized ratio of WAFAC/LEES, which is column 5 divide by column 4 , and normalized to the smallest aperture is listed in sixth column. Uncertainty listed in the seventh column was calculated from the deviations of the WAFAC readings, which dominate the type A uncertainty of the ratio. 


\begin{tabular}{|c|c|c|}
\hline $\begin{array}{c}\text { aperture } \\
\mathrm{mm}\end{array}$ & normalized & uncertainty \\
\hline 5.009 & 1.0000 & 0.0000 \\
\hline 7.013 & 1.0010 & 0.0008 \\
\hline 10.001 & 1.0017 & 0.0010 \\
\hline 15.033 & 1.0014 & 0.0011 \\
\hline 44.143 & 1.0019 & 0.0012 \\
\hline 60.080 & 1.0015 & 0.0012 \\
\hline 80.000 & 0.9997 & 0.0012 \\
\hline
\end{tabular}

Table 5.4: The Monte Carlo calculated aperture size effect provided by Dr. MainegraHing. The result for $5.009 \mathrm{~mm}$ aperture has zero uncertain because it is the reference value. 


\subsection{Validation with manufacturer's nominal $S_{\mathrm{k}}$ value.}

The project at this stage does not include a direct comparison with another national measurement institute. However, there were a few measurements using brachytherapy seeds provided by the local cancer center. Seeds used for this test were Model 6711 ${ }^{125}$ I seeds. Each seed had nominal air kerma strength $0.618 \mu \mathrm{Gy} \mathrm{m}{ }^{2} / \mathrm{h} \pm 7 \%$. Seeds were manufactured by Medi-Physics Inc. Their air kerma strength were measured by GE Healthcare, traceable to NIST.

\begin{tabular}{|c|c|cc|cc|cc|}
\hline Date & $\begin{array}{c}\text { Reference } \\
\text { date }\end{array}$ & \multicolumn{2}{|c|}{$\begin{array}{c}\text { DMM1 } \\
\mathrm{V}\end{array}$} & $U_{\mathrm{A}}$ & $\begin{array}{c}\text { DMM2 } \\
U_{\mathrm{A}}\end{array}$ & $\begin{array}{c}S_{\mathrm{k}} \\
\mathrm{V}\end{array}$ & $\begin{array}{c}U_{\mathrm{A}} \\
\mu \mathrm{Gy} \mathrm{m}^{2} / \mathrm{h}\end{array}$ \\
\hline $1 / 21 / 2014$ & $1 / 10 / 2014$ & 0.01340 & 0.00012 & 0.02850 & 0.00010 & 0.607 & 0.006 \\
\hline $4 / 30 / 2014$ & $4 / 25 / 2014$ & 0.01290 & 0.00011 & 0.02850 & 0.00011 & 0.625 & 0.006 \\
\hline $10 / 14 / 2015$ & $10 / 2 / 2015$ & 0.01374 & 0.00015 & 0.02882 & 0.00015 & 0.606 & 0.008 \\
\hline
\end{tabular}

Table 5.5: Air kerma measurement for ${ }^{125} \mathrm{I}$ seeds, model 6711 , which had nominal $S_{\mathrm{k}}=0.618 \pm 7 \% \mu \mathrm{Gy} \mathrm{m}^{2} / \mathrm{h}$ for each individual seed at their own reference time. The measurements used different seeds each time. Correction factors used for these measurement were listed in table 3.4 and an additional 1.0054 is included for position displacement described in subsection 3.2.1. DMM1 and DMM2 are digital multimeter reading at position 1 and 2 respectively. $U_{\mathrm{A}}$ is type A standard uncertainty.

Data listed in table 5.5 were obtained from measurements of 3 individual seeds over 21 months. Each measurement involved 20 or 30 repeat cycles. Correction factors used for calculating $S_{\mathrm{k}}$ are listed in table 3.4. The correction $k_{\mathrm{v}}=1.0054$ is 
also applied (the corrections for the displacement of cylinders described in subsection 3.2.1).

The mean value of air kerma strength measured for three seeds was $0.612 \mu \mathrm{Gy} \mathrm{m}^{2} / \mathrm{h}$ with variation of $2 \%$. The dispersion of individual seed measured at local hospital is $1-2 \%$. The measured value is $1 \%$ different from the nominal value, well within the stated uncertainty of $\pm 7 \%$.

\subsection{Uncertainty Estimation}

In equation 2.1, the accuracy of $C, d$ and $A$, representing capacitance, distance from seed center to aperture, and the area of aperture respectively, can be easily measured to $0.01 \%$, as well as $L_{\mathrm{p} 1}-L_{\mathrm{p} 2}$ as indicated in table 3.1. So the dominant parts of the uncertainty are $V_{\mathrm{p}_{1}}-V_{\mathrm{p}_{2}}$ and $\prod_{i} k_{i}$. The type A uncertainty of $S_{\mathrm{k}}$ is determined by $V_{\mathrm{p}_{1}}-V_{\mathrm{p}_{2}}$. From table 5.5 one can determine the uncertainty for positions 1 and 2 to be $0.97 \%$ and $0.42 \%$ respectively. The one sigma standard uncertainty in $V_{\mathrm{p}_{1}}-V_{\mathrm{p}_{2}}$ is estimated to be $1.1 \%$ for this particular case.

Type B uncertainties should include all other uncertainties including the uncertainties of correction factors, aluminum filter attenuation, and constants in equation 2.1 like $\frac{W}{e}$. The uncertainty of aluminum filter attenuation is $0.2 \%$ from experiment or $0.04 \%$ from Monte Carlo simulation. The aperture effect is also a source of uncertainty, which estimated to be $0.5 \%$ based on the variation obtained from figure 5.3, which will be further studied. In table 7 of NIST's work [2], type B uncertainties for the WAFAC were listed for ${ }^{125} \mathrm{I}$, except for the aperture effect. Type B uncertainties are listed based on NIST's work in table 5.6. Column 3 in table 5.6 are uncertainties used in this project to estimate the total uncertainty. Most of them 
are taken from NIST's work until we finish a complete reassessment, except the uncertainties for aluminum foil attenuation and aperture effect, which were determined in this work.

The combined type $\mathrm{B}$ uncertainty at $\mathrm{k}=1$ will be $0.7 \%$ including the aperture effect. Therefore the total uncertainty for the currently used model $6711^{125} \mathrm{I}$ seed will be $1.3 \%$ with $68 \%$ confidence level or $2.6 \%$ with $95 \%$ confidence level. 


\begin{tabular}{|c|c|c|}
\hline \multirow[b]{3}{*}{ Component } & \multicolumn{2}{|c|}{ Type B uncertainties \% } \\
\hline & NIST's & Used \\
\hline & values $[2]$ & here \\
\hline net current of signal & 0.06 & 0.06 \\
\hline mean energy per ion pair & 0.15 & 0.15 \\
\hline air density & 0.03 & 0.15 \\
\hline source-aperture distance & 0.24 & 0.24 \\
\hline effective volume & 0.01 & 0.01 \\
\hline correction to reference date & 0.02 & 0.02 \\
\hline recombination inside WAFAC & 0.05 & 0.05 \\
\hline Al filter attenuation & 0.61 & 0.2 \\
\hline air attenuation from aperture to center of chamber & 0.08 & 0.08 \\
\hline air attenuation from source to aperture & 0.24 & 0.24 \\
\hline inverse square correction for aperture & 0.01 & 0.01 \\
\hline humidity & 0.07 & 0.07 \\
\hline in chamber photon scatter & 0.07 & 0.07 \\
\hline scatter from source holder stem & 0.05 & 0.05 \\
\hline electron loss inside chamber & 0.05 & 0.05 \\
\hline aperture penetration & 0.02 & 0.02 \\
\hline external photon scatter & 0.17 & 0.17 \\
\hline aperture effect & & 0.5 \\
\hline
\end{tabular}

Table 5.6: Type B uncertainties listed in table 7 of NIST's work [2] and as used here. Most values used in NIST's work were chosen for this project except $k_{\text {foil }}$. The uncertainty caused by the aperture effect was added at the bottom of the table. 


\subsection{Long-term Stability with Check Source}

\begin{tabular}{|c|c|c|}
\hline Date & $S_{\mathrm{k}}$ & $U_{\mathrm{A}}$ \\
\hline $1 / 7 / 2014$ & 2.098 & 0.005 \\
\hline $1 / 6 / 2015$ & 2.096 & 0.003 \\
\hline $3 / 6 / 2015$ & 2.112 & 0.011 \\
\hline
\end{tabular}

Table 5.7: Check source ${ }^{241} \mathrm{Am}$ was used to check long term stability.

An Am-241 source is used as a check source to verify long term stability of the WAFAC due to its 432.6 years long half-life (although its average decay energy is 59 $\mathrm{keV})$. The WAFAC is not designed for radiation sources with energy level above 40 $\mathrm{keV}$ and the formulism used to establish $S_{\mathrm{k}}$ values in table 5.7 is actually for ${ }^{125} \mathrm{I}$ instead ${ }^{241} \mathrm{Am}$. So the $S_{\mathrm{k}}$ in table 5.7 is not a real $S_{\mathrm{k}}$ for ${ }^{241} \mathrm{Am}$. It is used only to check the consistency of results. The signal strength used for the check source at $\mathrm{NRC}$ is equivalent to the ${ }^{125} \mathrm{I}$ seeds used in this project, which have air-kerma strength $0.62 \mu \mathrm{Gy} \mathrm{m}^{2} / \mathrm{h}$. The ${ }^{241} \mathrm{Am}$ seed was measured occasionally and the results are listed in table 5.7. The measurement conditions were same as that used for ${ }^{125} \mathrm{I}$.

The data shown in table 5.7 are preliminary data to indicate the feasibility of using the ${ }^{241} \mathrm{Am}$ source. The long term stability of the WAFAC will only be established over a longer time period, once the instrument is in routine use. 


\section{Chapter 6}

\section{Conclusions and Future Work}

Overall the NRC WAFAC is in working condition. The leakage is normally less than $10 \mathrm{fA}$. The type A uncertainty is mainly caused by the variation of the charge measurements, so the value of type A uncertainty is related to the strength of signal. In the case of measuring an ${ }^{125} \mathrm{I}$ seed with nominal air kerma strength $0.618 \mu \mathrm{Gy} \mathrm{m}^{2} / \mathrm{h}$, the type A standard uncertainty is $1.1 \%$. The type B standard uncertainly is $0.7 \%$, so the total uncertainty for model $6711^{125}$ I used in this project is $1.3 \%$. This achieves the goal of a total uncertainty $<3 \%$ with $95 \%$ confidence level.

The comparison between the NRC WAFAC and the NRC primary low-energy exposure standard (LEES) gives the average of the ratio of measured results WAFAC/LEES as 1.002 with standard deviation 0.003 for four measurements with the air kerma strength ranging from 80 to $409 \mu \mathrm{Gy} \mathrm{m} \mathrm{m}^{2} / \mathrm{h}$. The comparisons with the seed nominal strength from the manufacturer's data sheet, which is traceable to NIST, shows $1 \%$ difference in the mean value from three measurements. An intercomparison with other national laboratories will take place in the near future. The long term stability test, using a ${ }^{241} \mathrm{Am}$ check source, shows the measured results were 
constant within $1 \%$ over 14 months.

The polarity effect had been observed to be very large during the measurements. Further study was carried out to determine the underlying causes of the polarity effect and to develop an approach used to eliminate it.

The effect of aperture size has been studied. The measured points in figure 5.3 from experimental observation show that the measured $\mathrm{x}$ ray beam strength increases with aperture size in the small aperture region and then decreases with largest aperture size, but the uncertainties of these results are too large to be definitive. The variation shown in figure 5.3 may include other factors like photon scatter and initial recombination. Repeat measurements and further study should be carried out with a wider range of aperture openings, and the uncertainty should be reduced for both measurement and the Monte Carlo method. Corrections for the different photon fluence at each point should also be considered.

The correction factors used for the NRC WAFAC were taken from NIST's work. It is necessary to reassess these correction factors using experiments and Monte Carlo simulations for NRC's particular situation. Based on the reassessment, the uncertainty budget needs to be completed before disseminating the standard to clients. The tungsten aperture diameter needs to be calibrated by the national primary standard laboratory, and the uncertainty should be included in the total uncertainty budget. 


\section{References}

[1] IAEA(International Atomic Energy Agency). Calibrations of photon and beta ray sources used in brachytherapy. Technical Report IAEA-TECDOC-1274, International Atomic Energy Agency, Vienna, Austria, 2002.

[2] Stephen M. Seltzer, Paul J. Lamperti, Robert Loevinger, Michael G. Mitch, James T. Weaver, and Bert M. Coursey. New National Air-Kerma-Strength Standards for ${ }^{125} \mathrm{I}$ and ${ }^{103} \mathrm{Pd}$ Brachytherapy Seeds. J. Res. Natl. Inst. Stand. Technol., 10:337 - 358, 2003.

[3] Prostate brachytherapy, wikipedia, 2015.

[4] Ravinder Nath, Lowell L. Anderson, Jerome A. Meli, Arthur. J. Olch, Judith Anne Stitt, and Jeffrey F. Willimson. Code of practice for brachytherapy physics: Report of the AAPM Radiation Therapy Committee Task Group No. 56. Med. Phys., 24:1557 - 1598, 1997.

[5] Sander T. Air kerma and absorbed dose standards for reference dosimetry in brachytherapy. Br J Radiol, 87, 2014.

[6] Frank Herbert Attix. Introduction to Radiological Physics and Radiation Docimetery. Wiley-VCH Verlag GmbH Co. KGaA, Weinheim, 2004. 
[7] Johns and Cunningham. The Physics of Radiology. CHARLES C THOMAS, Illinois, 1983.

[8] W. H. Henry and C. Garrett. The canadian standard free-air chamber for medium quality x-ray. Can. J. Pyys., 38:1677-1689, 1960.

[9] Mark J. Rivard, Bert M. Coursey, Larry A. DeWerd, William F. Hanson, M. Saiful Huq, Geoffrey S. Ibbott, Michael G. Mitch, Ravinder Nath, and Jeffrey F. Williamson. Update of AAPM Task Group No. 43 Report: A revised AAPM protocol for brachytherapy dose calculations. Med. Phys., 31:633 - 674, 2004.

[10] Oncura Inc (Arlington Heights, IL). Instruction for the use of RAPID Strand for Interstitial Brachytherapy Treatments, product manual, 2009.

[11] W. S. Culberson, L. A. DeWerd, D. R. Anderson, and J. A. Micka. Largevolume ionization chamber with variable apertures for air-kerma measurements of low-energy radiation sources. Rev. Sci. Instr., 77:015105-1-015105-9, 2006.

[12] H-M Kramer H-J Selbach and W S Culberson. Realization of referrence air-kerma rate for low-energy photon sources. Metrologia, 45:422 - 428, 2008.

[13] M. Baker, G.A. Bass, and M.J. Woods. Calibration of the NPL secondary standard radionuclide calibration for ${ }^{125} \mathrm{I}$ seeds used for prostate brachytherapy. Applied Radiation and Isotopes, 56:321 - 325, 2002.

[14] I Aubineau-Lanièce, B Chauvenet, D Cutarella, J Gouriou, J Plagnard, and $\mathrm{P}$ Aviles Lucas. LNE-LNHB air-kerma and absorbed dose to water primary standards for low dose-rate ${ }^{125}$ I brachytherapy sources. Metrologia, 49:S189 S192, 2012. 
[15] Michael G. Mitch. Primary Standards for Brachytherapy Sources. In D. W. O. Rogers and Joanna E. Cygler, editors, Clinical Dosimetry Measurements in Radiotherapy, pages 549 - 565. Medical Physics Publishing, Wisconsin, 2009.

[16] JP McCaffrey, F Tessier, and B Downton. Conference abstract MO-G-BRA-06: A Primary Standard for HDR Brachytherapy Calibrations. Med. Phys., 38:3734, 2011.

[17] Keithley Instruments Inc (Cleveland, OH). Model 642 Electrometer, Instruction Manual.

[18] IET Labs Inc (Long Island, NY). Primary Standard Capacitor-1404 series, User Manual.

[19] Patricia B. Scott and J. R. Greeniong. The Determination of Saturation Currents in Free-air Ionization Chambers by Extrapolation Methods. Phys. Med. Biol., 8:51- 57, 1963.

[20] Hideo Kubo. Exposure contribution from Ti $K$ x rays produced in the titanium capsule of the clinical I-125 seed. Med. Phys., 12:215 - 220, 1985.

[21] J. W. Boag. Distortion of the Electric Field in an Ionization Chamber due to a Difference in Potential between Guard Ring and Collector. Phys. Med. Biol., 9:25-32, 1964.

[22] H. Shen, W. S. Culberson, and C. K. Ross. An investigation of polarity effects for wide-angle free-air chambers. Med. Phys., accepted, April,2016.

[23] B.G. Fallone and E.B. Podgorsak. Saturation curves of parallel-plate ionization chambers. Med. Phys., 10:191 - 196, 1983. 
[24] B.G. Fallone and E.B. Podgorsak. Production of foil electrets by ionizing radiation in air. Phys. Rev. B, 27:2615-2618, 1983.

[25] Subcommittee SC 2 Radiation protection Technical Committee ISO/TC85, Nuclear energy. $\mathrm{X}$ and gamma reference radiation for calibrating dosemeters and doserate meters and for determining their response as a function of photon energy-Part1: Radiation characteristics and production methods . (ISO 40371:1996(E)), 1996. 